\title{
The Thoracic Morphology of Archostemata and the Relationships of the Extant Suborders of Coleoptera (Hexapoda)
}

\section{Citation}

Friederich, Frank, Brian D. Farrell, and Rolf G Beutel. 2009. The thoracic morphology of Archostemata and the relationships of the extant suborders of Coleoptera (Hexapoda). Cladistics 25, no. 1: 1-37.

\section{Published Version}

http://dx.doi.org/10.1111/j.1096-0031.2008.00233.x

\section{Permanent link}

http://nrs.harvard.edu/urn-3:HUL.InstRepos:3114645

\section{Terms of Use}

This article was downloaded from Harvard University's DASH repository, and is made available under the terms and conditions applicable to Other Posted Material, as set forth at http:// nrs.harvard.edu/urn-3:HUL.InstRepos:dash.current.terms-of-use\#LAA

\section{Share Your Story}

The Harvard community has made this article openly available.

Please share how this access benefits you. Submit a story.

\section{Accessibility}




\title{
Cladistics
}

Cladistics 25 (2009) 1-37

10.1111/j.1096-0031.2008.00233.x

\section{The thoracic morphology of Archostemata and the relationships of the extant suborders of Coleoptera (Hexapoda)}

\author{
Frank Friedrich $^{\mathrm{a}, *}$, Brian D. Farrell ${ }^{\mathrm{b}}$ and Rolf G. Beutel ${ }^{\mathrm{a}}$ \\ ${ }^{a}$ Institut für Spezielle Zoologie und Evolutionsbiologie, Friedrich-Schiller-University Jena, D-07743 Jena, Germany; ${ }^{b}$ Museum of Comparative Zoology, \\ Harvard University, Cambridge, MA 02138, USA
}

Accepted 28 May 2008

\begin{abstract}
Thoracic structures of Tetraphalerus bruchi are described in detail. The results were compared with features found in other representatives of Archostemata and other coleopteran suborders. Differences between thoracic structures of Tetraphalerus and members of other archostematan subgroups are discussed. External and internal characters of larval and adult representatives of 37 genera of the coleopteran suborders are outlined, coded and analysed cladistically, with four groups of Neuropterida as outgroup taxa. The results strongly suggest the branching pattern Archostemata + [Adephaga + (Myxophaga + Polyphaga)]. Coleoptera excluding Archostemata are supported with a high Bremer support. Important evolutionary changes linked with this branching event are simplifications of the thoracic skeleton resulting in reduced degrees of freedom (i.e. a restricted movability, especially at the leg bases), and a distinct simplification of the muscle system. This development culminates in Polyphaga, which are also strongly supported as a clade. Internalization of the partly reduced propleura, further muscle losses, and the fusion of the mesoventrites and metaventrites - with reversal in Scirtoidea and Derodontidae - are autapomorphies of Polyphaga. Archostemata is a small relict group in contrast to highly successful xylobiontic groups of Polyphaga. The less efficient thoracic locomotor apparatus, the lack of cryptonephric Malpighian tubules, and the rise of angiosperms with beetle groups primarily adjusted to them may have contributed to the decline of Archostemata.

(C) The Willi Hennig Society 2008.
\end{abstract}

\section{Introduction}

The key role of the small relict group Archostemata in the phylogenetic reconstruction of the extremely species-rich Coleoptera is reflected by the widely recognized preservation of many plesiomorphic features in the adult stage (Beutel and Haas, 2000; Kukalová-Peck and Lawrence, 2004), the strong representation in the early Mesozoic fossil record (Ponomarenko, 1969), and the controversy about its placement in older and recent phylogenetic studies. A scenario with Archostemata as the most ancestral branch and the small suborder Myxophaga closely related with the extremely species-rich Polyphaga was suggested by Crowson (1960). This scheme was presented as a Hennigian phylogenetic tree by Klausnitzer

*Corresponding author:

E-mail address: frank.friedrich@uni-jena.de
(1975), with 14 characters mapped on it. A different hypothesis with Archostemata as sister group of Adephaga was proposed by Baehr (1979) based on a non-numerical analysis of prothoracic features, similar to a scheme earlier suggested by Vulcano and Pereira (1975), with "Cupediformia" as a subordinate group of Adephaga. A branching pattern Polyphaga + [Archostemata + (Myxophaga + Adephaga)] was suggested by Kukalová-Peck and Lawrence (1993) based on an informal evaluation of characters of the hind wing. The first cladistic evaluation of a comprehensive morphological data set was presented by Beutel and Haas (2000). The results confirmed Crowson's idea, with the branching pattern Archostemata + [Adephaga + (Myxophaga + Polyphaga)]. This was again challenged by Kukalová-Peck and Lawrence (2004), who obtained the same pattern as in their earlier study with a numerical analysis of a similar set of wing characters. In a molecular study based on $18 \mathrm{~S}$ rDNA 
Adephaga and Polyphaga were placed as sister groups, with Archostemata and Myxophaga basal to them (Shull et al., 2001; see also Vogler, 2005). In another analysis of 18S rDNA data (Caterino et al., 2002), Archostemata was placed as sister group of the other suborders after constraining Coleoptera and the suborders as monophyletic, and Adephaga as sister taxon of Polyphaga, as in Shull et al. (2001). A sister-group relationship between Cupedidae (as the only archostematan terminal) and the myxophagan family Sphaeriusidae was obtained in a recent molecular study with a very comprehensive sampling of adephagan and polyphagan taxa (Hunt et al., 2007).

Despite the widely recognized phylogenetic importance of the group, the morphology of archostematan species, which are generally rare or extremely rare (Beutel et al., 2008), is still insufficiently studied. Whereas a considerable amount of information on larval features (Beutel and Hörnschemeyer, 2002a,b) and adult head structures (Hörnschemeyer et al., 2002, 2006; Beutel et al., 2008) has accumulated recently, to date, Priacma serrata was the only species of Archostemata with well-studied and documented thoracic features (Baehr, 1975). Therefore, an improved knowledge of archostematan thoracic structures appeared to be highly desirable. In 2006, a series of Tetraphalerus bruchi, a very rare species of Ommatidae, was collected by Adriana Marvaldi in the framework of the Beetle Tree of Life (BToL) project. Some specimens were used for extraction of DNA and others for morphological investigations. One purpose of the present study was the detailed documentation of thoracic features using innovative morphological techniques such as microcomputer tomography $(\mu-\mathrm{CT})$ imaging and computeraided three-dimensional reconstructions. The second aim is the re-evaluation of the interrelationships of the four coleopteran suborders. The available morphological data, not only concerning Archostemata, but also other groups of beetles has greatly increased during the last few years (Beutel and Hörnschemeyer, 2002a,b; Hörnschemeyer et al., 2002, 2006; Anton and Beutel, 2004, 2006; Beutel and Komarek, 2004; Hörnschemeyer, 2004, 2005; Lawrence, 2005; Leschen, 2005; Friedrich and Beutel, 2006; Ge et al., 2007; Beutel et al., 2008). Therefore, it appeared appropriate to readdress the issue of the subordinal interrelationships based on an extensive morphological data set involving characters of different life stages and external and internal structures of all body regions. The starting point was a data matrix presented in Beutel and Haas (2000). However, many data unavailable at that time, and potentially "ancestral" polyphagan taxa (Lawrence, 1999, p. 383) such as Eucinetidae, Scirtidae, Clambidae (Scirtoidea) and Dascillidae were added to the matrix. A third aim of this contribution was to develop an evolutionary scenario for the early evolution of beetles based on the results of the cladistic analyses, with the focus on the question of why Archostemata, which were a rather successful lineage in the early Mesozoic, became nearly extinct, whereas other wood associated groups such as Buprestidae and Cerambycidae were extremely successful.

\section{Materials and methods}

List of species studied (terminal taxa used in cladistic analysis in bold face). For additional taxa examined see Beutel and Haas (2000).

Owing to lack of material or unknown immature stages several terminal taxa included in the analyses (e.g. Raphidiidae, Corydalinae, Ommatidae, Cupedidae) are chimeras with different larval and adult representatives. This approach was used when both stages belong to different supraspecific taxa, which are however more closely related to each other than with any other taxon used in the analysis.

Archostemata: Cupedidae (chimera): Priacma serrata LeConte, 1861 (A = adult: $\mathrm{FAE}=$ formaldehydeethanol-acetic acid; diss. $=$ dissected, $\mathrm{SEM}=$ scanning electron microscopy; Montana, USA, collected by PD Dr Th. Hörnschemeyer [University of Göttingen]), Rhipisideigma raffrayi (Fairmaire, 1884) ( $\mathrm{L}=$ larva: ethanol; diss., micr. = microtome sections; northern Madagascar, Ambohitantely Nat. Res., collected by P. Švácha)

Ommatidae (chimera): Tetraphalerus bruchi Heller, 1913 (A: FAE; diss., micr., $\mu$-CT, SEM; Argentina, Provincia de Mendoza, collected by Dra. A. Marvaldi), Omma stanleyi Newman, 1839 [L: ethanol; external features examined (Australian National Insect Colletion, CSIRO Canberra)]

Micromalthidae: Micromalthus debilis Heller, 1913 (A: FAE; diss., micr., $\mu$-CT; collected from colonies in the labs of Prof. Dr. D. R. Maddison and T. Hörnschemeyer, respectively)

Myxophaga: Torridincolidae: Ytu zeus Reichardt, 1973 (L: micr., SEM; A: micr.; Brazil, provided by Prof. Dr. Cl. Costa), Satonius kurosawai (Satô, 1982) (L, A: ethanol; Japan, Aichi Prefecture, collected by the late Masataka Satô)

Microsporidae: Microsporus spp. (undetermined species from Arizona and Europe) (L, A: FAE; micr., SEM; Arizona, USA, collected by R. G. Beutel and D. R. Maddison)

Hydroscaphidae: Hydroscapha natans LeConte, 1874 (L: FAE; micr., SEM; A: FAE; micr., SEM; Arizona, USA, collected by R. G. Beutel and D. R. Maddison)

Adephaga: Gyrinidae: Spanglerogyrus albiventris Folkerts, 1979 [A: FAE; micr., SEM; Alabama, USA, collected by R. G. Beutel and Prof. Dr. R. E. Roughley (University of Manitoba)], Gyrinus substriatus Stephens, 
1828 (L, A: Bouin; micr.; Germany, collected by R. G. Beutel)

Haliplidae: Haliplus lineatocollis Marsham, 1802 (L: Dubosq-Brasil, FAE; micr.; A: Dubosq-Brazil; diss., SEM; Gönninger See, Germany, collected by R. G. Beutel)

Trachypachidae: Trachypachus holmbergi Mannerheim, 1853 (L: micr., SEM; A: FAE; diss., SEM; Edmonton, Canada, collected by R. E. Roughley)

Noteridae: Noterus crassicornis Müller, 1776 (L: FAE; diss., micr.; A: FAE; diss.; Jena, Germany, collected by R. G. Beutel)

Amphizoidae: Amphizoa lecontei Matthews, 1872 (L: ethanol; diss., micr.; A: FAE; diss., SEM; British Columbia, Canada, collected by R. G. Beutel)

Hygrobiidae: Hygrobia tarda (Herbst, 1804) (L: Bouin; diss.; A: Bouin; micr., diss., SEM; Münsterland, Germany, collected by R. G. Beutel)

Dytiscidae: Dytiscus marginalis Linnaeus, 1758 (L: FAE; diss.; A: FAE; diss.; Jena, Germany, collected by R. G. Beutel)

Carabidae: Carabus spp. (L: FAE; micr.; A: FAE, diss.; Jena, Germany, collected by R. G. Beutel)

Polyphaga: Staphylinoidea, Hydraenidae: Ochthebius spp. (L, A: FAE; micr., SEM; Thüringer Wald, Germany, collected by R. G. Beutel)

Agyrtidae: Necrophilus hydrophiloides Guérin-Menneville, 1835 (L: micr.; Field Museum, made available by Dr. A. F. Newton) (data on adults taken from the literature; e.g. Newton, 2005).

Leiodidae: Catops sp. (L: micr.; A: diss., micr.; Jena, Germany, collected by E. Anton)

Silphidae: Nicrophorus spp. (L: FAE; diss.; A: ethanol; diss., micr.; Jena, Germany, collected by R. G. Beutel)

Hydrophiloidea, Hydrophilidae: Hydrophilus piceus (Linnaeus, 1758) (L, A: FAE; diss.; Muldeauen, Dessau, Germany, collected by R. G. Beutel)

Helophoridae: Helophorus sp. (L: micr., diss., SEM; A: diss., SEM; Jena, Germany, collected by R. G. Beutel)

Scarabaeoidea, Scarabaeidae: Cetonia aurata Linnaeus, 1758 (L, A: FAE; diss.; Jena, Germany, collected by R. G. Beutel)

Dascilloidea, Dascillidae: Dascillus cervinus Linnaeus, 1758 (A: ethanol; diss., micr., SEM; Jena, Germany, collected by E. Anton)

Scirtoidea, Eucinetidae: Eucinetus sp. (L: ethanol; micr; A: ethanol; diss., micr., SEM; Blue Ridge Pkwy., USA, collected by A. F. Newton [Field Museum of Natural History, Chicago, USA])

Clambidae: Calyptomerus sp. (A: ethanol; micr.; Germany, collected by E. Anton) (larval characters taken from Lawrence, 1991 and Leschen, 2005).

Scirtidae: Elodes sp. (L: ethanol; diss.; A: FAE; diss., micr., SEM; Jena, Germany, collected by F. Friedrich)
Byrrhidae (chimera): Byrrhus sp. (A: FAE; diss.), Cytilus alternatus Say, 1825 (L: ethanol; diss.; provided by Dr. P. J. Johnson [South Dakota State University)

Elateridae: Selatosomus aeneus (Linnaeus, 1758) (A: dried; collection of the Phyletisches Museum) (thoracic musculature treated in Larsén, 1966)

Cantharidae: Cantharis spp. (L: FAE; diss.), Cantharis fusca (Linnaeus, 1758) (A: FAE; diss.; Jena, Germany, collected by R. G. Beutel)

Derodontidae: Derodontus maculatus Melsheimer, 1844 (L: ethanol; A: FAE; diss., micr., SEM; Arkansas, USA, provided by R. Leschen)

Coccinellidae: Coccinella sp. (L, A: FAE; diss.; Jena, Germany, collected by R. G. Beutel)

Tenebrionidae: Tenebrio molitor Linnaeus, 1758 (L, A: FAE; diss.; Jena, Germany, collected by R. G. Beutel)

Chyrsomelidae: Leptinotarsa decemlineata (Say, 1824) (L, A: FAE, 70\% ethanol; diss.; Jena, Germany, collected by R. G. Beutel), several undetermined species (L: FAE; diss.; Jena, Germany, collected by R. G. Beutel)

Outgroup:

Megaloptera, Sialidae: Sialis sp. (L, A: FAE; diss.; Jena, Germany, collected by R. G. Beutel)

Corydalidae, Corydalinae (chimera): Neohermes sp. (L: FAE; diss.; Arizona, USA, coll. By D. R. Maddison), Corydalus sp. (A, L: ethanol; loan from the Zoologische Staatssammlung München)

Raphidioptera, Raphidiidae (chimera): Raphidia sp. (L: FAE; diss., micr., SEM; A: FAE, ethanol; diss.; Jena, Germany, collected by F. Hünefeld and R. G. Beutel) (data on adults of Agulla taken from Ferris and Pennebaker, 1939 and Matsuda, 1956)

Neuroptera, Myrmeleontidae: Myrmeleon sp. (L, A: FAE; diss.; Jena, Germany, collected by R. G. Beutel and E. Anton), Myrmelontidae spp. (A: FAE; undetermined species from Provincia de Mendoza, Argentina, collected by R. G. Beutel)

Three representatives of Scirtoidea and Dascillidae not included in Beutel and Haas (2000) were added to the matrix. A number of characters were excluded either because they were uninformative, insufficiently documented, or not clearly definable as discrete states.

Additional data were extracted from the literature (e.g. thoracic muscles of adults of Coleoptera: Larsén, 1966; Baehr, 1975 etc.; muscles of Neuropterida: Matsuda, 1956, 1970; Maki, 1936, 1938; Korn, 1943; Czihak, 1953; Kelsey, 1954, 1957; Mickoleit, 1973; larval morphology: Böving and Craighead, 1931; Lawrence, 1991, 2005; LeSage, 1991; Leschen, 2005; etc.).

Only few specimens of Tetraphalerus bruchi were available for this study. We used one specimen 
for $\mu$-CT-imaging, one specimen for scanning electron microscopy, and one for microtome sectioning.

\section{Microcomputer tomography}

A male specimen of Tetraphalerus was dehydrated in an ethanol series and critical-point-dried (Balzer CPD 030 Critical Point Dryer). The $\mu$-CT scan was performed by Dr. J. Goebbels and J. Nötel at the Federal Institute for Materials Research (BAM), Berlin (see Goebbels et al., 2002) using a three dimensional (3D)-CT II X-ray tomograph. The image stack has a resolution (isovoxel size) of $2.5 \mu \mathrm{m}$.

\section{Computer-based 3-D reconstruction}

Volume renderings of the $\mu-\mathrm{CT}$ image stack were created using Bitplane Imaris 5.7 software. Threedimensional images of the volume rendering (to be used with 3-D glasses) were taken using the screenshot function. Detailed drawings of the skeletomuscular system based on virtual longitudinal sections of the volume rendering were made with Adobe Illustrator CS2 software.

\section{Scanning electron microscopy}

For the examination of external skeletal structures a specimen was cleaned with ultrasonic sound, dehydrated in an ethanol series, dried and coated with gold (EmiTech K500 sputter coater). Pictures were taken with a Philips XL 30 ESEM and Scandium software. For the study of the endoskeleton the same specimen was rehydrated, macerated over night in $5 \% \mathrm{KOH}$ solution at $55^{\circ} \mathrm{C}$ and dissected.

\section{Cladistic analysis}

Character analysis was carried out with NONA (Goloboff, 1995) and PAUP 4.0b10 (Swofford, 2001). Bremer-support values (Bremer, 1994) were calculated with NONA. Raphidiidae, Corydalinae, Myrmeleon sp. and Sialis sp. were used as outgroup taxa and treated as all other groups in the analysis (simultaneous analysis; Nixon and Carpenter, 1993).

\section{Bayesian analysis}

Bayesian analysis was conducted with MrBayes 3.1.2 (Huelsenbeck and Ronquist, 2001) using the Mkv model (Lewis, 2001). Four chains were run simultaneously in two independent runs, using the default values for priors and other parameters. The analysis started from random trees and run for $3.2 \times 10^{6}$ generations, sampling chains every 100th generation. "Burn-in" values were established after visual examination of a plot of the standard deviation of the split frequencies between two simultaneous runs.

\section{Morphological results}

Thoracic skeleton of Tetraphalerus bruchi

The thorax is about 0.35 times as long as the total body length (Fig. 1A). The maximum length-width ratio of the thorax is about 0.55 . The dark brown thoracic skeleton is strongly sclerotized and densely covered with tubercles and whitish scale-like setae except for the parts covered by the elytra (Figs 2,3). The exposed sclerites are closely attached to each other, without externally visible membranous parts. A membranous cervical region or distinct cervical sclerites are also absent.

The femora and tibiae of all legs are completely covered with scale-like setae (see Fig. 4A). The tibal spurs are short and robust (see Fig. 4A: tibs). The 5-segmented tarsi bear stiff setae without apical branching. The dorsal and ventral side of the tarsi show an equal density of setae. An arolium or other adhesive structures are absent from the legs of both sexes (see Fig. 4B,C).

Prothorax. With about $40 \%$ of the total length of the thorax the slender prothorax is the longest thoracic segment. The dorsal half is formed by the large pronotum (Fig. 2D). The posterior part of this saddleshaped sclerite covers the mesonotum in front of the elytral bases. The anterior pronotal margin is part of the articulation socket for the head. A distinctly visible dorsomedian suture with a corresponding well-developed internal ridge is present (see Fig. 8C: mrp). Laterally, the pronotum is broadly contiguous with the propleura. The anterior-most part is firmly connected with the anterolateral edges of the proventrite.

The slender, elongate propleura shows no external or internal subdivision (Figs 1A,2D). Its dorsal rim is folded into the thoracic lumen and forms a cryptopleura (Figs 5A and 8C: cpl). The inner surface lacks an invaginated propleural apodeme (Fig. 5A). Anteriorly, the propleural margin does not contact the head capsule. A short, broad process of the posterior part of the ventral propleural rim articulates with the lateral procoxal rim. The ventral margin anterad of the pleurocoxal joint is firmly connected with the lateral edge of the proventrite and a distinct anapleural cleft is present (Figs 1A and 2D: apc1). The posterior-most part of the propleura protrudes posterad (Figs 1A,2D and 3B: ppp), overlying the impressed anterior part of the mesanepisternum (Figs 1A and 2D). A smooth area on the medial face of this propleural protrusion (Fig. 3B: 
A

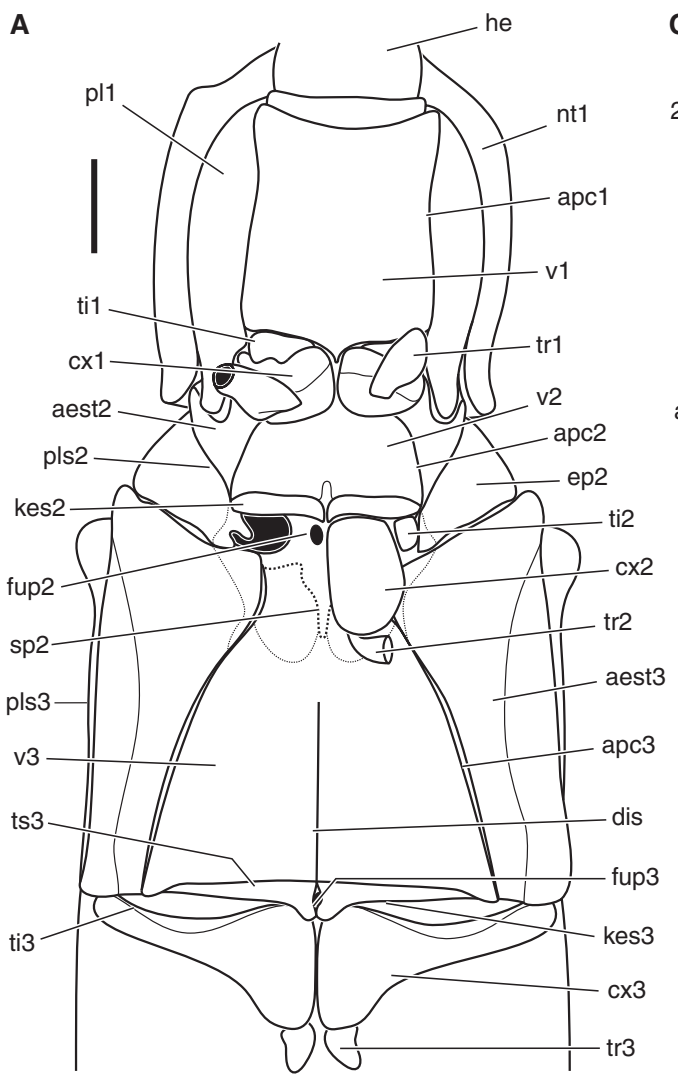

C

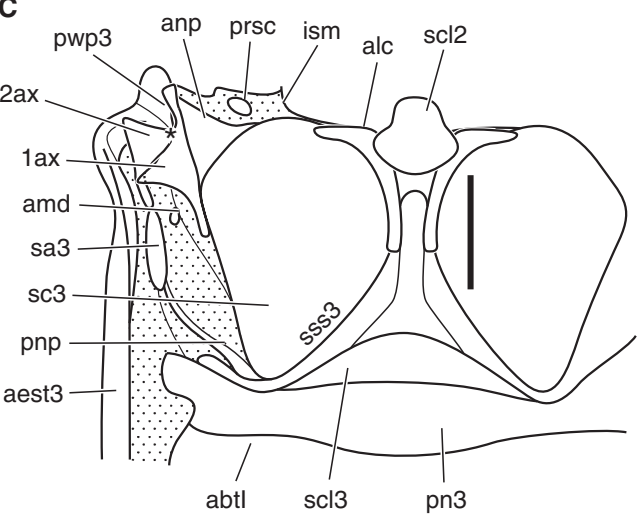

B

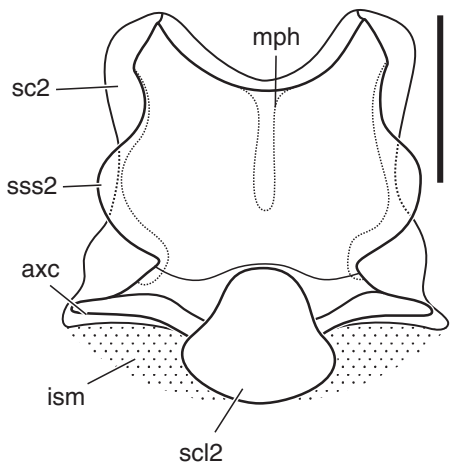

Fig. 1. Thoracic skeleton of Tetraphalerus bruchii. (A) ventral view; (B) dorsal view of mesonotum; (C) dorsal view of metathorax.1/2ax, first/second axillary; abtI, first abdominal tergite; aest2/3, mes-/metanepisternum; alc, alacrista; amd, axillary muscle disc; anp, anterior notal process; apc1/2/3, anapleural cleft; axc, axillary cord; cx1/2/3, pro-/meso-/metacoxa; dis, discrimen; ep2, mesepimeron; fup2/3, furcal pit of meso/metathorax; he, head; ism, intersegmental membrane; kes2/3, meso-/metathoracic katepisternum; mph, median ridge of prophragma; nt1, pronotum; pl1, propleura; pls2/3, meso-/metathoracic pleural suture; pn3, metapostnotum; pnp, posterior notal process; prsc, prealar sclerite; pwp3, pleural wing process of metathorax; sa3, metathoracic subalare; sc2/3, meso-/metascutum; scl2/3, meso-/metascutellum; sp2, mesospina; sss2/3, meso-/metathoracic scutoscutellar suture; til/2/3, pro-/meso-/metathoracic trochantin; tr1/2/3, pro-/meso-/metathoracic trochanter; ts3, transverse suture of metaventrite; v1/2/3, pro-/meso-/metaventrite. Scale bar: $500 \mu \mathrm{m}$.

c1) articulates with a strong mesopleural condyle (see below) forming a promesothoracic interlocking mechanism.

The anterior rim of the rectangular proventrite forms the ventral half of the thoracic articulation socket ring for the head. In the anterior-most part, the inner surface shows two well-defined rounded areas (Figs 5A and $8 \mathrm{~B}: \mathrm{cv})$. These structures are very likely vestiges of cervical sclerites completely merged with the ventrite (see below). The inner surface of the proventrite forms a distinctly developed transverse ridge in front of the procoxal cavities (see Fig. 8C: tvr). The small prosternal process does not separate the globular procoxae (Figs 1A and 2A). The movements of the procoxae are mainly restricted to rotation, but during rotation anterior-posterior-directed motions can also be accomplished.

The large, triangular trochantin is fully exposed anterior of the procoxa (Figs 1A and 2A,D: ti1). The trochantino-coxal joint is formed by the anterolateral edge of the procoxa and the posterolateral process of the trochantin.

The lateral arms of the large profurca are broad and strongly sclerotized (Fig. 5A: fu1). A short common stem is present. The posteriorly directed profurcal parts are merged with the sclerotized origin of M. 42. A prothoracic spinasternum could not be identified. It is apparently absent or indistinguishably fused with the ventrite (the spinal muscles are also absent, see below).

Mesothorax. The mesothorax is somewhat smaller than the metathorax. It is less than half as long (Fig. 1A). The mesonotum is short and largely covered by the pronotum and metanotum and the anterior part of the elytra. The concealed parts are weakly sclerotized. Only the prominent exposed median part of the scutellum (scutellar shield) is strongly sclerotized and covered with 

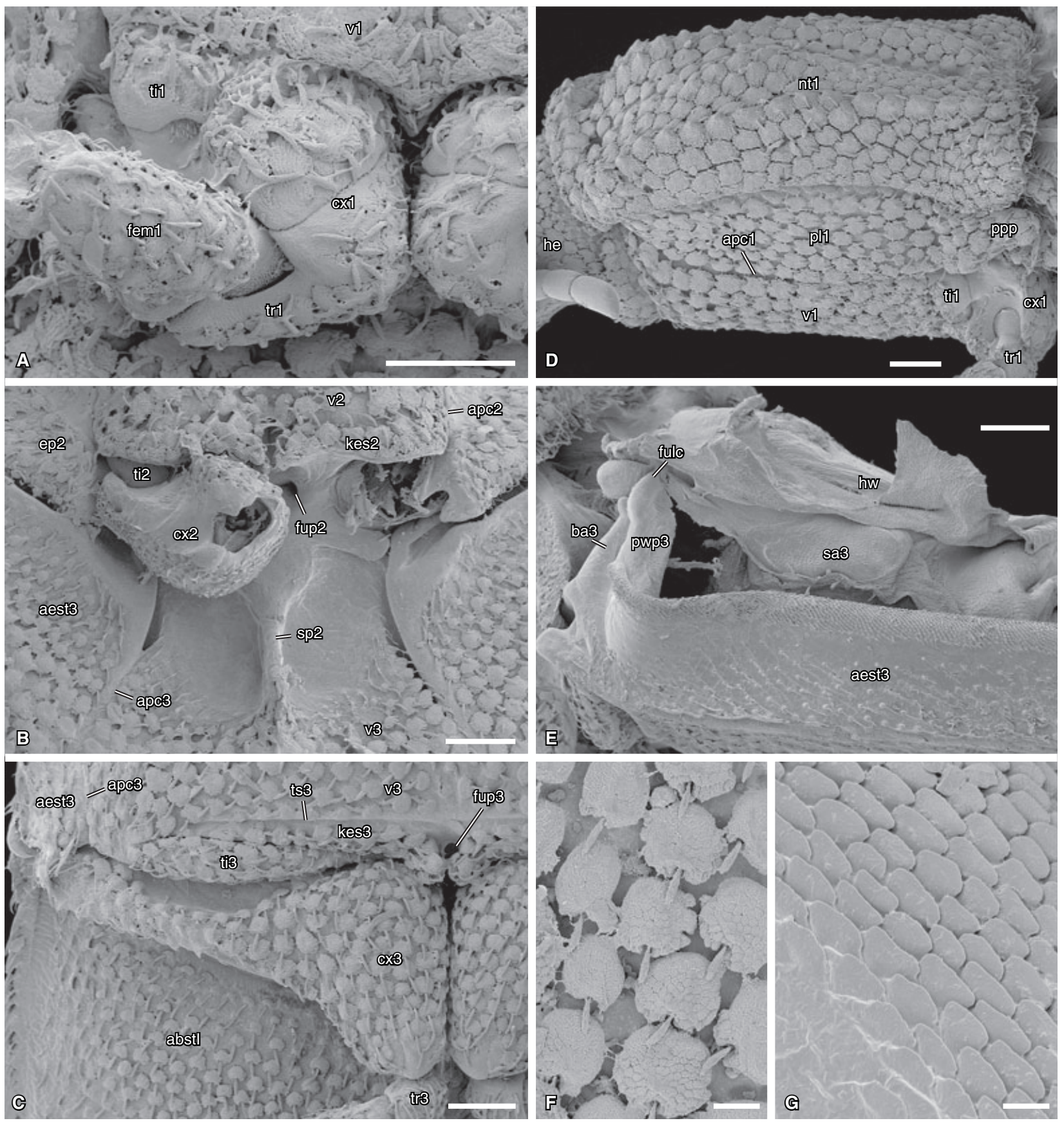

Fig. 2. Scanning electron micrographs, external thoracic structures of Tetraphalerus bruchii. (A) procoxa, ventral view; (B) mesocoxal region, ventral view (mesocoxa artificially bent upwards); (C) metacoxal region, ventral view; (D) prothorax, lateral view; (E) metathoracic wing base, lateral view; (F) surface sculpture of scale like setae; (G) semilunar microtrichia on surface of alacrista. abstI, first abdominal sternite; aest3, metanepisternum; apc1/2/3, anapleural cleft; ba3, external part of metathoracic basalare; cx1/2/3, pro-/meso-/metacoxa; ep2, mesepimeron; fem1, prothoracic femur; fulc, fulcrum; fup2/3, furcal pit of meso-/metathorax; he, head; hw, hind wing; kes2/3, meso-/metathoracic katepisternum; nt1, pronotum; pl1, propleura; ppp, posterior propleural protrusion; pwp3, pleural wing process of metathorax; sa3, metathoracic subalare; sp2, mesospina; til/2/3, pro-/meso-/metathoracic trochantin; tr1/3, pro-/metathoracic trochanter; ts3, transverse suture of metaventrite; vl/2/3, pro/meso-/metaventrite. Scale bar: (A-E) $200 \mu \mathrm{m}$; (F) $50 \mu \mathrm{m}$; (G), $10 \mu \mathrm{m}$.

scales. The ventrally oriented lateral part of the notum is formed by the mesoscutum (Fig. 1B: sc2). The laterally directed posterior notal process is formed by the posterolateral mesonotal edge, which is connected with the elytral base by the axillary cord (Fig. 1B: axc). Anteriorly, the mesonotum is bent downward, thus 


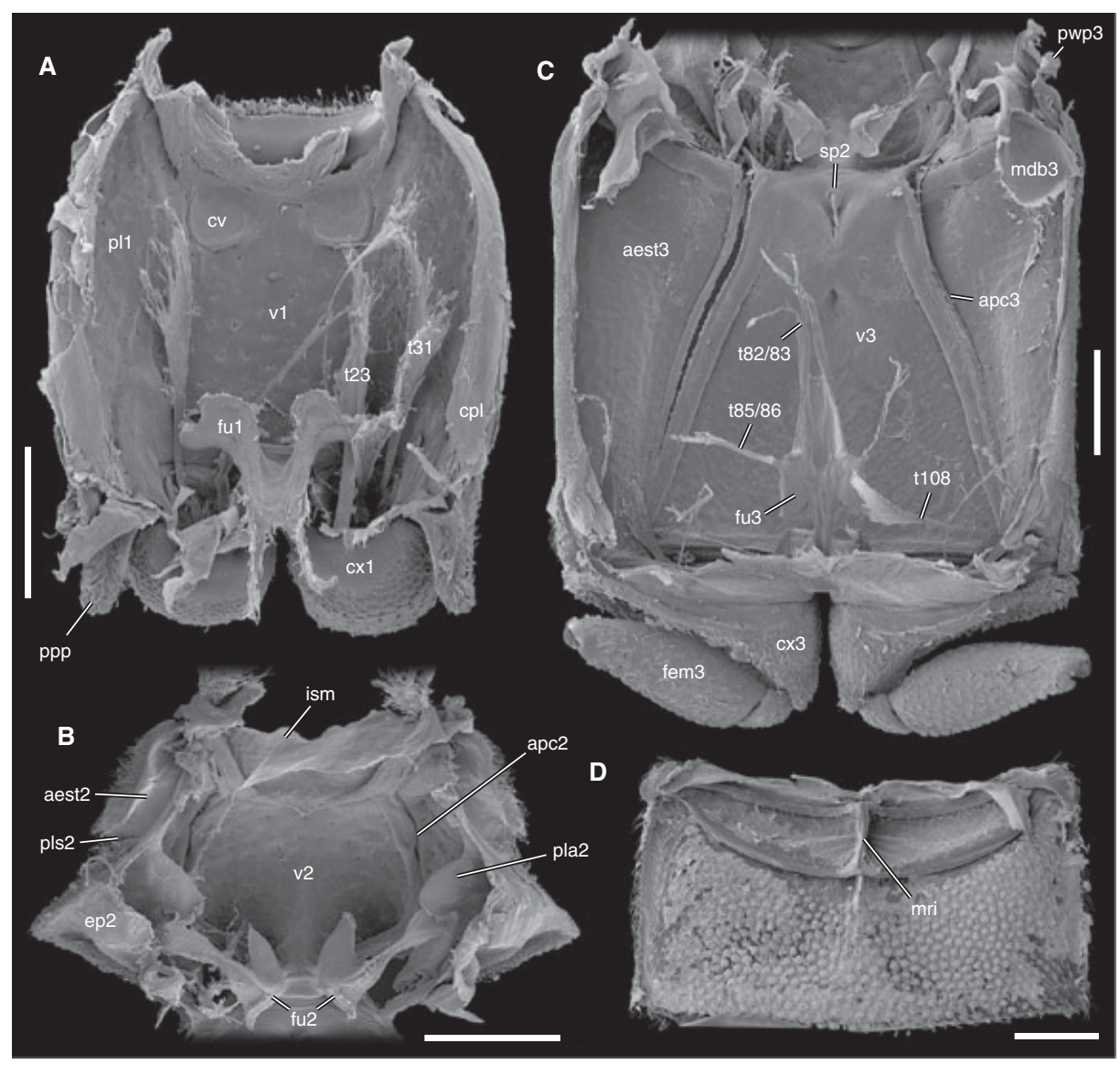

Fig. 3. Scanning electron micrographs, pro-mesothoracic interlocking device of Tetraphalerus bruchii. (A) posterolateral edge of pronotum, ventral view; (B) posterior propleural protrusion, dorsomedian view; (C,D) anterior region of mesanepisternum; (C) lateral view (concavity of mesanepisternum outlined), (D) ventral view. aest2, mesanepisternum; apc2, mesothoracic anapleural cleft; c1/2, articulary cavity of joint 1/2; cx1, procoxa; ep2, mesepimeron; nt1, pronotum; p1/2, articulary process of joint 1/2; pl1, propleura; pls2, mesothoracic pleural suture; ppp, posterior propleural protrusion; v2, mesoventrite. Scale bar: (A) $100 \mu \mathrm{m}$, (B,C) $50 \mu \mathrm{m}$.

forming a well-developed, undivided prophragma (see Fig. 10A: ph1). Starting on the posterior face of the prophragma a well-developed median ridge stretches posterad across half of the mesonotal total length (Figs 1B and 10A,E: mph).

The mesopleura is separated into the anepisternum and epimeron by the pleural suture (Figs $1 \mathrm{~A}$ and 5B: pls2). Its dorsal part is deeply impressed. The ventral half of the suture is less distinct but still easily recognizable by the lack of tubercles. Internally, the anterior part of the strongly-developed pleural ridge bears the large, plate-like pleural arm (Fig. 5B: pla2). Ventrally, the pleural ridge articulates with the lateral coxal rim, thus forming the pleuro-coxal joint. The anterodorsal edge of the mesanepisternum forms a large semilunar process (Fig. 3C,D: p1), which is completely covered by pronotum and propleura (Fig. 2D). The smooth surface of the ventrolateral part of this process articulates with the posteromedial wall of the propleura (Fig. 3B: c1; anterior part of the propleural protrusion). The dorsal rim of the mesanepisternal process bears a long, slender carina (Fig. 3C: p2) and interacts with a notch of the posterolateral pronotum (Fig. 3A: c2). Below this process, a distinct concavity of the mesanepisternum (indicated by interrupted line in Fig. 3C) receives the posterior propleural protrusion (Figs 1A and 2D). This promesothoracic interlocking mechanism impedes lateral movements between the both segments. Thus, the mobility of the prothorax is restricted to the sagittal plane. The broad dorsal part of the wedge-shaped mesepimeron is covered by the elytra and is posteriorly closely adjacent with the anterior rim of the metanepisternum. Narrow membranous areas between the pleural parts of the pterothoracic segments are only visible internally. A distinct anapleural cleft separates the mesanepisternum and the mesoventrite (Figs 1A,2B and 5B: apc2).

The short mesoventrite lacks an external discriminal line and an internal median ridge (Figs $1 \mathrm{~A}$ and $5 \mathrm{~B}$ : 


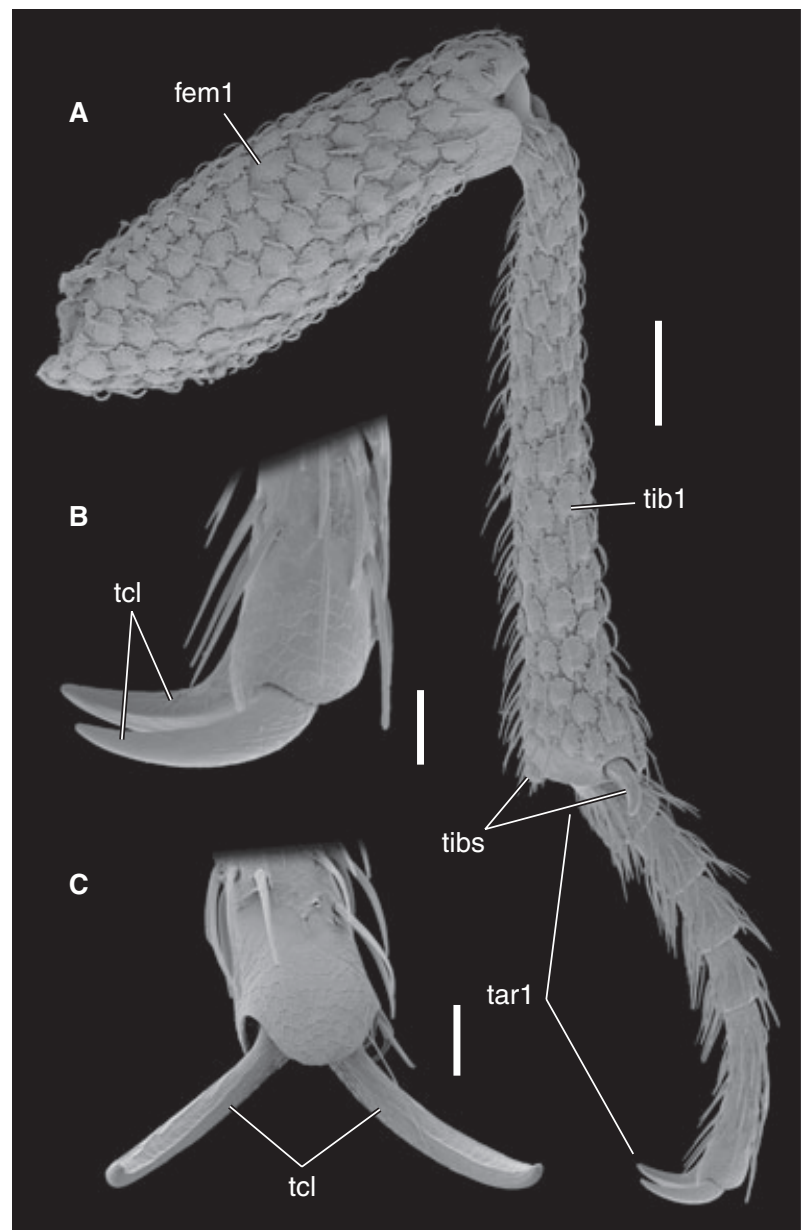

Fig. 4 Scanning electron micrographs, fore leg of Tetraphalerus bruchii. (A) posterior view; (B, C) distal half of 5th tarsomere; (B) posterior view, (C) medial view. fem1, prothoracic femur; tar1, protarsus; tcl, tarsal claws; tib1, prothoracic tibia; tibs, tibial spurs. Scale bar: (A): $100 \mu \mathrm{m},(B, C) 50 \mu \mathrm{m}$.

v2). The paired, broad katepisterna are clearly separated from the main part of the mesoventrite by a transverse suture (Figs 1A and 2B: kes2). They form a distinct condyle mesally, which articulates with the anteromesal edge of the mesocoxa (Figs 1A and 2B). The small, externally visible trochantin is located posterad of the katepisternum and articulates with the anterolateral rim of the mesocoxa (Figs 1A and 2B: ti2).

The mesocoxae are more posteriorly directed and flattened than the procoxae (Fig. 1A). The degrees of freedom of the mesocoxae are strongly reduced. Rotation is nearly impossible, but there is a limited potential for promotion and remotion and abduction and adduction. The main action of the proximal part of the mid leg results from the extensive movability of the trochanter, which is articulated with the posterior coxal rim (Fig. 1A: tr2).
A distinct spinasternum II is present posterad of the mesocoxal cavities (Fig. 1A: sp2). The posterior part of this sclerite is fused with the metaventrite, but internally defined by a V-shaped incision (Fig. 5C: sp2). The compact mesofurca consists of two separate arms without a common stem (Fig. 5B: fu2). The middle part and the tip of the furcal arms are broadened. The apices reach almost to the mesopleural arm (Fig. 5B).

Elytra (Fig. 6). The long, slender elytra show a specific regular pattern resulting from the non-homogeneous sclerotization (i.e. the presence of rows of window punctures and the parallel longitudinal ridges, which are entirely covered with scales; Fig. 6I). The elytra cover the complete dorsal face of the pterothorax (except for the scutellar shield) and of the abdomen. The inner rim of the elytral base bears two patches of microtrichia (Fig. 6B,E,F), which interact with corresponding fields located on both the mesonotum and metanotum (e.g. alacristae: see Figs $1 \mathrm{~A}$ and $2 \mathrm{G}$ ). The outer rim of the elytron is bent inwards thus forming the epipleura (Fig. 6A: epl). It bears several rows of small, pointed microtrichia (Fig. 6C,D,G). These microstructures interact with the equally shaped spines of the dorsal metanepisternal rim (Fig. 2E) and the lateral face of the abdomen. The inner rims of both elytra are strongly flattened. The ventral surface is smooth on the left elytron, and densely covered with small, claw-shaped microtrichia dorsally (Fig. $6 \mathrm{H}, \mathrm{J})$. On the right elytron, the pattern is reversed. These fields of microtrichia provide an additional locking mechanism and keep the elytra in their resting position.

Metathorax. The large metathorax is strongly flattened (see Fig. 8). The dorsal portion of the metathoracic skeleton, which is covered by the elytra, is weakly sclerotized and partly membranous.

The metascutum is the largest part of the metanotum (Fig. 1C). It is subdivided by few lines or sutures: the anterolateral scutal line demarcates the triangular anterior notal process; a distinct scuto-scutellar suture separates the scutellum from the posterior part of the scutum (Fig. 1C). The anterior notal margin forms the strongly developed mesophragma (see Fig. 10E,G: ph2). The small prealar sclerite is embedded in the extensive dorsal intersegmental membrane in front of the anterior notal process (Fig. 1C: prsc). The slender posterior notal process originates on the posterolateral edge of the metascutum (Fig. 1C: pnp). The process is connected with the posterior margin of the wing by the axillary ligament.

The first axillary sclerite articulates with the mesal edge of its triangular body with the anterior process of the mesonotum (Fig. 1C: 1ax). The angle $\alpha$ (see Hörnschemeyer, 1998; Fig. 3) between the lateral border of the 1 st axillary body and the mesonotum equals $c .52^{\circ}$. 


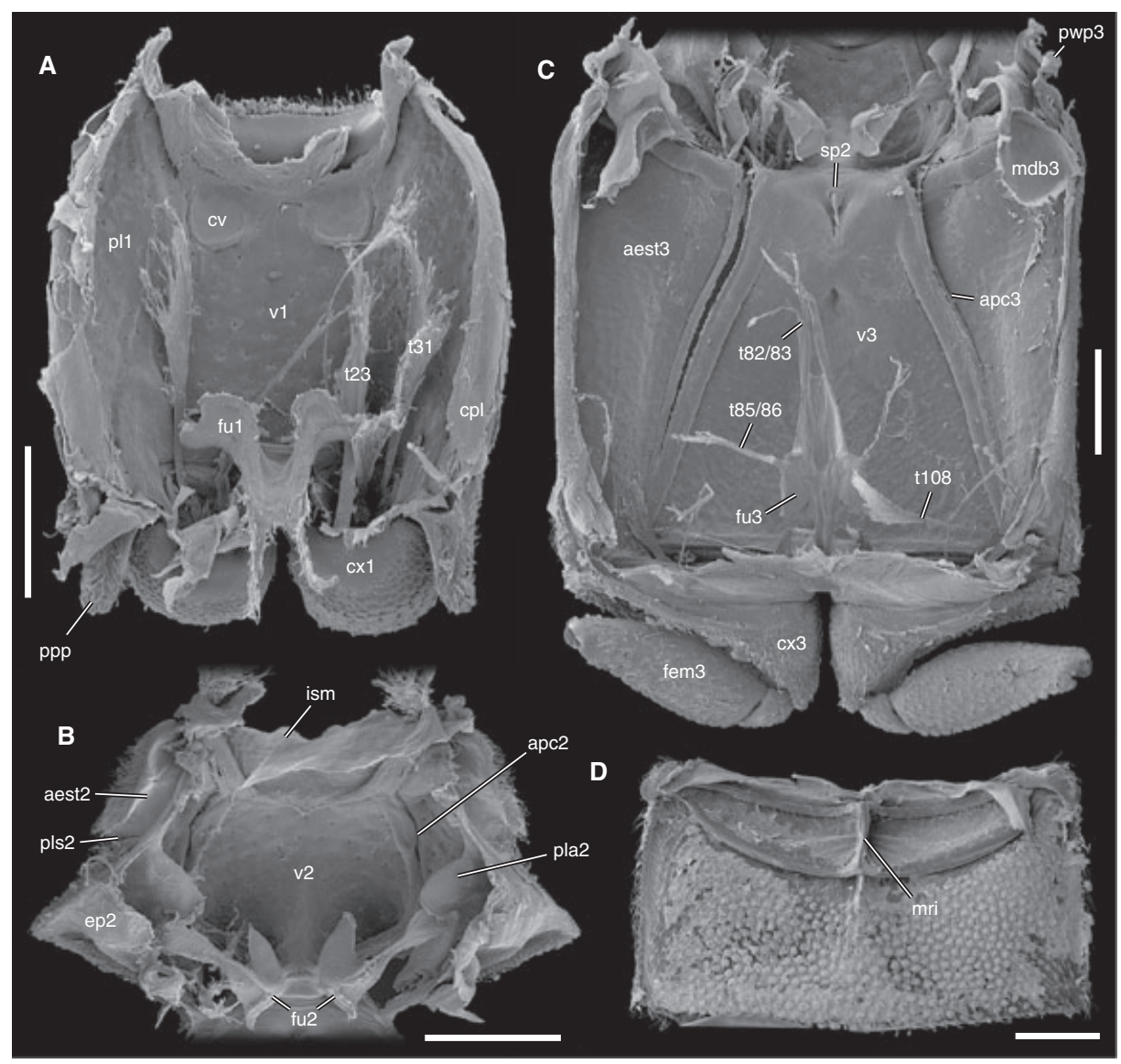

Fig. 5. Scanning electron micrographs, isolated sclerites of Tetraphalerus bruchii. (A-C) ventral thoracic parts, dorsal view; (A) prothorax, (B) mesothorax, (C) metathorax; (D) abdominal ventrite 1, ventral view. aest2/3, mes-/metanepisternum; anp, anterior notal process; apc2/3, anapleural cleft; cpl, cryptopleura; cv, vestiges of cervical sclerites?; cx1/3, pro-/metacoxa; ep2, mesepimeron; fem3, metathoracic femur; fu1/2/3, pro-/meso/metafurca; ism, intersegmental membrane; mdb3, muscle disc of metathoracic basalare; mri, median ridge; p11, propleura; pla2, mesopleural arm pls2, mesothoracic pleural suture; ppp, posterior propleural protrusion; pwp3, pleural wing process of metathorax; sp2, mesospina; v1/2/3, pro/meso-/metaventrite; t23, tendon of M. noto-coxalis prothoracis; t31, tendon of M. pleura-trochanteralis prothoracis; t82/83, common tendon of Mm. metasterni primus/secundus metathoracis; t85/86, common tendon of Mm. dorsoventrales secundus/tertius metathoracis; t108, tendon of M. furca-coxalis lateralis prothoracis. Scale bar: $500 \mu \mathrm{m}$.

The triangular head of the second axillary articulates with the neck region of the first axillary sclerite. The pleural wing joint (fulcrum) lies below of this articulation (Fig. 1C: asterisk). The posteriorly directed arm of the second axillary sclerite contacts the most medial part of the third axillary. An axillary muscle disc is located in the pleural membrane between the subalare and the lateral margin of the metanotum (Fig. 1C: amd). It is connected with the third axillary sclerite by a tendon.

The scutellum is short, but reaches about mid length of the scutum medially (Fig. 1C: scl3). The posteriorly adjacent short postnotum bears a low median ridge internally; its posterior part forms the short, medially divided metaphragma (Fig. 1C: pn3). The alacristae enclose the anterior half of the median scutal impression (Fig. 1C: alc). Their surface is covered by overlapping flat microtrichia (Fig. 2G), which interact with corresponding patches on the elytra (Fig. 6E) in resting position.

The anteromesal edge of the large, elongate metanepisternum forms the posterolateral part of the mesocoxal cavity (Figs 1A and 2C: aest3). On its dorsal margin, the anepisternum is separated from the epimeral parts of the metapleura by a nearly horizontal pleural suture (Fig. 1A: pls3). The internally corresponding pleural ridge is indistinct and completely obliterated in the mid part (see Fig. 8C: plr3). The pleural arm is absent. A distinct anapleural cleft is present, separating the ventral anepisternal margin and the metaventrite (Figs 1A, 5C, and 8C: apc3). Externally, the basalare is fused with the anterior face of the pleural wing process (Fig. 2E). The internalised part of the basalare forms an extensive muscle disc (Fig. 5C: mdb3). 

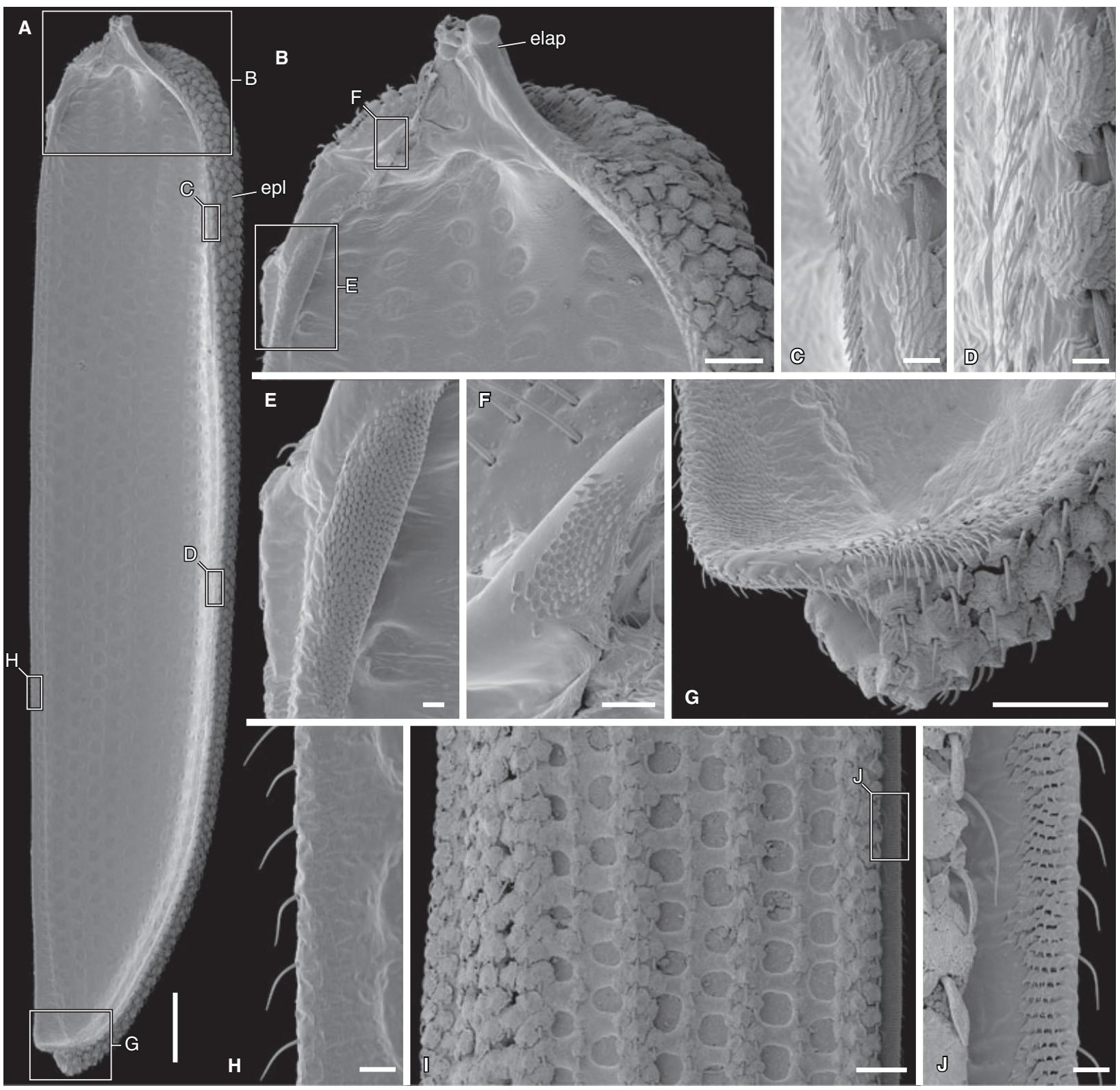

Fig. 6. Scanning electron micrographs, left elytron of Tetraphalerus bruchii. (A-H) ventral view; (A) overview; (B) elytral base; (C) proximal part of outer rim; (D) mid part of outer rim; (E) first patch of elytral base; (F) second patch of elytral base; (G) elytral apex; (H) inner rim; (I, J) dorsal view; (I) mid part of elytral surface with window-punctures; (J) medial rim. elap, articulation process of elytron; epl, epipleuron. Scale bar: (A) $500 \mu$ m; (B,G,I) $150 \mu \mathrm{m} ;(\mathrm{C}-\mathrm{F}, \mathrm{H}, \mathrm{J}), 20 \mu \mathrm{m}$.

The epimeral parts are mainly membranous or semimembranous (Fig. 1C). The ellipsoid subalare is embedded in this membranous region below the posterior notal process (Figs 1C, 2E: sa3). Similar to the basalare, the internal part of the subalare is a large, elongate disc representing a muscle attachment area.

The pentagonal metaventrite is posteriorly divided by a distinct median dicriminal line (Fig. 1A: v3, dis). A corresponding internal ridge is not existent. Together with the metanepisterna, it forms the posterior half of the mesocoxal cavities (Figs 1A and 2C). The anteromedian part of the sclerite represents the mesothoracic spinasternum (Fig. 5C). The well-developed katepisterna are separated from the posterior part of the ventrite by the transverse suture (Figs 1A and 2C: kes3, ts 3 ). A mesal katepisternal process articulates with the anteromesal metacoxal rim (Fig. 2C).

The large trochantin is exposed externally between katepisternum, anepisternum and the metacoxa (Figs 1A, 2C: ti3). The very broad, short metacoxae are almost 


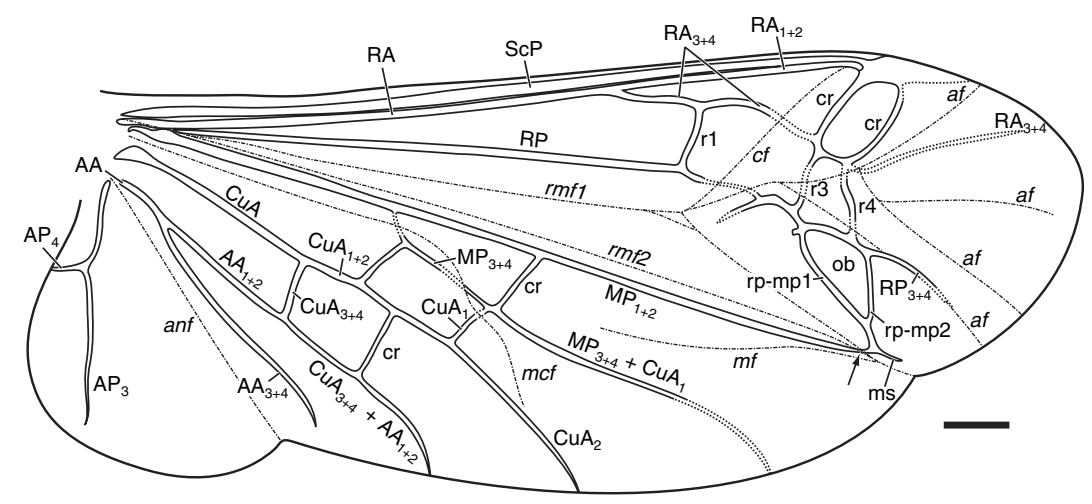

Fig. 7. Hind wing venation of Tetraphalerus bruchii (terminology following Kukalová-Peck and Lawrence, 1993). Wing folds indicated by chaindotted lines; indistinct, low pigmented parts of vein in dotted lines. AA, anterior anal vein; af, apical fold; anf, anal fold; AP, posterior anal vein; cf, central fold; cr, cross-vein; $\mathrm{CuA}$, anterior cubital vein; $\mathrm{CuA}_{3+4}+\mathrm{AA}_{1+2}$, fusion of $\mathrm{CuA}_{3+4}$ and $\mathrm{AA}_{1+2}$; mcf, medio-cubital fold; mf, medial fold; $\mathrm{MP}$, posterior medial vein; $\mathrm{MP}_{3+4}+\mathrm{CuA}_{1}$, fusion of $\mathrm{MP}_{3+4}$ and $\mathrm{CuA}_{1}$; ms, medial spur; ob, oblongum; r1/3/4, first/third/fourth radial cross-vein; rmf1/2, first/second radio-medial fold; RA, anterior radial vein; RP, posterior radial vein; rp-mp1/2, first/second radio-medial crossvein; $\mathrm{ScP}$, posterior subcostal vein. The venal branches are termed by subscripted numbers. The arrow refers to the weakness of the medial bar $\left(\mathrm{MP}_{1+2}\right)$. Scale bar: $1 \mathrm{~mm}$.

immovable (Figs 1A,2C and 5C: cx3). Only a slight degree of forward and backward deflection is possible.

The anterior arms of the comparatively small metafurca are fused proximally and continuous with the tendons of Mm. 82/83 (Fig. 5C: fu3). The bases of the lateral arms are broadened, but the distal parts are slender. The long furcal stem ends in a pit medially between the katepisterna (Fig. 1A and 2C: fup3).

Hind wing (Fig. 7). For the description of the hind wing structures, the terminology established by KukalováPeck and Lawrence (1993) is used.

The hind wing is large (male about $25 \mathrm{~mm}$ ) and slender. The dorsal and ventral surfaces of the wing are densely covered with minute microtrichia. Larger microtrichia are only present at the proximal end of the anterior margin. The anterior and posterior wing margins are approximately parallel. The apex is slightly rounded, but the apical field is short and small. It is separated from the medial field by a moderate incision. The apical part is rolled in resting position. A second incision is located in the posterior margin between the well-developed anal field and the medial field. The radial bar is formed by radius anterior (RA) and subcosta posterior $(\mathrm{ScP})$ and shows no distinct weakness in its apical part, in spite of the crossing area of the central fold. The two branches of radius anterior $\left(\mathrm{RA}_{1+2}\right.$; $\mathrm{RA}_{3+4}$ ) delimit the radial cell, which is subdivided by a cross ridge. The indistinct $\mathrm{RA}_{3+4}$ continues into the apical field. A stiff radius posterior (RP) is present. In the apical field, the branch $\mathrm{RP}_{3+4}$ is present, but its distal part is faint. Between the anterior and posterior radial branches, three radial cross veins are developed $(\mathrm{r} 1, \mathrm{r} 3, \mathrm{r} 4)$. The oblongum cell (ob) is bordered by $\mathrm{RP}_{3+4}$ and two radio-medial cross veins $(\mathrm{rp}-\mathrm{mp} 1,2)$ in the central field of the wing. The fused posterior ends of the cross veins contact the distal part of the medial bar $\left(\mathrm{MP}_{1+2}\right) \cdot \mathrm{MP}_{1+2}$ shows a small weak zone in front of this connection (bending zone; Fig. 7: arrow). The medial spur is short and straight laterally directed. The venation of the medial field is well developed: $\mathrm{MP}_{1+2}$ and $\mathrm{MP}_{3+4}$ are connected by two cross veins; most branches of the anterior cubital vein $(\mathrm{CuA})$ are fused distally with branches of media posterior $\left(\mathrm{MP}_{3+4}+\right.$ $\left.\mathrm{CuA}_{1}\right)$ or anal anterior $\left(\mathrm{CuA}_{3+4}+\mathrm{AA}_{1+2}\right)$, only $\mathrm{CuA}_{2}$ runs solitary to the posterior margin of the wing. Vein areas crossed by wing folds (Fig. 7: chain-dotted lines) are indistinct and low pigmented (dotted lines).

\section{Thoracic musculature of Tetraphalerus bruchi}

The set of muscles present in Tetraphalerus was evaluated using the $\mu$-CT image stack and Imaris 5.7 software. The muscular terminology and grouping system is mainly adopted from Beutel and Haas (2000). The homologies with muscles described in beetles by Larsén (1966) and Baehr (1975) and with the generalized muscle nomenclature for neopteran insects by Friedrich and Beutel (2008) will be provided as an electronic supplement (Appendix S1).

Prothorax (Figs 8, and 10A-F). Dorsal longitudinal muscles: M. 1 M. pronoti primus, fan-shaped; O (=origin): central pronotum (adjacent to median pronotal ridge), I (=insertion): dorsolateral area of postocciput. M. 2 M. pronoti secundus, long, slender; O: median part of prophragma, I: dorsal part of postocciput (mediad of M. 3). M. 3 M. pronoti tertius, slender (laterad of M. 2); O: lateral face of prophragma (close to M. 6), I: dorsolateral part of neck membrane. M. 6 M. pronoti 

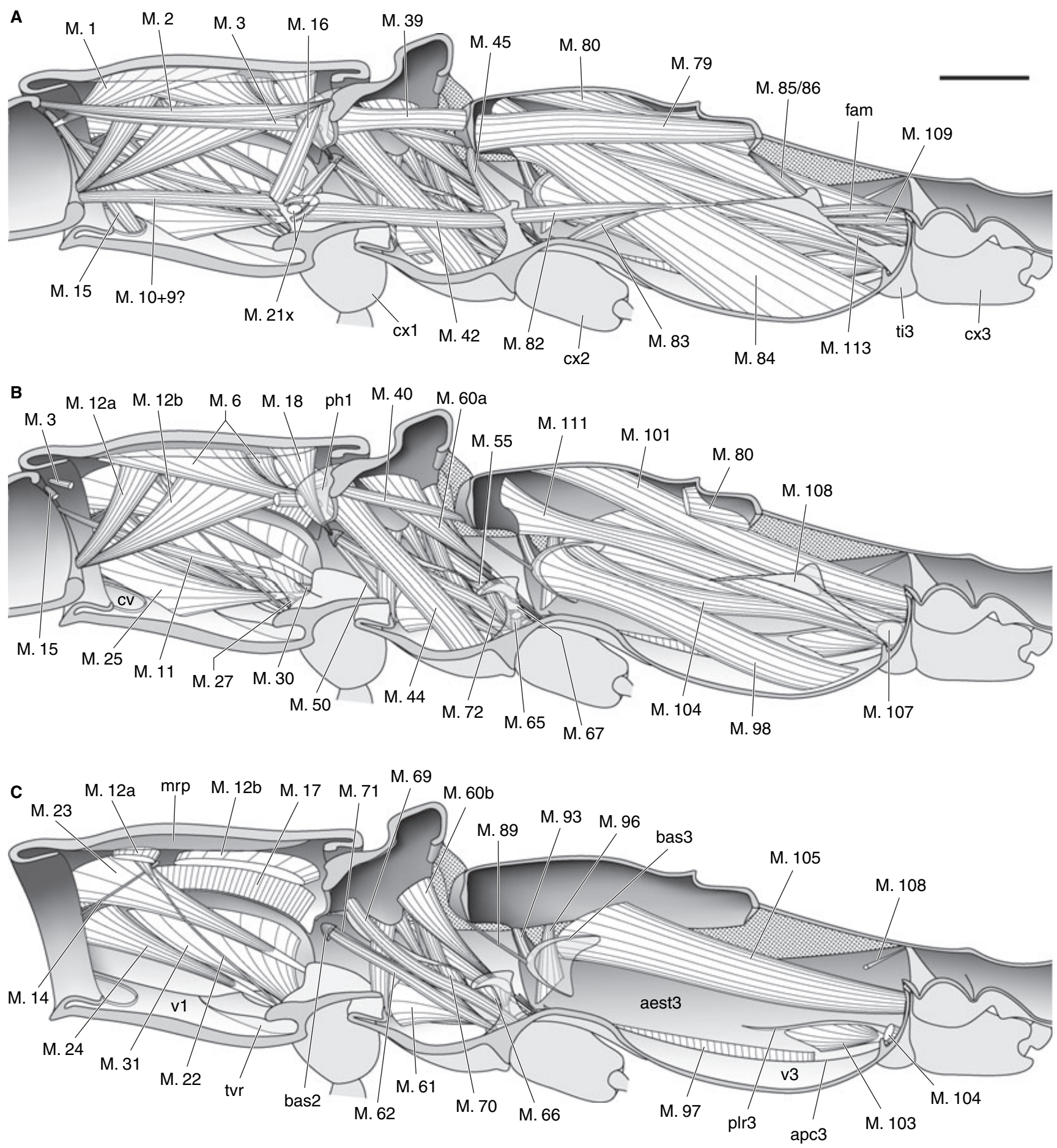

Fig. 8 Thoracic skeletomuscular system of Tetraphalerus bruchii (based on $\mu$-CT images). (A) sagittal section; (B) median muscle layer removed; (C) lateral muscles. aest3, metanepisternum; apc3, anapleural cleft of metathorax; bas2/3, meso-/metabasalare; cv, vestiges of cervical sclerites?; cx1/2/3, pro-/meso-/metacoxa; fam, furca-abdominal muscle; mrp, median ridge of pronotum; plr3, metathoracic pleural ridge; ph1, prophragma; ti3, metathoracic trochantin; tvr, transverse ridge of proventrite; v1/3, pro-/metaventrite. For muscle terminology see text. Scale bar: $500 \mu \mathrm{m}$.

quartus, two bundles of different thickness; O: central area of pronotum (laterad of M. 1), I: lateral part of prophragma (laterad of M. 3).
Ventral longitudinal muscles: M. 9 M. prosterni primus, not delimitable from M. 10, probably absent. M. $10 \mathrm{M}$. prosterni secundus, well developed, straight; O: 
anterior face of profurcal arm (anterad of M. 16), I: posterolateral postocciput (close to Mm. 12a, b).

Dorsoventral muscles: M. $11 \mathrm{M}$. furco-cervicalis, slender; O: anterior face of profurcal apex, I: lateral postocciput. M. $12 \mathrm{M}$. dorsoventralis primus, strongly developed muscle composed of two bundles; O: a., anterior third of pronotum (laterad of M. 6), b., posterior half of pronotum (laterad of M. 6 and M. 18), I: ventrolateral face of postocciput. M. $13 \mathrm{M}$. dorsoventralis secundus, absent. M. 14 M. dorsoventralis tertius, extremely slender; $\mathrm{O}$ : lateral rim of pronotum (dorsad of M. 17, posterad of M. 23); I: lateral edge of neck membrane. M. $15 \mathrm{M}$. dorsoventralis quartus, well developed; O: dorsolateral postocciput (between M. 2 and M. 11), I: rounded area of anterior region of proventrite (vestige of cervical sclerite). M. $16 \mathrm{M}$. dorsoventralis quintus, strongly developed muscle; O: dorsal face of profurcal arm, I: prophragma.

Lateral muscles: M. 17 M. noto-pleuralis, short but very broad; O: lateral part of pronotum, I: dorsal face of cryptopleura. M. $18 \mathrm{M}$. pronoto-mesepisternalis, well developed, conical; $\mathrm{O}$ : posterior part of pronotum, I: intersegmental membrane between proand mesothorax and anterior face of mesobasalare. $\mathbf{M}$. 20 (=M. 51) M. episterno-spinalis, absent. M. 21x M. profurca-mesepisternalis, slender, transverse muscle; $\mathrm{O}$ : dorsal face of proximal profurcal arm (one or two bundles), I: mesothoracic basalare of opposite side.

Leg muscles: M. 22 M. noto-trochantinalis, very slender; $\mathrm{O}$ : anterolateral edge of pronotum (laterad of M. 12, mediad of M. 23), I: median edge of trochantin by extremely long, thin tendon. M. 23 M. noto-coxalis; $\mathrm{O}$ : anterior third of pronotum, I: with strong tendon on posterior procoxal rim (closely posterad of pleuro-coxal joint). M. 24 M. episterno-coxalis; O: anterodorsal propleural margin (laterad of M. 25), I: anterior procoxal rim. M. $25 \mathrm{M}$. epimero-coxalis, very strong muscle; $\mathrm{O}$ : anterior parts of cryptopleura, propleura and proventrite, I: posterior rim of procoxa. M. $27 \mathrm{M}$. sterno-coxalis, short muscle, O: ventral face of proximal profurcal arm, I: anterior procoxal rim. M. 30 M. furcacoxalis, moderately sized; O: ventral part of profurcal arm (posterad of M. 27), I: posterolateral procoxal rim (close to M. 23). M. 31 M. pleura-trochanteralis, very broad and strong muscle composed of several bundles; $\mathrm{O}$ : posterior three quarter of propleura (posterad to $\mathrm{M}$. 24), I: protrochanter.

Mesothorax (Figs 8,9 and 10D-F). Dorsal longitudinal muscles: M. 39 M. mesonoti primus, strong; O: median part of prophragma, I: median part of mesophragma. M. $40 \mathrm{M}$. mesonoti secundus, moderately sized; O: dorsolateral area of prophragma (laterad of M. 39), I: ventrolateral edge of mesophragma.
Ventral longitudinal muscles: M. 42 M. mesosterni primus, equally sized as M. 10; O: posterior margin of proximal profurcal arm, I: anterior face of mesofurcal arm. M. 43 M. mesosterni secundus, not observed, absent or fused with M. 42.

Dorsoventral muscles: M. $\mathbf{4 4}$ M. mesonoto-sternalis, strongest muscle of mesothorax; $\mathrm{O}$ : anterior part of mesonotum and dorsal rim of prophragma, I: central area of mesoventrite. M. $45 \mathrm{M}$. dorsoventralis; O: dorsolateral part of mesofurcal arm, I: ventrolateral edge of mesophragma.

Lateral muscles: M. 46 M. noto-pleurocostalis longus, very strong muscle composed of at least two bundles; $\mathrm{O}$ : middle of mesopleural ridge, I: lateral and posterolateral mesonotal rim. M. 47 M. noto-pleuralis, small muscle; O: dorsal part of epimeral face of mesopleural ridge (below mesopleural wing process), I: prealar sclerite. M. $50 \mathrm{M}$. episterno-sternalis; O: anterior part of mesanepisternum (ventrad of mesobasalare), I: anterolateral edge of mesoventrite. M. 52 M. epimero-subalaris, not present. M. 53 M. pleura-alaris a, long, strongly developed muscle; O: anteroventral edge of mesanepisternum (dorsad of anapleural cleft), I: third axillary sclerite (dorsad of M. 54). M. 54 M. pleura-alaris b, less than half as long as M. 53; O: epimeral face of dorsal part of mesopleural ridge, I: third axillary sclerite. M. 55 M. furca-pleuralis, short; O: tip of mesofurca, I: mesopleural arm.

Leg muscles: M. 59 M. noto-trochantinalis, absent. M. 60a, b Mm. noto-coxales, two stong, flattened bundles; O: central and posterior part of lateral mesonotum, I: posterior mesocoxal rim by means of two separate tendons. M. 61 M. episterno-coxalis, strongly flattened, fan-shaped; $\mathrm{O}$ : ventral half on mesanepisternum, epimeral side of pleural ridge and lateral rim of mesoventrite, I: anterolateral part of mesocoxal rim by means of a short, but strong tendon (laterad M. 62). M. $62 \mathrm{M}$. coxa-basalaris, long, slender; O: posterior face of mesobasalare, I: anterolateral ege of mesocoxa (mediad of M. 61). M. 64 M. coxa-subalaris, well developed; O: ventral half of subalare, I: posterior mesocoxal rim (laterad of M. 60). M. 65 M. furca-coxalis anterior, short; O: lateral face of proximal mesofurca, I: anterior mesocoxal rim (close to trochantino-coxal joint). M. $66 \mathrm{M}$. furca-coxalis lateralis, largest furca-coxal muscle; O: ventral side of mesofurcal arm (laterad of M. 67), I: lateral mesocoxal rim (immediately posterad of pleurocoxal joint). M. $67 \mathrm{M}$. furca-coxalis posterior, moderately sized; O: lateral face of mesofurcal arm (dorsal of M. 65), I: posterolateral mesocoxal rim. M. $69 \mathrm{M}$. mesonoto-trochanteralis, long and comparatively slender; O: anterolateral part of mesonotum (laterad of $\mathrm{M}$. 44), I: combined tendon of mesotrochanteral muscles. M. 70 M. episterno-trochanteralis, short, strong bundle; $\mathrm{O}$ : episternal face of central mesopleural ridge, I: trochanteral tendon (together with M. 69). M. 71 M. trochantero-basalaris, very slender; O: lateral part of 
inner basalar surface, I: trochanteral tendon (fusion with M. 69). M. 72 M. furca-trochanteralis, well developed; O: mesofurcal arm (anterad of M. 66), I: trochanteral tendon (below fusion of Mm. 69 and 70). M. 74 M. Sterno-trachanteralis, absent.

Metathorax (Figs 8, 10E-G). Dorsal longitudinal muscles: M. 79 M. metanoti primus, large muscle; O: mesal part of mesophragma, I: mesal part of metaphragma. M. 80 M. metanoti secundus, well developed; O: central area of pronotum, I: lateral part of metaphragma (laterad M. 79).

Ventral longitudinal muscles: M. 82 M. metasterni primus, slender; O: posterior face of mesofurcal arm, I: anterior metafurcal arm by long, thin tendon. M. 83 M. metasterni secundus; O: mesospina, I: anterior metafurcal arm (combined tendon with M. 82). fam M. furcaabdominalis, short, moderately sized; O: posterior face of metafurca, I: anterior rim of first abdominal sternum.

Dorsoventral muscles: M. 84 M. metanoto-sternalis, largest muscle of metathorax; $\mathrm{O}$ : anterior rim of metanotum and lateral part of mesophragma, I: paramedially on posterior half of metaventrite. Mm. 85/86 Mm. dorsoventrales secundus/tertius, moderately sized, slender; $\mathrm{O}$ : dorsal surface of lateral metafurcal arm, I: ventrolateral edge of metaphragma.

Lateral muscles: M. 87 M. episterno-spinalis, not observed, probably absent. M. 88 M. mesofurcabasalaris, absent. M. 89 M. noto-episternalis brevis, very slender; O: ventral rim of mesophragma (laterad of M. 45), I: anterior face of metabasalar muscle disc (mediad of M. 93). M. 90 M. pleura-praealaris, very thin; O: prealar sclerite, I: dorsal end of pleural ridge. M. 92 M. noto-pleuralis, absent. M. 93 M. noto-basalaris, short, thin muscle; $\mathrm{O}$ : anterolateral edge of mesonotum, I: anterolateral area of metabasalare. $\mathbf{M}$. 94 M. epimero-subalaris, not observed, very small or absent. M. 95 M. pleura-alaris a, thin; O: dorsal end of metapleural ridge (below metapleural wing process), I: third axillary sclerite. M. 96 M. pleura-alaris b, strong muscle; O: anterior part of metanepisternum (laterad of basalar muscle disc), I: muscle disc of third axillary. $\mathbf{M}$. 97 M. sterno-episternalis, short, but very broad; O: ventral rim of metanepisternum (dorsad of anapleural cleft), I: lateral margin of metaventrite. M. $98 \mathrm{M}$. sterno-basalaris, very strong muscle; $\mathrm{O}$ : mesal half of basalare muscle disc, I: posterior area of metaventrite (laterad of M. 84).

Leg muscles: M. 100 M. noto-trochantinalis, absent. M. 101 M. noto-coxalis anterior, well developed; O: metanotum (laterad of M. 80), I: posterior metacoxal rim. M. 102 M. noto-coxalis posterior, inseparably fused with M. 101. M. 103 M. episterno-coxalis, fan-shaped; O: lower part of pleural ridge, I: anterior rim of metacoxa (close to M. 104). M. 104 M. coxa-basalaris, long, slender; O: dorsolateral part of metabasalare, I: anterior metacoxal rim. M. 105 M. coxa-subalaris, strongly developed, flattened; $\mathrm{O}$ : ventral face of subalare, I: posterior rim of metacoxa (laterad M. 101). M. $107 \mathrm{M}$. furca-coxalis anterior, short, conical; O: lateral surface of metafurcal base, I: anterior metacoxal rim. M. $108 \mathrm{M}$. furca-coxalis lateralis, strong, conical muscle with long tendon; O: distal part of metafurcal stem and basis of furcal arm, I: lateral metacoxal rim (close to pleuro-coxal joint). M. 109 M. furca-coxalis posterior, very slender; $\mathrm{O}$ : posterior face of metafurcal stem (ventrad of fam), I: posterior metacoxal rim (mediad of M. 101). M. 111 M. nototrochanteralis; O: anterolateral edge of metanotum (laterad of M. 84), I: trochanteral tendon. M. 112 M. trochantero-basalaris, absent. M. 113 M. furca-trochanteralis, well developed; $\mathrm{O}$ : posterior face of metafurcal stem (ventrad of $\mathrm{M}$. 109), I: trochanteral tendon.

\section{List of characters}

Characters added to the list in Beutel and Haas (2000) or new states are marked by an asterisk. Characters 2, 22, 31, 32, 47, 69, 70, 81, 82 and 99 from Beutel and Haas (2000) were omitted. The data matrix in WinClada format is provided as electronic supplement (Appendix S2).

Larvae, head:

1. Dorsal endocarina (1. in Beutel and Haas, 2000 [= B\&H in the following]): (0) absent; (1) present. Present in Archostemata (Beutel and Hörnschemeyer, 2002a,b) and some groups of Polyphaga (taxa not under consideration here). With a very short common stem and diverging anteriorly in Omma (Lawrence, 2001).

2. (3. in $\mathrm{B} \& \mathrm{H})$ Caudal tentorial arms: (0) absent or short; (1) elongated, attached to posteroventral part of head capsule. Elongated and posteriorly connected with the head capsule in Amphizoidae, Hygrobiidae, Dytiscidae, and Aspidytidae (Balke et al., 2005). Short in larvae of Trachypachidae. Absent from larvae of other beetle and from outgroup taxa.

$3^{*}$. Orientation of head: (0) subprognathous, slightly to moderately inclined; (1) horizontal or bent upwards, distinctly prognathous or hyperprognathous; (2) hypognathous. Distinctly prognathous in Archostemata, Adephaga, Hydrophiloidea (with the exception of Spercheidae; Beutel, 1999) and some other groups of Polyphaga (e.g. Elateroidea, Cantharoidea). Hypognathous in Scarabaeoidea and in most groups of Chrysomelidae (Carlson, 1991; Lawson, 1991).

4*. Head shape of later instars: (0) not transverse, not strongly rounded laterally; (1) transverse, distinctly broader than long, strongly rounded laterally. Transverse in later instars of Cupedidae and Micromalthidae (Beutel and Hörnschemeyer, 2002a,b), and also in Myxophaga (Beutel et al., 1999) and some larvae of Scirtidae (LeSage, 1991; coded as 1 for Scirtidae). 
$5^{*}$. Deep dorsal and ventral posteromedian emargination: (0) absent; (1) present. Present in Archostemata (Beutel and Hörnschemeyer, 2002a,b).

6.* Hemispherical projection of head capsule: (0) absent; (1) present. Present between the mandibular and maxillary articulation and bearing a long seta in Hydraenidae, Leiodidae, Agyrtidae and Ptiliidae (Beutel and Leschen, 2005).

7*. Articulation of labrum: (0) free; (1) partly fused; (2) completely fused. Fused in Adephaga and Hydrophiloidea s.l. (sensu Lawrence and Newton, 1995) and some other groups (e.g. Cantharidae). Partly fused in Dascillidae (Lawrence, 1991).

8. (4. in $\mathrm{B} \& \mathrm{H})$ Number of antennomeres: (0) more than thirteen; (1) five; (2) four; (3) three; (4) two. Multisegmented in larvae of Scirtidae (Lawrence, 2005) and some larvae of Neuroptera (Tauber, 1991). Foursegmented in Cupedidae, Ommatidae (Lawrence, 1999), Adephaga (with few exceptions), and in few taxa of Polyphaga. Five-segmented in the scarabaeid taxa included (see also Crome, 1957). Three-segmented in Chrysopidae (Neuroptera; Tauber, 1991), Micromalthidae (Beutel and Hörnschemeyer, 2002a), and Polyphaga (with few exceptions). Two-segmented in Myxophaga.

9. (5. in B\&H) Exposure of mouthparts: (0) partly internalized, labrum laterally fused with triangular genal lobe; (1) mouthparts exposed, lateral margin of labrum free. Partly internalised in larvae of Hydroscaphidae and Sphaeriusidae (Beutel and Haas, 1998).

10. (6. in $\mathrm{B} \& \mathrm{H})$ Mandibular apex: (0) slender, with one or several pointed teeth; (1) three blunt and strong teeth; (2) blunt, with more than three apical teeth. With three blunt and strong apical teeth in Archostemata (Beutel and Hörnschemeyer, 2002a,b). With more than three teeth arranged in a row in Leptinotarsa and other chrysomelid larvae (Lawson, 1991).

11. (7. in $\mathrm{B} \& \mathrm{H})$ Mandibular mola: (0) present, not quadrangular, not delimited by distinct margin; $(1 *)$ present, quadrangular, delimited by distinct margin; (2) absent. Present in Archostemata (Beutel and Hörnschemeyer, 2002a,b), Myxophaga, and many groups of Polyphaga (e.g. Scirtoidea; Lawrence, 1991, 2005). Quadrangular and delimited by a distinct margin in Cupedidae and Micromalthidae (Beutel and Hörnschemeyer, 2002a,b).

12. (8. in $\mathrm{B} \& \mathrm{H})$ Prostheca: (0) absent; (1) present, rounded and semimembranous; (2) present, slender. Rounded, semimembranous, with small, posteriorly directed spines in Torridincolidae and Hydroscaphidae (Beutel et al., 1999). Slender, with one or several apices in Hydraenidae, Agyrtidae, Leiodidae (partim, Newton, 1991; Beutel and Molenda, 1997), Clambidae, Eucinetidae (Lawrence, 1991, 2005; coded as absent for Scirtidae), Derodontidae, and others.
13*. Accessory ventral process of mandible: (0) absent; (1) present. Present in Clambidae (partim), Scirtidae (LeSage, 1991), Dascillidae (Lawrence, 1991), Scarabaeoidea (Carlson, 1991) and Derodontidae (Lawrence, 1991).

14. (9. in B\&H) Intramaxillary movability: (0) fully retained; (1) reduced, no maxillolabial complex; (2) reduced, maxillolabial complex present; (3) reduced, maxilla forms sucking apparatus together with mandible. Movability reduced to a degree of maximally $20^{\circ}$ in Raphidioptera, Adephaga (excl. Gyrinidae), Hydrophiloidea, and Histeroidea (Beutel, 1993, 1994a, 1999). Maxillolabial complex present in most groups of Elateriformia (Beutel, 1995b) and Cleroidea (Beutel and Pollock, 2000).

15*. Cardo: (0) not subdivided into several sclerites; (1) subdivided into several sclerites. Subdivided into several sclerites in Hydrophiloidea s.str. (sensu Hansen, 1997) (e.g. Beutel and Leschen, 2005).

16. (10. in B\&H) Separate galea: (0) present; (1) absent. Absent from Myxophaga, in Hygrobia, in most subgroups of Staphylinidae, in Clambidae (with the exception of Calyptomerus; Lawrence, 1991; coded as 0), and in Cucujiformia.

17*. Insertion of galea: (0) stipes or unsclerotized proximomesal part of palpifer 1; (1) distal part of palpifer. Inserted on distal part of palpifer in Hydrophiloidea s.l. (e.g. Beutel, 1999).

18*. Submentum and mentum: (0) not fused and narrowed between maxillary fossae; (1) fused and narrowed between maxillary fossae. Fused and narrowed between maxillary fossae in larvae of Archostemata (Beutel and Hörnschemeyer, 2002a,b).

19. (11. in B\&H) Ligula: (0) not wedge-shaped and enlarged; (1) ligula enlarged and wedge-shaped (Lawrence, 1982). Distinctly enlarged, sclerotized, and wedge-shaped in larvae of Archostemata (Beutel and Hörnschemeyer, 2002a,b).

Larvae, thorax:

20. (12. in B\&H) Leg segments: (0) six; (1) five, tibia fused with tarsus. Five-segmented (including tarsungulus) in Myxophaga and Polyphaga (Lawrence, 1982).

$21 *$. Ventral asperities on prosternum: (0) absent; (1) present. Present in Cupedidae and Micromalthus (Beutel and Hörnschemeyer, 2002a).

22. (13. in B\&H) Claws: (0) double; (1) single. With single claw in Haliplidae, Myxophaga, Polyphaga, and first instar larvae of Priacma (Lawrence, 1999; coded as 0\&1 for Cupedidae).

Larvae, abdomen:

23. (14. in $\mathrm{B} \& \mathrm{H})$ Abdominal tergal ampullae: (0) absent; (1) present. Present in Archostemata (Lawrence, 1991, 1999; Beutel and Hörnschemeyer, 2002a,b).

24. (15. in $\mathrm{B} \& \mathrm{H})$ Abdominal segment IX: (0) well developed, tergum present; (1) largely reduced, tergum absent. Largely reduced in Dytiscoidea with the 
exception of Aspidytidae (Beutel, 1995a; Balke et al., 2005).

25. (16. in B\&H) Size and position of spiracles VIII: (0) not enlarged and terminal; (1) enlarged and terminal. Enlarged in Noteridae, Amphizoidae, and Dytiscidae. Closed and replaced by ventral gills in Hygrobiidae (Beutel, 1986) (coded as 0).

26. (17. in B\&H) Spiracular gills: (0) absent; (1) present. Present in Myxophaga with the exception of Lepiceridae (Beutel et al., 1999; J. Lawrence, pers. comm.).

27. (18. in $\mathrm{B} \& \mathrm{H})$ Pointed sclerotized process of tergum IX: (0) absent; (1) present. Present in Cupedidae and Micromalthidae (Lawrence, 1991; Beutel and Hörnschemeyer, 2002a,b). Absent from Omma (Lawrence, 1999).

28*. Asperities of sternite IX: (0) absent; (1) present. Present in Cupedidae and Micromalthus (Beutel and Hörnschemeyer, 2002a).

29*. Eversible lobes of segment IX: (0) absent; (1) present. Present in Cupedidae and Micromalthus (Beutel and Hörnschemeyer, 2002a).

30. (19. in B\&H) Urogomphi: (0) absent; (1) present. Articulated or fixed urogomphi absent from Archostemata (Lawrence, 1991; Beutel and Hörnschemeyer, 2002a,b), Hydroscaphidae, and Microsporidae, and in many groups of Polyphaga (e.g. Scarabaeidae, Scirtoidea, Dascillidae; LeSage, 1991; Lawrence, 1991).

Adults, general:

31. (20. in B\&H) Sclerites: (0) connected by extensive, externally exposed membranes; (1) firmly connected, no membranes exposed externally. Sclerites not covered by elytra closely attached to each other in Coleoptera (with few exceptions). Thus, external membranes absent.

32. (22. in B\&H) Scale-like cuticular structures: (0) absent; (1) present. Inserted on cuticular tubercles in Cupedidae and Ommatidae (Fig. 2F; e.g. Lawrence, 1982; Hörnschemeyer et al., 2002).

Adults, head:

33*. Constricted neck and postocular extensions: (0) absent or indistinct; (1) present. Strongly constricted, well defined neck region and conspicuous postocular extensions present in Tetraphalerus and other groups of Archostemata except for Micromalthus.

34. (21. in B\&H) Gula: (0) absent; (1) present, broad. Present in Coleoptera with few exceptions (Doyen, 1966; Schneider, 1981; Beutel, 1986, 1989a; Belkaceme, 1991).

35. (23. in B\&H) Compound eyes: (0) undivided; (1) completely divided. Completely divided in Gyrinidae.

36. (24. in B\&H) Number of antennomeres: (0) more than thirteen; (1) eleven; (2) less than eleven. Multisegmented in Neuropterida (Aspöck and Aspöck, 1991; New, 1991; Theischinger, 1991) and other endopterygote groups. Eleven-segmented in most groups of beetles (e.g. Archostemata, Dytiscoidea, Carabidae, Eucinetidae, Scirtidae, Derodontidae). Less than 11 antennomeres in Gyrininae, Hydroscaphidae, Hydraenidae (partim), Hydrophiloidea, Clambidae and Scarabaeidae (Lawrence, 1982).

37. (25. in $\mathrm{B} \& \mathrm{H})$ Antennal club formed of three distal antennomeres: $\left(0^{*}\right)$ absent or club formed by more or less segments, without breathing function; $(1 *)$ present, symmetrical, used as accessory breathing organ; $\left(2^{*}\right)$ present, asymmetrical. Three-segmented pubescent club present and used as accessory breathing organ in Hydrophiloidea (coded as 0 for Nicrophorus). Club usually asymmetrical and three-segmented in Scarabaeoidea (Scholtz and Grebennikov, 2005). Five-segmented club present and used as accessory breathing organ in most groups of Hydraenidae (not coded here).

$38^{*}$. (25. in B\&H): Pedicellus (0) cylindrical, not earshaped; (1) enlarged, ear-shaped, with fringe of long hairs. Highly modified pedicellus functions as receptor of vibrations of the water surface in Gyrinidae.

39. (26. in B\&H) Mandibular mola: (0) absent; (1) present. Absent from Archostemata, Adephaga, and in adults of several groups of Polyphaga (e.g. Staphylinidae (partim), Scirtidae (partim), Eucinetidae (partim), Dascillidae, Scarabaeidae, Elateroidea, Cantharoidea; Blackwelder, 1936; Lawrence, 1982). Present in Myxophaga and in different polyphagan groups such as Hydraenidae, Leiodidae, Silphidae, Hydrophiloidea, Clambidae, Eucinetidae (major part), Scirtidae (partim), Byrrhidae, Derodontidae, Coccinellidae, Tenebrionidae, and Chrysomelidae (Lawrence, 1982; Lawrence and Newton, 1982).

40. (27. in $\mathrm{B} \& H)$ Single mandibular preapical tooth: (0) absent; (1) present on left mandible (Reichardt, 1973). Present on left mandible in Myxophaga (Reichardt, 1973; Lawrence, 1982).

41. (28. in B\&H) Galea: $\left(0^{*}\right)$ present, not palp-like, without curved setae arranged in several rows; $(1 *)$ palplike; $\left(2^{*}\right)$ with several rows of curved hairs arranged in regular rows (fimbriate); $\left(3^{*}\right)$ vestigial; $(4)$ fused with lacinia. Palp-like and usually composed of two cylindrical smooth segments in Adephaga. Usually with several rows of regularly arranged hairs in Hydrophiloidea and Hydraenidae (partim; not in Ochthebius). Vestigial in Micromalthus and completely fused with lacinia in Myxophaga.

42. (29. in B\&H) Lateral face of mentum: (0) without lobes; (1) rounded lobes present. Lobes present in Adephaga.

43. (30., 31. in B\&H) Cervical sclerites: $\left(0^{*}\right)$ present; (1*) absent; $(2 *)$ vestigial. Present in Neuropterida (Ferris and Pennebaker, 1939; Czihak, 1953, 1957; Matsuda, 1956, 1970). Usually absent from Archostemata (Baehr, 1975) (vestigial in Tetraphalerus: Fig. 5A: cv). Always absent from Adephaga (Larsén, 1966; Baehr, 1979), and Myxophaga. Also lacking in some groups of Polyphaga such as Tenebrionidae and Curculionidae. Very small or vestigial in adults of Chrysomelidae and related families (Larsén, 1966). 
Adult, prothorax:

44. (33. in B\&H) Protibial apex: (0) without antenna cleaning organ; (1) antenna cleaning organ present. Present in Trachypachidae and Carabidae.

45. (34. in $\mathrm{B} \& \mathrm{H})$ Prothoracic trochantin: $\left(0^{*}\right)$ not fused with propleura; $\left(1^{*}\right)$ fused with propleura. Fused with propleura in Myxophaga and Polyphaga (Hlavac, 1972, 1975). Notum, sternum, pleura, and trochantin completely fused in Micromalthus (also coded as 1; Lawrence and Newton, 1982).

46. (35. in B\&H) Propleura: (0) part of external body wall; (1) concealed, distinctly reduced in size. Greatly reduced in size and concealed in Polyphaga (Hlavac, 1972, 1975; Lawrence, 1982).

47. (36. in B\&H) Spinasternum I: (0) well developed; (1) vestigial or absent. Present in Neuropterida (excl. Sialidae; Matsuda, 1970) and Cupedidae (Baehr, 1975; Beutel and Haas, 2000). The presence or absence in Tetraphalerus and Micromalthus could not be assessed unambiguously with the material at hand. Absent or strongly reduced in non-archostematan beetles (Campau, 1940; Doyen, 1966; Baehr, 1975; Beutel, 1986, 1989b, 1990a,b, 1994b; Beutel and Haas, 2000; Beutel and Komarek, 2004; Friedrich and Beutel, 2006).

48. (37. in $\mathrm{B} \& \mathrm{H})$ Apical part of procoxa: (0) without condyle; (1) condyle present. Procoxal condyle present in Adephaga (excl. Gyrininae). Partly reduced in Dytiscidae (coded as 1) (Baehr, 1979).

49. (38. in $\mathrm{B} \& \mathrm{H})$ Prothoracic defensive glands: (0) absent; (1) present. Present in Hygrobiidae and Dytiscidae (Beutel, 1995a).

50. (39. in B\&H) M. pleuro-occipitalis (M. 7): (0) present; (1) absent. Present in Chrysopa (53.; Miller, 1933), Sialis (M. pl. occ.; Czihak, 1953), and Corydalus (60.; Kelsey, 1954). Absent from Agulla (Raphidioptera; Matsuda, 1956), Myrmeleon (Neuroptera; Korn, 1943), and Coleoptera (e.g. Larsén, 1966; Baehr, 1975; Friedrich and Beutel, 2006; Ge et al., 2007).

51. (40. in $\mathrm{B} \& \mathrm{H}) \mathrm{M}$. cervicale-occipitalis torquatus (M. 8): (0) present; (1) absent. Absent from Chrysopa (Neuroptera; Miller, 1933) and Coleoptera (e.g. Larsén, 1966; Baehr, 1975; Beutel and Komarek, 2004; Friedrich and Beutel, 2006; Ge et al., 2007).

52. (41. in B\&H) M. mesonoto-postpleuralis (M. 19): (0) present; (1) absent. Absent from Neuroptera (Miller, 1933; Korn, 1943) and Coleoptera (Larsén, 1966; Baehr, 1975; Beutel and Komarek, 2004; Ge et al., 2007).

53. (42. in B\&H) M. cervicale-coxalis (M. 26): (0) present; (1) absent. Absent from Agulla (Raphidioptera; Matsuda, 1956), Neuroptera (Miller, 1933; Korn, 1943; Matsuda, 1970) and Coleoptera (e.g. Larsén, 1966; Baehr, 1975, 1979; Beutel and Komarek, 2004; Ge et al., 2007).

54. (43. in B\&H) M. sterno-coxalis (M. 27): (0) present; (1) absent. Absent from Myrmeleon (Neuroptera; Korn, 1943), Gyrininae (Larsén, 1966; Beutel, 1989b), Haliplidae, and most groups of Polyphaga (Larsén, 1966; Baehr, 1979; Beutel and Komarek, 2004; Ge et al., 2007).

55. (44. in B\&H) M. pleura-trochanteralis (M. 31): (0) present; (1) absent. In contrast to Beutel and Haas (2000) present in Megaloptera (Czihak, 1953; Kelsey, 1954) and Coleoptera (Figs 8C,10C,D; Larsén, 1966; Baehr, 1975, 1979; Beutel, 1986, 1989b; Beutel and Komarek, 2004; Ge et al., 2007). Absent from Agulla (Raphidioptera; Matsuda, 1956) and Neuroptera (Matsuda, 1970).

Adult, pterothorax:

56. (45. in $\mathrm{B} \& \mathrm{H})$ Ventrites of mesothorax and metathorax: (0) mesoventrite and metaventrite separated; (1) connected by intersegmental membrane, metasternal process articulates with mesoventrite; (2) both sclerites firmly connected. Distinctly separated from each other in Neuropterida and Archostemata (Baehr, 1975; Beutel and Haas, 2000). Metasternal process articulating with posterior mesoventrite in Adephaga (Beutel, 1986, 1992, 1994b; Belkaceme, 1991). Mesothoracic and metathoracic ventrites directly attached to each other within mesocoxal cavities in Myxophaga and Polyphaga with few exceptions (Scirtoidea, Derodontidae, Leiodidae ]partim; see Friedrich and Beutel, 2006; Ge et al., 2007]).

57. (46. in $\mathrm{B} \& \mathrm{H})$ Katepisternal mesocoxal joint: (0) present; (1) absent. Present in outgroup taxa (e.g. Maki, 1936; Beutel and Haas, 2000), Ommatidae (Figs 1A and 2B) and Cupedidae (Baehr, 1975). Absent from Adephaga, Myxophaga, and Polyphaga (Larsén, 1966; Beutel and Haas, 2000; Friedrich and Beutel, 2006).

58. (48. in $\mathrm{B} \& \mathrm{H})$ Mesothoracic transverse ridge: (0) present; (1) absent. Present in Neuropterida (e.g. Ferris and Pennebaker, 1939; Matsuda, 1956, 1970), Cupedidae (Baehr, 1975), Ommatidae (Figs 1A and 2B) and Sikhotealinea (Beutel et al., 2008; Fig. 13). Absent from Micromalthidae, Crowsoniellidae and non-archostematan beetles (e.g. Doyen, 1966; Larsén, 1966; Friedrich and Beutel, 2006).

59. (49. in $\mathrm{B} \& \mathrm{H})$ Mesofurca: (0) origin between mesocoxae with common stem; (1) mesofurcal arms distinctly separated at base. The mesofurca arises with common base between mesocoxae in Neuropterida (Maki, 1936; Ferris and Pennebaker, 1939; Acker, 1958), Cupedidae (Baehr, 1975), and Ommatidae (Fig. 5B). Arms separated from each other at their base in Micromalthus, Adephaga (except for few Gyrinidae), Myxophaga, and Polyphaga (e.g. Doyen, 1966; Larsén, 1966; Friedrich and Beutel, 2006).

60. (50. in B\&H) Mesothoracic meron: (0) present; (1) absent (Larsén, 1945a). Meron and associated muscles (Larsén, 1945a) absent from Coleoptera (see Larsén, 1945b; Friedrich and Beutel, 2006)

61. (51. in B\&H) Fore wings: (0) unsclerotized; (1) partly sclerotized, with reticulate pattern (window 
punctures); (2) fully sclerotized. Transformed into elytra with lateral epipleura in Coleoptera (Lawrence and Newton, 1982). Reticulate pattern preserved in $†$ Protocoleoptera (Kukalová-Peck, 1991), Cupedidae (extant and fossil species), and Ommatidae (Fig. 6I).

62. (52. in $\mathrm{B} \& \mathrm{H})$ Mesothoracic elytra-locking device: (0) absent; (1) present. Median part of mesoscutellum transformed into triangular elytra-locking device in Coleoptera (Heberdey, 1938).

63. (53. in $\mathrm{B} \& \mathrm{H}) \mathrm{M}$. scutello-postnotalis mesothoracis (M. 41): (0) present; (1) absent. Absent from Coleoptera (Larsén, 1966; Baehr, 1975; Beutel and Haas, 2000; Beutel and Komarek, 2004; Friedrich and Beutel, 2006; Ge et al., 2007).

64. (54. in B\&H) M. mesosterni secundus (M. 43.): (0) present; (1) absent. Absent from Micromalthus (pers. obs. F. Friedrich), some Adephaga and all Polyphaga (Larsén, 1966; Beutel and Komarek, 2004; Friedrich and Beutel, 2006; Ge et al., 2007) with the exception of Lytta and Meloe. Not distinctly differentiable in Tetraphalerus.

65. (55. in $\mathrm{B} \& \mathrm{H}) \mathrm{Mm}$. noto-sternales mesothoracis (M. 44): (0) present; (1) absent. Absent from nonarchostematan beetles (Larsén, 1966; Baehr, 1975; Beutel and Komarek, 2004; Friedrich and Beutel, 2006; Ge et al., 2007).

66. (56. in $\mathrm{B} \& \mathrm{H}) \mathrm{M}$. noto-pleurocostalis longus mesothoracis (M. 46): (0) present; (1) absent. Absent from Agulla (Raphidioptera; Matsuda, 1956) and nonarchostematan beetles (Larsén, 1966; Baehr, 1975; Beutel and Komarek, 2004; Friedrich and Beutel, 2006; Ge et al., 2007).

67. (57. in $\mathrm{B} \& \mathrm{H}) \mathrm{M}$. noto-episternalis longus mesothoracis (M. 48): (0) present; (1) absent. Absent from Agulla (Raphidioptera; Matsuda, 1956) and Coleoptera (Larsén, 1966; Baehr, 1975; Beutel and Haas, 2000; Beutel and Komarek, 2004; Friedrich and Beutel, 2006; Ge et al., 2007).

68. (58. in $\mathrm{B} \& \mathrm{H}$ ) M. episterno-sternalis mesothoracis (M. 50): (0) present; (1) absent. Absent from nonarchostematan beetles (Larsén, 1966; Beutel and Komarek, 2004; Friedrich and Beutel, 2006; Ge et al., 2007).

69. (59. in $\mathrm{B} \& \mathrm{H}) \mathrm{M}$. pleura-alaris a and $\mathrm{b}(\mathrm{Mm}$. pleurocosta-alaris and episterno-alaris mesothoracis) (M. 53, M. 54): (0) clearly separated; (1) single muscle or two branches inserting on one tendon (Larsén, 1966: M36). With separate origins and insertions in Neuropterida (Maki, 1936; Korn, 1943; Czihak, 1953; Kelsey, 1957), Cupedidae (Baehr, 1975), Ommatidae (Fig. 9) and Micromalthus (pers. obs. F. Friedrich), but not in non-archostematan beetles (Larsén, 1966; Beutel, 1986; Belkaceme, 1991; Beutel and Komarek, 2004; Friedrich and Beutel, 2006; Ge et al., 2007).

70*. M. pleura-alaris mesothoracis a (M. 53): (0) short, attached to dorsal part of episternum; (1) long, attached to ventral part of episternum. Long M. 53 (episternal origin ventrad of that of M. 61) only present in Coleoptera (Fig. 9; e.g. Larsén, 1966; Baehr, 1975; Friedrich and Beutel, 2006).

71. (60. in $\mathrm{B} \& \mathrm{H}) \mathrm{M}$. intraepisternalis mesothoracis (M. 56): (0) present; (1) absent. Absent from Myrmeleon (Neuroptera; Korn, 1943), Agulla (Raphidioptera; Matsuda, 1956) and Coleoptera (Larsén, 1966; Baehr, 1975; Beutel and Komarek, 2004; Friedrich and Beutel, 2006; Ge et al., 2007).

72. (61. in $\mathrm{B} \& \mathrm{H}) \mathrm{M}$. pleurocosto-praenotalis mesothoracis (M. 57): (0) present; (1) absent. Absent from Coleoptera (Larsén, 1966; Baehr, 1975; Beutel and Komarek, 2004; Friedrich and Beutel, 2006; Ge et al., 2007).

73. (62. in $\mathrm{B} \& \mathrm{H}) \mathrm{M}$. noto-trochantinalis mesothoracis (M. 59): (0) present; (1) absent. Absent from Micromalthus (mesotrochantin not exposed; pers. obs. F. Friedrich) and Tetraphalerus, some genera of Adephaga and in Myxophaga and Polyphaga (Larsén, 1966; Beutel and Haas, 2000; Beutel and Komarek, 2004; Friedrich and Beutel, 2006; Ge et al., 2007).

74. (63. in $\mathrm{B} \& \mathrm{H}) \mathrm{M}$. coxa-subalaris mesothoracis (M. 64.): (0) present; (1) absent. Absent from Polyphaga (Larsén, 1966; Beutel and Komarek, 2004; Friedrich and Beutel, 2006; Ge et al., 2007).

75. (64. in $\mathrm{B} \& \mathrm{H}) \mathrm{M}$. episterno-trochantinalis mesothoracis (M. 68): (0) present; (1) absent. Absent from Myrmeleon (Neuroptera; Korn, 1943) and Coleoptera (Larsén, 1966; Baehr, 1975; Beutel and Haas, 2000; Beutel and Komarek, 2004; Friedrich and Beutel, 2006; Ge et al., 2007).

76. (65. in $\mathrm{B} \& \mathrm{H}) \mathrm{M}$. noto-trochanteralis mesothoracis (M. 69): (0) present; (1) absent. Absent from Microsporus and all adults of Polyphaga examined (Larsén, 1966; Beutel and Haas, 2000; Beutel and Komarek, 2004; Friedrich and Beutel, 2006; Ge et al., 2007).

77. (66. in B\&H) Mesal metacoxal walls: (0) not fused; (1) metacoxae attached to each other along ventromedian edge; (2) mesal walls fused. Fused in adults of Trachypachidae and Dytiscoidea (e.g. Beutel and Roughley, 1987, 1988). Connected along ventromesal edges in Gyrininae.

78. (67. in $\mathrm{B} \& \mathrm{H})$ Transverse metascutal fissure: (0) absent; (1) present (Brodsky, 1994). Membranous, transverse metascutal fissure or area present in Coleoptera (Campau, 1940; Doyen, 1966; Larsén, 1966; Brodsky, 1994; Ge et al., 2007).

79. (68. in $\mathrm{B} \& \mathrm{H})$ Metathoracic elytra-locking device: (0) absent; (1) present. Posteriorly converging alacristae present in Coleoptera (Figs 1C, 2; Campau, 1940; Doyen, 1966; Larsén, 1966; Friedrich and Beutel, 2006; Ge et al., 2007).

80. (71. in $\mathrm{B} \& \mathrm{H})$ Metacoxae: (0) transverse, recessed into cavities; (1) not transverse, not recessed into cavities; (Lawrence, 1982). Distinctly transverse in 




Fig. 9. Skeletomuscular system of the mesothoracic wing base of Tetraphalerus bruchii (based on $\mu$-CT images). 3ax, third axillary sclerite; aest2, mesanepisternum; bas2, mesobasalare; ep2, mesepimeron; icm, intracoxal muscle; nt2, mesonotum; pcj2, mesothoracic pleuro-coxal joint; plr2, mesothoracic pleural ridge; ti2, mesotrochantin; tr2, mesothoracic trochanter; trt, trochanteral tendon; sa2, mesothoracic subalare; v2, mesoventrite; M. 46, M. noto-pleurocostalis longus; M. 47, M. noto-pleuralis; Mm. 53/54, M. pleura-alares a/b; M. 61, M. episterno-coxalis; M. 62, M. coxa-basalaris; M. 64, M. coxa-subalaris, Mm. 65/66/67 Mm. furca-coxales anterior/lateralis/posterior; M. 71, M. trochantero-basalaris. Scale bar: $250 \mu \mathrm{m}$.

Coleoptera with few exceptions (Larsén, 1966; Matsuda, 1970; Baehr, 1975; Lawrence, 1982; Friedrich and Beutel, 2006; Ge et al., 2007).

81. (72. in $\mathrm{B} \& \mathrm{H})$ Metathoracic trochantin: (0) broad, well developed; (1) reduced, not visible externally. Well developed and visible externally in Neuropterida (Maki, 1936; Ferris and Pennebaker, 1939; Ferris, 1940; Acker, 1958; Matsuda, 1970), Cupedidae and Ommatidae (Figs 1A and 2C: ti3; Baehr, 1975). Completely absent from external surface in non-archostematan beetles (e.g. Friedrich and Beutel, 2006; Ge et al., 2007).

82. (73. in $\mathrm{B} \& \mathrm{H})$ Number of costal cross veins: (0) less than five; (1) more than five. More than five present in Raphidioptera (Aspöck and Aspöck, 1991), Neuroptera (New, 1991), and Megaloptera (partim; Theischinger, 1991; Beutel and Haas, 2000).

83. (74. in B\&H) Hind wing folding: (0) absent; (1) longitudinal and transverse hind wing folding, wings completely covered under elytra in repose (Lawrence, 1982). Folded in Coleoptera with very few exceptions (Haas, 1998; Haas and Beutel, 2001).

84. (75. in $\mathrm{B} \& \mathrm{H})$ Apical part of hind wing in resting position: (0) unfolded; (1) rolled; (2) folded. Apical part rolled in resting position in Archostemata, Spanglerogyrus, Haliplidae, in some small dytiscids, and in few representatives of Polyphaga (e.g. Artematopus; Kukalová-Peck and Lawrence, 1993). Folded in other adults of Coleoptera examined (Beutel and Haas, 2000).
85. (76. in $\mathrm{B} \& \mathrm{H})$ Oblongum of hind wing: (0) present; (1) absent (Kukalová-Peck and Lawrence, 1993). Present in Ommatidae, Cupedidae, Myxophaga (with few exceptions), and Adephaga (Fig. 7: ob; Beutel and Haas, 2000; Beutel et al., 2008).

86. (77. in B\&H) Subcubital binding patch: (0) absent; (1) present. Present in Trachypachus and Dytiscoidea (excl. Hygrobiidae; Beutel and Roughley, 1988; Beutel and Haas, 2000). A similar katastigma is present in groups of Polyphaga (Heberdey, 1938).

87. (78. in $\mathrm{B} \& \mathrm{H})$ Anterior margin of hind wing: (0) not flexible; $(1 *)$ flexible, with or without distinct bending zone; (2) marginal joint (Haas, 1998). Anterior margin flexible in Coleoptera, but not in outgroup taxa (Haas, 1998; Haas and Beutel, 2001). Costal margin of Scarabaeoidea marked by marginal joint ("Randgelenk"; Schneider, 1978).

88*. Bending zone in medial bar of hind wing: (0) present; (1) absent. Present in Archostemata (except for Sikhothealinea; Lafer, 1996), Adephaga and Myxophaga (Kukalová-Peck and Lawrence, 1993). Absent from Polyphaga (e.g. Kukalová-Peck and Lawrence, 1993) except for Scirtidae and Eucinetidae (Friedrich and Beutel, 2006).

89. (79. in $\mathrm{B} \& \mathrm{H})$ Distal part of $\mathrm{MP}_{1+2}$ : (0) straight or bent anteriorly; (1) bent posteriorly (Haas, 1998). $\mathrm{MP}_{1+2}$ straight or bent anteriorly in non-coleopteran Endopterygota, Archostemata, Adephaga and Hydroscaphidae. Bent posteriorly in all adults of Polyphaga examined (Haas, 1998; Friedrich and Beutel, 2006).

90. (81. in $\mathrm{B} \& \mathrm{H})$ Triangular fold: (0) completely absent; (1) $\mathrm{RA}_{3+4}$ cut twice by triangular fold; (2) $\mathrm{RA}_{3+4}$ not cut twice by triangular fold (Kukalová-Peck and Lawrence, 1993). Basal portion of $\mathrm{RA}_{3+4}$ cut twice by triangular fold in Archostemata, Myxophaga, and Adephaga, but not in Polyphaga (Kukalová-Peck and Lawrence, 1993).

91. (83. in $\mathrm{B} \& \mathrm{H})$ Fulcrum: (0) underneath second axillary; (1) underneath first and second axillary; (2) underneath first axillary (Hörnschemeyer, 1998). Fulcrum placed underneath second axillary in Archostemata and under first axillary in Myrmeleontidae, Adephaga, Myxophaga, and Polyphaga. Located under both axillary sclerites in Megaloptera and Raphidioptera (Fig. 1C; Hörnschemeyer, 1998; Friedrich and Beutel, 2006).

92. (84. in B\&H) second axillary: (0) without a lateral process; (1) process present. Lateral process originating from ventral side of second axillary present in nonarchostematan beetles. Absent from Neuropterida and Archostemata (Hörnschemeyer, 1998).

93. (85. in $\mathrm{B} \& \mathrm{H})$ Angle between the axis anterior notal process-first axillary and the disto-cranial margin of first axillary: (0) $50^{\circ}$ or more; (1) less than $45^{\circ}$ (Hörnschemeyer, 1998). Angle of $50^{\circ}$ or more in Neuropterida, Archostemata, Adephaga and Myxophaga 
(Hörnschemeyer, 1998). $45^{\circ}$ or less in adults of Polyphaga (Hörnschemeyer, 1998; Friedrich and Beutel, 2006).

94. (86. in $\mathrm{B} \& \mathrm{H})$ M. scutello-postnotalis metathoracis (M. 81): (0) present; (1) absent. Absent from Agulla (Raphidioptera; Matsuda, 1956), Neuroptera (Miller, 1933; Korn, 1943), and Coleoptera (Larsén, 1966; Beutel, 1986, 1988, 1990a,b, 1994b; Belkaceme, 1991; Beutel and Haas, 2000; Beutel and Komarek, 2004; Friedrich and Beutel, 2006; Ge et al., 2007).

95. (87. in B\&H) M. metasterni primus (M. 82): (0) present; (1) absent. Present in all adults of Coleoptera except for Hydroscapha, Microsporus and very few polyphagan beetles (e.g. Cantharis; Larsén, 1966; Beutel and Haas, 2000).

96. (88. in B\&H) M. metasterni secundus (M. 83): (0) present; (1) absent. Present in most outgroup taxa (Matsuda, 1970), in Cupedidae (Baehr, 1975), Ommatidae (Figs 8A and 10G), Trachypachidae (Beutel, 1988, 1994b), in Haliplus, and in most groups of Carabidae (Larsén, 1966). Absent from Neuroptera (Korn, 1943; Czihak, 1957), Myxophaga and Polyphaga (Friedrich and Beutel, 2006).

97. (89. in $\mathrm{B} \& \mathrm{H}) \mathrm{Mm}$. noto-episternales breves metathoracis (M. 89): (0) present; (1) absent. Present in Neuroptera (Korn, 1943; Matsuda, 1970) and Megaloptera (Maki, 1936; Czihak, 1953; Kelsey, 1957). Present but thin in adults of Archostemata (Fig. 8C; Baehr, 1975). Absent from all other groups of Coleoptera (Larsén, 1966; Baehr, 1975; Beutel, 1986, 1988, 1990a,b, 1994b; Belkaceme, 1991; Beutel and Haas, 2000; Beutel and Komarek, 2004; Friedrich and Beutel, 2006).

98. (90. in $\mathrm{B} \& \mathrm{H}) \mathrm{M}$. noto-pleuralis metathoracis a (M. 91.): (0) present in mature adults; (1) absent from mature adults. Present in Megaloptera (Maki, 1936; Czihak, 1953; Kelsey, 1957). Absent from Neuroptera (Korn, 1943) and all examined mature adults of Coleoptera (in contrast to Beutel and Haas, 2000) (Larsén, 1966; Baehr, 1975; Beutel and Komarek, 2004; Friedrich and Beutel, 2006; Ge et al., 2007).

99. (91. in B\&H) M. noto-pleuralis metathoracis b (M. 92): (0) present; (1) absent. Present in Neuropterida (Maki, 1936; Korn, 1943; Czihak, 1953; Kelsey, 1957; Matsuda, 1970) and, in contrast to Beutel and Haas (2000), also in Cupedidae (Baehr, 1975). Absent from Tetraphalerus, Micromalthus (pers. obs. F. Friedrich) and non-archostematan beetles (Larsén, 1966; Beutel and Komarek, 2004; Friedrich and Beutel, 2006; Ge et al., 2007).

100. (92. in $\mathrm{B} \& \mathrm{H}) \mathrm{M}$. pleura-alaris metathoracis a and b (Mm. 95, 96): (0) separate; (1) with common insertion (Larsén, 1966; M71). Areas of origin and insertion separated in Neuroptera (Korn, 1943), Megaloptera (Maki, 1936; Czihak, 1953; Kelsey, 1957; Matsuda, 1970), Cupedidae (Baehr, 1975),
Ommatidae and Micromalthus (pers. obs. F. Friedrich). Common insertion on a small sclerite proximad of third axillary in non-archostematan beetles (Larsén, 1966; Beutel, 1986, 1988; Belkaceme, 1991; Beutel and Komarek, 2004; Friedrich and Beutel, 2006; Ge et al., 2007).

101. (93. in B\&H) Mm. furco-pleurocostales metathoracis (M. 99): present; (1) absent. Always absent from Coleoptera (Larsén, 1966; Baehr, 1975; Beutel and Haas, 2000; Beutel and Komarek, 2004; Friedrich and Beutel, 2006; Ge et al., 2007).

102. (94. in B\&H) M. noto-trochantinalis metathoracis (M. 100): (0) present; (1) absent. Absent from Tetraphalerus, Adephaga, Hydroscapha, Microsporus, Hydrophilidae and Cetonia (Larsén, 1966; Beutel, 1986, 1988, 1990a,b, 1994b; Belkaceme, 1991).

103*. M. noto-coxalis posterior metathoracis (M. 102): (0) present; (1) absent. Absent from Hydroscapha, Microsporus and Niptus (Larsén, 1966; Beutel and Haas, 2000).

104. (95. in $\mathrm{B} \& \mathrm{H}) \mathrm{M}$. episterno-coxalis metathoracis (M. 103): (0) present; (1) absent. Absent from Adephaga, Elateridae and Scirtoidea (Larsén, 1966; Baehr, 1975; Belkaceme, 1986, 1991; Beutel, 1986, 1988, 1990a,b, 1994b; Friedrich and Beutel, 2006; Ge et al., 2007).

105. (96. in B\&H) M. sterno-coxalis metathoracis (M. 106): (0) present; (1) absent. Absent from Coleoptera except for Ips (Larsén, 1966; Belkaceme, 1986, 1991; Beutel, 1986, 1988, 1990a, 1994b; Friedrich and Beutel, 2006; Ge et al., 2007).

106*. M. furca-coxalis posterior metathoracis (M. 109): (0) present; (1) absent. Present in outgroup taxa and all beetles examined with the exception of Dytiscoidea (Larsén, 1966; Beutel, 1986, 1988, 1990a, 1994b; Belkaceme, 1991) and Scirtoidea (Friedrich and Beutel, 2006).

107. (97. in B\&H) M. episterno-trochantinalis metathoracis (M. 110): (0) present; (1) absent. Absent from Coleoptera (Larsén, 1966; Baehr, 1975; Beutel and Haas, 2000; Beutel and Komarek, 2004; Friedrich and Beutel, 2006; Ge et al., 2007) and Neuroptera (Korn, 1943).

108. (98. in B\&H) M. trochantero-basalaris metathoracis (M. 112): (0) present; (1) absent. Absent from all non-archostematan beetles and Tetraphalerus (Larsén, 1966; Baehr, 1975; Beutel and Haas, 2000; Beutel and Komarek, 2004; Friedrich and Beutel, 2006; Ge et al., 2007).

Adults, abdomen:

109. (100. in B\&H) Abdominal sternite I: (0) strongly reduced or absent, not visible externally; (1) present, exposed. Strongly reduced and not exposed in Coleoptera (Lawrence and Newton, 1982).

110. (101. in B\&H) Abdominal sternite II: (0) not divided by hind coxae; (1) completely divided. Completely divided in Adephaga. 


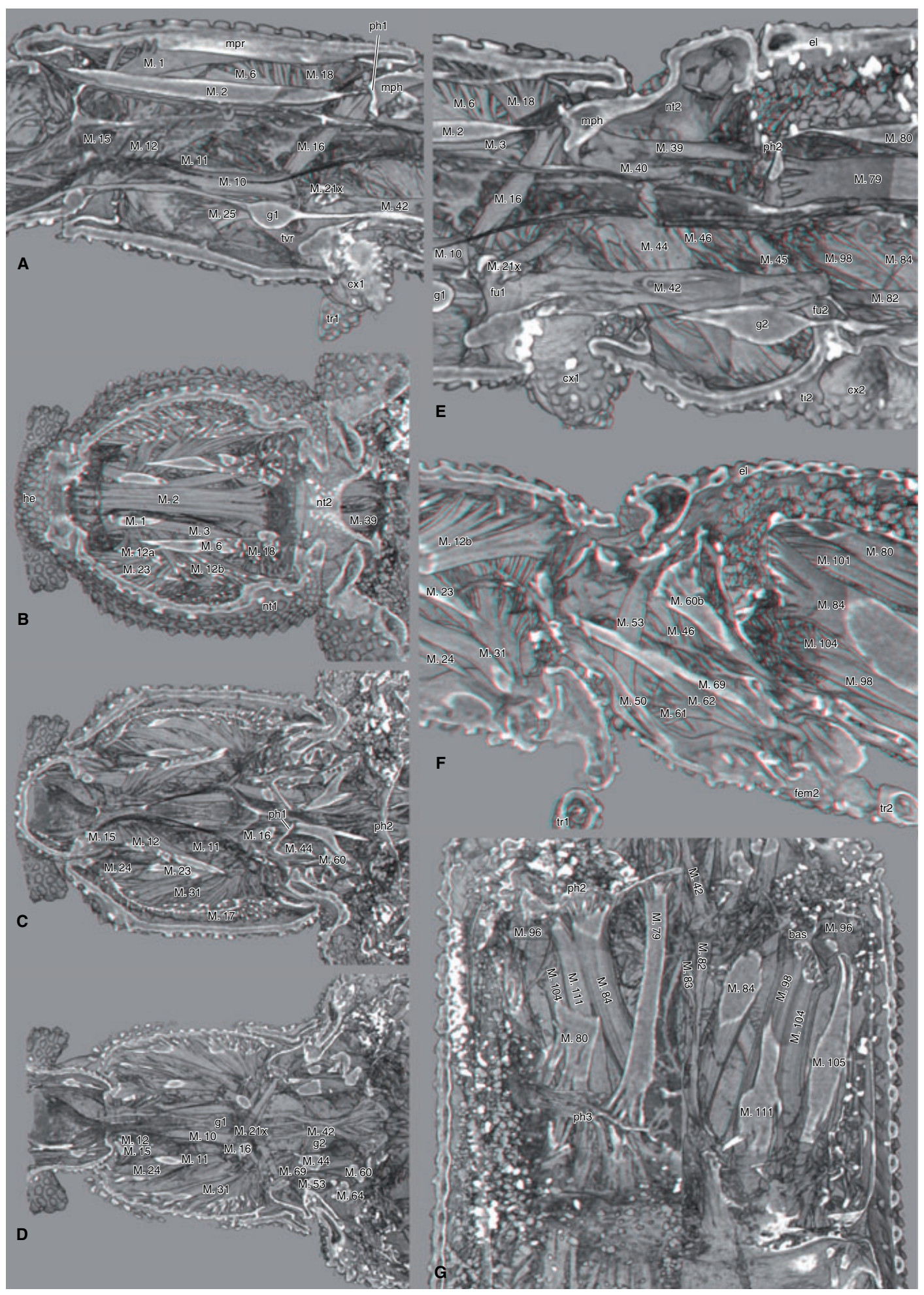

Fig. 10. Three-dimensional volume renderings of the thorax of Tetraphalerus bruchii (based on $\mu$-CT images stack). To use with red/cyan threedimensional glasses. (A-D) prothorax; (A) sagittal section; (B-D) horizontal sections on different levels, dorsal view; (E) mesothorax, sagittal section; (F) mesothorax, median muscle layer removed; (G) metathorax, horizontal sections on level of phragmata (left) and furcae (right). bas, metabasalare; cx1/2, pro-/mesocoxa; el, elytron; fem2, mesothoracic femur; fu1/2, pro-/mesofurca; g1/2, pro-/mesothoracic ganglion; mph, median ridge of prophragma; mpr, median ridge of pronotum; nt1/2, pro-/mesonotum; ph1/2/3, pro-/meso-/metaphragma; ti2, mesotrochantin; trl/2, pro-/mesothoracic trochanter; tvr, transverse ridge of proventrite. For muscle terminology see text. 
111*. Median ridge on ventrite 1: (0) absent; (1) present. Present in Cupedidae and Ommatidae (Fig. 5D: mri; Beutel et al., 2008).

112. (102. in $\mathrm{B} \& \mathrm{H})$ Abdominal segments IX and $\mathrm{X}$ : (0) exposed; (1) retracted into abdominal apex. Concealed within the preceding abdominal segments in Coleoptera.

113. (103. in B\&H) Genital appendages IX of females: (0) separate; (1) fused, with intrinsic muscles. Fused and equipped with intrinsic muscles in females of Neuropterida (Mickoleit, 1973).

114. (104. in B\&H) Number of Malpighian tubules in adults: (0) eight; (1) six; (2) four. Eight in Neuroptera (excl. Coniopterigidae; New, 1989) and Corydalinae (Megaloptera; New and Theischinger, 1993). Six in Raphidioptera (Aspöck and Aspöck, 1991), Sialinae (Megaloptera; New and Theischinger, 1993), Мyxophaga, Hydrophiloidea, Eucinetoidea, Dascilloidea, Derodontidae, and some other groups of Polyphaga (e.g. Byrrhidae, Tenebrionidae, Chrysomelidae; Lawrence, 1982). Four in Archostemata, Adephaga, and many groups of Polyphaga (e.g. Scarabaeoidea, Elateroidea and Catharoidea; Lawrence, 1982).

115. (105. in $\mathrm{B} \& \mathrm{H})$ Condition of Malpighian tubules in adults: (0) free; (1) cryptonephric. Cryptonephric Malpighian tubules in Cucujiformia (excl. Nosodendridae and Derodontidae; Lawrence and Newton, 1982).

116. (106. in B\&H) Eversion of aedeagus: (0) absent; (1*) present. Rotated through $90^{\circ}$ during repose and through $180^{\circ}$ during copulation in males of Adephaga (excl. Gyrinidae) (Beutel and Roughley, 1988). Also everted asymmetrically in Scydmaenidae, Silphidae and Staphylinidae (Beutel and Leschen, 2005).

117. (107. in B\&H) Eggs: (0) laid without cocoon or egg case; $\left(1^{*}\right)$ one side of single egg covered by web; (2) eggs enclosed in silk cocoons or egg case. One side of single egg covered by web in Hydraenidae (e.g. Hansen, 1997). Eggs enclosed in a silk cocoon or egg case in Hydrophiloidea (sensu Hansen, 1997).

All characters were equally weighed in the analyses. Character 61 (fore wings) is treated as additive.

\section{Results}

The cladistic analysis using NONA (Multiple TBR + TRB, 300 replications) yielded 30 equally parsimonious trees (233 steps, CI 0.60, RI 0.86). In the strict consensus tree (Fig. 11; 244 steps, CI 0.57, RI 0.84 ), nine nodes are collapsed within Polyphaga. The suborders and their interrelationships are well supported by characters and Bremer-Support values (BS). Following, the autapomorphies of selected taxa (see Fig. 11) resulting from the analysis are listed.

Constraint trees calculated with PAUP 4.0b10 (Swofford, 2001) yielded 249 steps for the branching pattern
Polyphaga + (Archostemata + (Myxophaga + Adephaga)) (Kukalová-Peck and Lawrence, 1993, 2004) and 239 steps for Archostemata + [Myxophaga + (Adephaga + Polyphaga)] (Caterino et al., 2002) (versus 235 steps without constraints).

1. Coleoptera (BS 24): 31.1 (firmly connected sclerites of adults), 36.1 (11 antennomeres), 43.1 (cervical sclerites absent [secondarily present in Polyphaga]), 51.1 (M. cervicale-occipitalis torquatus [M. 8] absent), 60.1 (mesothoracic meron absent), 61.1 (fore wings incompletely sclerotized, with window punctures, 62.1 (mesoscutellum forms elytra-locking device), 63.1 (M. scutello-postnotalis mesothoracis [M. 41] absent), 67.1 (M. noto-episternalis longus [M. 48] absent), 70.1 (long M. pleura-alaris mesothoracis [M. 53] attached to ventral part of episternum), 72.1 (M. pleurocostopraenotalis mesothoracis [M. 57] absent), 78.1 (transverse metascutal fissure present), 79.1 (alacristae present), 80.0 (metacoxae transverse), 82.0 (less than five costal cross veins), 83.1 (hind wings folded under elytra), 85.0 (oblongum present), 87.1 (flexible anterior margin of hind wing), 88.0 (bending zone of hind wing), 90.1 (triangular fold intersected twice by $\mathrm{RA}_{3+4}$ ), 101.1 (Mm. furco-pleurocostales metathoracis [M. 99] absent), 105.1 (M. sterno-coxalis metathoracis [M. 106] absent), 109.1 (abdominal sternite I strongly reduced), 112.1 (abdominal segments IX and X retracted), 113.0 (genital appendages IX of females separate).

2. Coleoptera excl. Archostemata (BS 11): 47.1 (spinasternum I strongly reduced or absent), 57.1 (mesothoracic katepisternal joint absent), 58.1 (mesothoracic transverse ridge absent) (also absent from Mircomalthus), 61.2 (elytra fully sclerotized), 65.1 (Mm. noto-sternales mesothoracis [M. 44] absent), 66.1 (M. noto-pleurocostalis longus mesothoracis [M. 46] absent), 68.1 (M. episterno-sternalis mesothoracis [M. 50] absent), 69.1 (M. pleurocosta-alaris and M. episterno-alaris mesothoracis not separated), 81.1 (metathoracic trochantin reduced and not exposed), 84.2 (apical part of hind wing folded), 92.1 (second axillary with lateral process), 97.1 (Mm. noto-episternales breves metathoracis [M. 89] absent), 99.1 (M. noto-pleuralis metathoracis b [M. 92] absent), 100.1 (Mm. pleura-alares metathoracis $\mathrm{a}$ and $\mathrm{b}[\mathrm{Mm} .95,96]$ with common insertion). 108.1 (M. trochantero-basalaris metathoracis [M. 112] absent) (unfortunately also absent from Tetraphalerus), more species (e.g. Omma) necessary).

3. Myxophaga + Polyphaga (BS 4): 3.0 (head of larvae subprognathous) [also in Sialis], 20.1 (larvae with five leg segments), 22.1 (larval leg with single claw [also in Haliplus]), 39.1 (mandible of adults with mola), 45.1 (prothoracic trochantin and pleura fused [also in Micromalthus]), 56.2 (mesoventrite and metaventrite firmly connected) (only with delayed transformation [DEL]: groundplan condition of common ancestor of Coleoptera excl. Archostemata is unknown). 


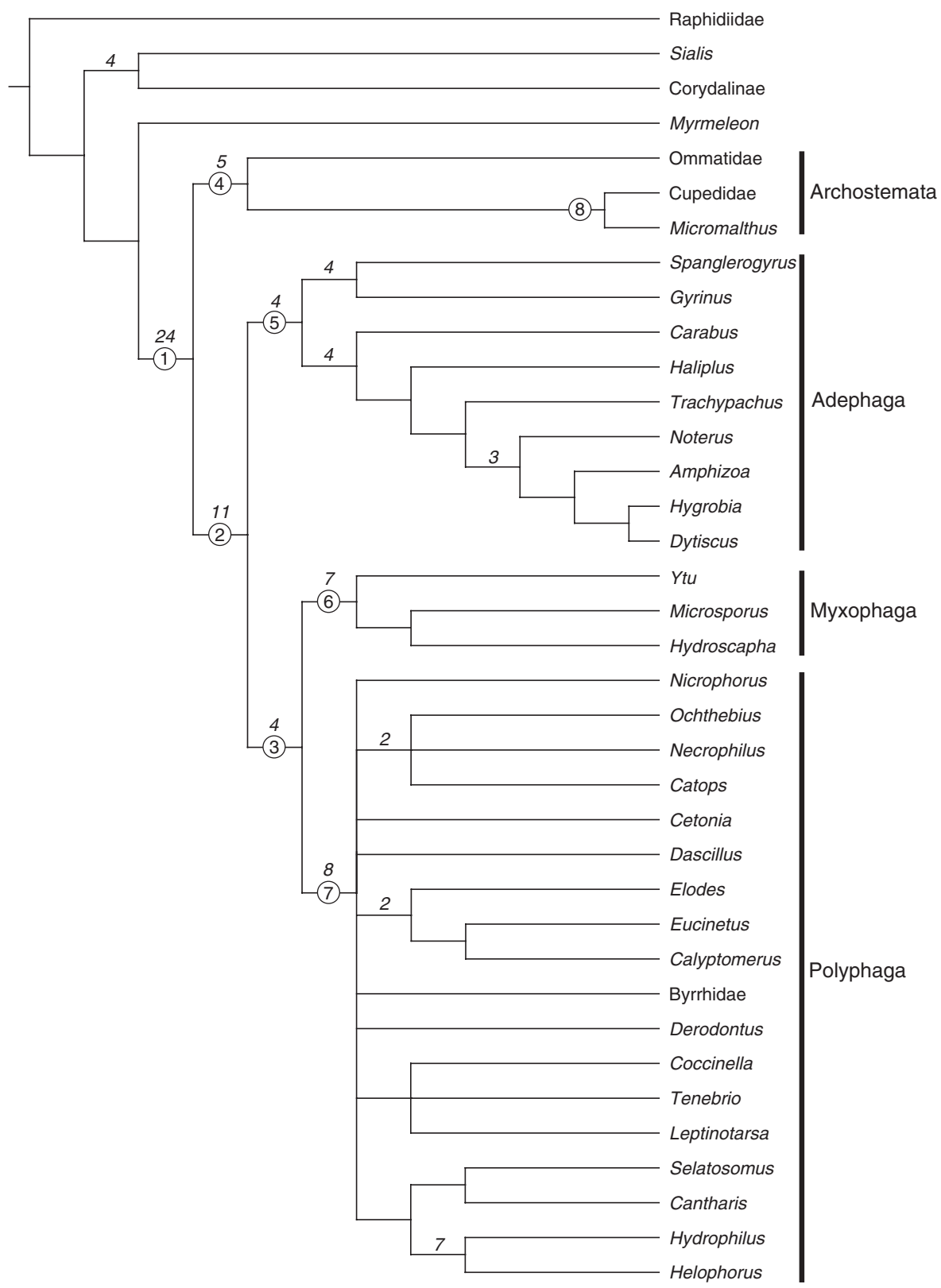

Fig. 11. Strict consensus tree of 30 equally parsimonious trees (244 steps, CI 0.57, RI 0.84). Bremer Support values ( $>1)$ noted in italics. For description of numbers in circles see text.

4. Archostemata (BS 5): 1.1 (endocarina present in larvae), 5.1 (posteromedian emargination on head of larvae), 10.1 (larval mandible with three blunt apical teeth), 18.1 (larval mentum and submentum fused and narrowed), 19.1 (larval ligula enlarged, wedge-shaped), 23.1 (larval abdomen with tergal ampullae), 91.0 (fulcrum underneath second axillary), 111.1 (abdominal ventrite 1 with median ridge).

5. Adephaga (BS 4): 7.2 (completely fused articulation of labrum in larvae [also present in Myrmeleon]), 41.1 (palp-like galea), 42.1 (larval mentum with rounded lateral lobes), 104.1 (M. episterno-coxalis metathoracis [M. 103] absent [also absent from Scirtoidea and Elateridae]), 110.1 (abdominal sternite II completely divided by metacoxae).

6. Myxophaga (BS 7): 8.4 (larvae with two-segmented antennae), 12.1 (rounded prostheca in larvae), 10.1 (larval galea absent), 26.1 (larval spiracular gills), 40.1 (left mandible of adults with articulated tooth), 41.6 (galea fused with lacinia), 95.1 (M. metasterni primus [M. 82] absent) [condition in Ytu unknown, absent from Cantharis], 103.1 (M. noto-coxalis posterior 
metathoracis [M. 102] absent) [condition in Ytu unknown; otherwise absent only in Niptus].

7. Polyphaga (BS 8): 43.0 (cervical sclerites present), 46.1 (propleura distinctly reduced), 54.1 (M. sternocoxalis prothoracis [M. 27] absent) [also absent from Myrmeleon and few adephagans], 64.1 (M. mesosterni secundus [M. 43] absent) [also absent from some adephagans], 74.1 (M. coxa-subalaris mesothoracis [M. 64] absent), 85.1 (oblongum of the hind wing absent) (also absent from miniaturized beetles such as Hydroscapha and Micromalthus), 88.0 (bending zone of the hind wing absent), 89.1 ( $\mathrm{MP}_{1+2}$ of the hind wing bent posteriorly) [also in simplified wing of Hydroscapha], 90.1 RA $_{3+4}$ cut twice by triangular fold), 93.1 (angle between the metanotum and first axillary less than $45^{\circ}$ ).

8. Cupedidae + Micromalthus (BS 1): 4.1 (transverse head in later larval instars) [also in Myxophaga and some Scirtidae], 11.1 (quadrangular mola in larvae) (with ACC [=accelerated transformation] and DEL optimization, but not in unambiguous tree; the groundplan condition in Archostemata is uncertain), 21.1 (ventral asperities on larval prosternum), 27.1 pointed process on larval tergum IX), 28.1 (asperities on larval sternite IX), 29.1 (larval segment IX with eversible lobes)

Bayesian analyses (tree see Fig. 12)

The two runs of MrBayes converged at c. $2.5 \times 10^{6}$ generations, with a standard deviation of the split frequencies below 0.006 . Trees before this value were considered as "burn-in" and discarded, leaving 14000 trees sampled and summarized to obtain the results.

Model parameters. Model parameter summaries over the runs sampled in files (summaries are based on a total of 14000 samples from two runs. Each run produced 32000 samples of which 7000 samples were



Fig. 12. Tree resulting from Bayesian analyses (two runs of MrBayes converged at ca. $2.5 \times 106$ generations, with a standard deviation of the split frequencies below 0.006). 
included) for detailed parameters electronic supplement (Appendix S3).

The branching pattern obtained with MrBayes is largely in agreement with the results of the parsimony analyses. A branching pattern \{Archostemata + $[$ Adephaga $+($ Myxophaga + Polyphaga $)]\}$ was confirmed.

\section{Discussion}

\section{Morphology}

A tuberculate surface structure of the exposed sclerotized parts is present in Tetraphalerus and Omma (Figs 2A-F,4A,6I), and all genera of Cupedidae, but is absent from the miniaturized species of the monospecific genera Micromalthus and Crowsoniella, and in Sikhotealinia and non-archostematan beetles with very few exceptions (Beutel et al., 2008). The presence is a derived groundplan feature and autapomorphy of Coleoptera in the broadest sense (Beutel and Haas, 2000; Beutel et al., 2008). The same condition is present in $†$ Tshekardocoleidae and other members of the stem-group (=stem lineage). The presence of scales inserted on the tubercles is a potential autapomorphy of Archostemata (Beutel et al., 2008), even though it cannot be excluded that similar structures were already present in stem-group beetles, but not preserved in the fossils. This character shows the same distribution pattern as the tuberculate surface structure. The scales are very narrow and lancetlike in Tetraphalerus. This is likely an autapomorphy of the genus.

A five-segmented tarsus, as it is present in Tetraphalerus, is a plesiomorphic groundplan feature of Coleoptera. Tarsi with five segments are present in many groups of beetles and in most other endopterygote taxa (see Beutel and Gorb, 2001). The tarsal setae are unbranched in Tetraphalerus (Fig. 4), but show a feather-like pattern in Priacma serrata (Beutel and Gorb, 2001: Fig. 5C,D,F). At present, the ancestral condition of Archostemata cannot be assessed. Information on more taxa is needed for a reliable evaluation.

Tetraphalerus is well sclerotized, like most other members of Archostemata and Coleoptera. A low degree of sclerotization, as found in Micromalthidae and in some lineages of Polyphaga (e.g. Scirtoidea; Friedrich and Beutel, 2006), is possibly correlated with a short life span of the adults.

A prothorax, which is shorter than wide is likely a groundplan feature of Coleoptera s.l. (including the stem-group; e.g. Ponomarenko, 1969) and Archostemata (e.g. Baehr, 1975). The strong elongation of the segment is another autapomorphy of Tetraphalerus.

The prothoracic skeleton is compact and devoid of externally visible membranes in Tetraphalerus as in other representatives of Archostemata including Sikhotealinia (Hlavac, 1972, 1975; Baehr, 1975; Beutel et al., 2008), in Adephaga, Myxophaga, in most lineages of Polyphaga (not in Leiodidae and Scirtoidea and some other groups of Elateriformia; Campau, 1940; Hlavac, 1975: p. 169), and in fossils belonging to the coleopteran stem-group (Ponomarenko, 1969; Beutel et al., 2008). The mechanical reinforcement of this segment within Archostemata is increased in Crowsoniellidae, were pronotum and propleura are indistinguishably fused (Pace, 1975; Fig. 2) and culminates in Micromalthidae, which are characterized by the complete fusion of all prothoracic sclerites (Hlavac, 1972; Barlet, 1996: Fig. 3).

The strongly developed connections between pronotum, pleura and the ventrite in stem-group beetles (e.g. $\dagger$ Tshekardocoleidae, †Permocupedidae, $†$ Rhombocoleidae; Ponomarenko, 1969; Beutel et al., 2008) have rendered internal bracing of the skeleton superfluous. An internal stabilization system formed by a muscular or skeletal interconnection of the pleural apophysis and the profurca is usually present in endopterygote insects, but is generally absent from extant beetles including Archostemata (in contrast to Evans, 1974; see also Hlavac, 1975), owing to the loss of the propleural apophysis. At least vestiges of this structure were probably present in $†$ Tshekardocoleidae and †Permocupedidae as a distinct propleural suture is visible externally (Ponomarenko, 1969; Fig. 29; Beutel et al., 2008: Fig. 12A).

A shield-like pronotum with a distinct lateral edge and a more or less broad, inflected epipleural part is likely an autapomorphy of Coleoptera s.l. This condition is already distinct in stem-group beetles (e.g. Ponomarenko, 1969). The complete absence of the lateral edge in Micromalthus is certainly a derived condition. Another autapomorphy of beetles is the presence of an internalized cryptopleuron connected or fused with the lateral pronotal margin (Baehr, 1976; Beutel and Haas, 2000). Pronotum and propleura distinctly overlap in Neuropterida and Mecopterida but are not connected as in beetles (e.g. Maki, 1936). Baehr (1976: p. 53) interpreted this as a possible precursor state of the coleopteran condition. Infolded pleural parts occurring in some hemimetabolous insects (e.g. Orthoptera, Zoraptera; Gwynne, 1995; Friedrich and Beutel, 2008) have very likely evolved independently.

A large, prominent and distinctly delimited propleuron as part of an anterior tripartite prothoracic collar (Hlavac, 1972; Fig. 10) is present in Priacma (Hlavac, 1975; Fig. 1), in Myxophaga (Hlavac, 1975; Figs 13-15) and in most of the stem group fossils (e.g. †Permocupedidae, $\uparrow$ Rhombocoleidae; Ponomarenko, 1969; Hlavac, 1975; Beutel et al., 2008; Fig. 12). This is apparently a groundplan feature of Coleoptera. A collar formed only by the pronotum and proventrite has likely 
independently evolved in Ommatidae, within Cupedidae, in Adephaga and in Polyphaga (see Figures in Hlavac, 1975). The pleura are fused with the notum in Micromalthus and Sikhotealinia.

Exposed cervical sclerites are absent from Archostemata as in Myxophaga and Adephaga (Baehr, 1979). The rounded structures, found on the internal surface of the anterior rim of the proventrite of Tetraphalerus (Fig. 5A: cv) are probably internalized vestiges. This interpretation is supported by the attachment of $\mathrm{M}$. dorsoventralis quartus (M. 15), which connects these structures with the dorsal part of the occipital region of the head. This muscle is present in the majority of pterygote insects (Friedrich and Beutel, 2008; Idvm2/3; Matsuda, 1970; op-cv 2/3) and is primarily associated with the lateral cervical sclerites. M. 15 inserts on the cervical sclerites and the proventrite in Polyphaga (see, e.g. Beutel and Komarek, 2004; Ge et al., 2007) and on the anterior rim of the proventrite in non-polyphagan beetles (Larsén, 1966; Baehr, 1975; Belkaceme, 1991). The area of origin of $\mathrm{M}$. dorsoventralis quartus in Archostemata and Adephaga is often distinctly delimited against the proventrite (Hlavac, 1975, p. 139; "sternal flange [of Archostemata] with paired internal regions, as in Adephaga"), sometimes forming a hooklike structure (Noteridae: prosternal apodeme; Belkaceme, 1991). Unfortunately, detailed information on the internal surface of the proventrite is unavailable for most members of Archostemata, Adephaga, and Myxophaga.

Along the noto-pleural suture of Cupedidae and Ommatidae, the lateral rim of the pronotum forms a long ridge, fitting movably into a deep furrow of the dorsal propleural rim (pers. obs. F. Friedrich; Baehr, 1979). A similar but much shorter joint between notum and pleura occurs in several polyphagan taxa (Baehr, 1979). The reduced length apparently results from the reduced size of the propleuron in this suborder. Polyphaga and Myxophaga share the fusion of the pleura and trochantin in the prothorax. The trochantinopleura of the latter taxon is connected with the lateral pronotum by a membrane. The fusion of the pronotum and propleura in Adephaga results in the complete immovability of the noto-pleural suture. Whether the flexible connection is a groundplan feature of Coleoptera s.str. remains unclear as the condition cannot be assessed in stem-group fossils.

In Tetraphalerus, the propleura is delimited from the proventrite by a distinct anapleural cleft (Figs 1A, and 2D: apc1). This is likely the plesiomorphic condition for Ommatidae and Archostemata. Both sclerites are indistinguishably fused in Omma (Hlavac, 1975; Fig. 4), and in Sikhotealinia (Beutel et al., 2008) and in the miniaturized species Micromalthus debilis (pers. obs. F. Friedrich) and Crowsoniella relicta (Pace, 1975: Fig. 2). Partial or complete reduction of the anapleural cleft has apparently taken place several or many times independently. It is also absent from different lineages of nonarchostematan beetles.

The promesothoracic interlocking device formed by a propleural cavity and a mesanepisternal process (Fig. 3) is a shared feature of both ommatid genera (Hlavac, 1975: p. 140; Lawrence, 1999: p. 370) and very likely an autapomorphy of the family (Beutel et al., 2008). The alternative interlocking mechanisms involving a propleural process and a mesanepisternal pit is present in Cupedidae and probably an autapomorphy of this family (Hlavac, 1975; Lawrence, 1999). The first detailed description of the "ommatid type" of the articulation is presented in the present contribution (Fig. 3), whereas a sufficient documentation of the "cupedid type" is not available yet. Further detailed investigations of these structures in members of Cupedidae and in species of Omma are required.

The trochantin of Tetraphalerus and Omma is quadrangular and slightly overlapped by the propleuron, whereas it is more triangular and completely exposed in Cupedidae (Figs 1A, and 2A,D; Hlavac, 1975; Baehr, 1975) and Sikhotealinea (Lafer, 1996). Probably caused by miniaturization, the protrochantin is fused at least with the proventrite in Micromalthus (pers. obs. F. Friedrich) and Crowsoniella (Pace, 1975; Fig. 2). The trochantin is movable but not exposed in Adephaga and completely fused with the pleuron in Myxophaga and Polyphaga (see above and character 45). A separate, externally exposed protrochantin is obviously a plesiomorphic groundplan feature of Archostemata and Coleoptera. The same condition is present in stem group fossils (e.g. $†$ Tshekardocoleidae, $†$ Triadocupedinae; Ponomarenko, 1969; Figs 29, 43, 45) and most neuropteroid outgroup taxa (except Raphidioptera; Ferris and Pennebaker, 1939; Matsuda, 1970).

A distinctly developed prosternal process is present in stem group fossils (e.g. $†$ Tshekardocoleidae, $†$ Permocupedidae; Beutel et al., 2008; Ponomarenko, 1969), Cupedidae, Adephaga, and many lineages of Polyphaga. The extremely shortened condition or absence is a feature shared by Ommatidae, Micromalthus, Crowsoniella and Sikhotealinia (Figs 1A, and 2A; Lafer, 1996; Pace, 1975; Beutel et al., 2008), which is plesiomorphic or may have evolved several times independently. The process is broad and apically truncate in the coleopteran stem group taxa, whereas it is narrow in the extinct $\dagger$ Triadocupedinae, Cupedidae (Beutel et al., 2008) and the majority of non-archostematan beetles. The loss of the broad apical part is likely an autapomorphy of Coleoptera s.str. (Beutel, 1997). Prosternal processes with a broadened apical part have secondary evolved in some representatives of non-archostematan taxa such as, for example, Torridincolidae (Myxophaga), Cicindelinae, and Rhysodidae (Adephaga) (Beutel and Vanin, 2005; Beutel et al., 2008). 
A broad external posterior closure of the procoxal cavities is present in the coleopteran stem group taxa with the exception of + Triadocupedinae (Beutel et al., 2008; Fig. 12; Ponomarenko, 1969). The absence is a synapomorphy of $†$ Triadocupedinae and Coleoptera s.str. (Beutel et al., 2008). Like a prosternal process with a broad apex, a broad postcoxal bridge has evolved secondarily several times (e.g. Cicindelinae, Rhysodidae). It is apparent that both features, which contribute to the mechanic rigidity of the prothorax are closely correlated.

A distinctly developed spinasternum I, since it is present in Priacma (Baehr, 1975), is likely a groundplan feature of Coleoptera as it is also present in most neuropteroid taxa (e.g. Ferris and Pennebaker, 1939; Matsuda, 1956, 1970). The spinasternum I and its corresponding muscles (see below) are absent from nonarchostematan taxa, and also lost in Tetraphalerus (Fig. 8) and in Micromalthus (Barlet, 1996: fig. 1, p. 376; pers. obs. F. Friedrich).

The mesothorax of Archostemata is longer than in other recent beetles (Figs 5B, and 8; Baehr, 1975). This is apparently a groundplan feature of the order. The gradual shortening of the segment in the non-archostematan suborders is likely correlated with the complete loss of the flight function of the elytra and the loss of mesothoracic muscles (see below). In contrast to other beetles, the elytra are still actively moved during the flight in Archostemata (Atkins, 1958). The mesonotum and the elytral base are rather uniform in Coleoptera and this does also apply to most parts of the pleural region. However, the mesobasalar muscle disc of Cupedidae and Ommatidae is distinctly larger than its counterpart in Adephaga, Myxophaga, Polyphaga, and the miniaturized archostematan species (Fig. 8: bas2; Baehr, 1975: Fig. 15).

The mesoventrite and the mesocoxal cavities of most members of Archostemata show a number of plesiomorphic features belonging to the coleopteran ground plan: a katepisternal area is delimited from the posterior part of the mesoventrite by a distinct transverse suture in Ommatidae, Cupedidae, in coleopteran stem group fossils, and very likely in Sikhotealinia (Figs 1A, and 2B; Baehr, 1975; Lafer, 1996; Beutel et al., 2008; Figs 12, and 13), and a third mesocoxal joint is formed by a posteromesal katepisternal process in members of these taxa (Fig. 1A; Baehr, 1975; Beutel and Haas, 2000). A separate mesothoracic katepisternum and the mesal coxal articulation are absent from the small-sized archostematan species Micromalthus debilis and Crowsoniella relicta, and in all non-archostematan beetles (e.g. Beutel and Haas, 2000; Friedrich and Beutel, 2006; Beutel et al., 2008). Another coleopteran groundplan feature preserved in Archostemata is a mesocoxal cavity laterally bordered by parts of the metanepisternum (Beutel et al., 2008). This condition is present in
Tetraphalerus and most other members of Archostemata (Fig. 2B; Baehr, 1975; Beutel et al., 2008), but does also occur in few groups of Adephaga (†Eodromeinae, Amphizoidae, Aspidytidae; Beutel et al., 2008) and Polyphaga (Derodontidae; Ge et al., 2007). Another plesiomorphic feature, the presence of a spinasternum II does occur in Archostemata and Neuroptera (Matsuda, 1970) but not in other beetles. However, to date it is only documented for Priacma (Baehr, 1975) and Tetraphalerus (Fig. 5C: sp2). It is likely absent from Micromalthus (Barlet, 1996: Fig. 1, p. 376).

Elytra with epipleura and mesothoracic and metathoracic locking mechanisms (e.g. Beutel, 1997) are autapomorphies of Coleoptera s.l. A regular pattern of window punctures is a groundplan feature of Coleoptera s.l. and straight, parallel longitudinal ridges a groundplan feature of Coleoptera s.l. excluding $†$ Tshekardocoleidae (Beutel et al., 2008). Both features are preserved in Tetraphalerus (Fig. 6A, I) and Omma, and in all genera of Cupedidae, but secondarily absent from the miniaturized species Micromalthus debilis and Crowsoniella relicta, and in Sikhotealinia (Lafer, 1996). The elytra are usually complete in Archostemata (i.e. entirely covering the dorsal side of the abdomen). However, they are distinctly shortened and apically truncate in Micromalthus (Hörnschemeyer, 2005).

The metathorax of Ommatidae and Cupedidae is also characterized by a number of plesiomorphic features belonging to the groundplan of Coleoptera s.l. A large metathoracic trochantin is exposed in all members of these families as in stem-group Coleoptera (Figs 1A, and 2C; Baehr, 1975; Beutel and Haas, 2000; Beutel et al., 2008), and in Sikhotealinia (Lafer, 1996: p. 390). Like several other plesiomorphic features it is absent from the miniaturised archostematan species, and from all nonarchostematan beetles.

The metafurca of Tetraphalerus bruchi (Fig. 5C: fu3) is very similar in shape to that of Micromalthus (Crowson, 1944; Fig. 5). Both species possess a very slender metafurca with a long stalk and short, but well sclerotized lateral arms. The anterior furcal arms are fused and form a median attachment structure for the ventral longitudinal muscles (Fig. 8A: M. 82, M. 83). The metafurca of Cupedidae (Cupes, Crowson, 1944; Fig. 2; Priacma, Baehr, 1975; Fig. 8) is also similar, but the lateral arms are highly reduced. Crowson interpreted the conditions of the archostematan metafurca as the ancestral condition in Coleoptera (Crowson, 1938, 1944). However, this interpretation needs further support. It is conceivable that at least the fusion of the anterior arms is an autapomorphy of the suborder, and the reduced condition of the lateral arms an autapomorphy of Cupedidae. The latter assumption is suggested by the presence of this condition in Priacma, which is very likely the sister taxon of all other cupedid genera (Beutel et al., 2008). 
The sclerites of the hind wing base of Tetraphalerus (Fig. 1C), Cupedidae and Micromalthus (Hörnschemeyer, 1998; Figs 8, 11, 13, 16A, 17) are similar in shape and arrangement. An angle wider than $50^{\circ}$ between the disto-cranial margin of the first axillary sclerite and the axis connecting this element with the anterior notal process is likely a groundplan feature of Coleoptera and Neuropterida (Hörnschemeyer, 1998; Beutel and Haas, 2000; Friedrich and Beutel, 2006). This presumably plesiomorphic condition is preserved in Tetraphalerus and other members of Archostemata. An autapomorphy of the suborder is the placement of the fulcrum underneath the second axillary sclerite (Fig. 1C: asterisk; Hörnschemeyer, 1998). A position of the fulcrum below the first axillary sclerite is plesiomorphic for Coleoptera. The same condition is found in Neuropterida (except Raphidioptera) (Hörnschemeyer, 1998; Beutel and Haas, 2000). Archostemata and Neuropterida lack a lateral process of the second axillary underlying the first axillary. The presence is likely a synapomorphy of Adephaga, Myxophaga and Polyphaga (Hörnschemeyer, 1998).

The general shape and venation of the hind wing is very similar in Tetraphalerus (Fig. 7), Omma and Cupedidae (Kukalová-Peck and Lawrence, 1993; Figs $30,33-35)$ and probably represents the ground plan condition of Archostemata. The apical field is very small and crossed by three more or less distinct radial veins. It is rolled and not folded in resting position, as it is the case in the miniaturized Myxophaga (Reichardt, 1973: Figs 34, 35) and few small species of Adephaga (e.g. Haliplidae) and Polyphaga (Kukalová-Peck and Lawrence, 1993; Beutel and Haas, 2000). The radius anterior is split into two branches $\left(\mathrm{RA}_{1+2}\right.$ and $\left.\mathrm{RA}_{3+4}\right)$ which delimit the broad radial cell. It is distally bordered and internally subdivided by cross-veins (Fig. 7: cr). A zone of weakness forming a more or less distinct radial hinge in the distal parts of the radius anterior (RA) and the subcosta posterior (ScP) is an autapomorphy of Coleoptera and present in all coleopteran suborders (Kukalová-Peck and Lawrence, 1993: p. 199). A welldeveloped radius posterior (RP) crosses the radial field and forms the anterior delimitation of the oblongum cell in all winged members of Archostemata and in Adephaga and Myxophaga, but is proximally obliterated in polyphagan beetles (Kukalová-Peck and Lawrence, 1993; Figs 30, 33-35). The radius posterior splits distally in two branches in Ommatidae and Cupedidae, with the anterior one usually ill-defined (see $\mathrm{RP}_{1+2}$ in KukalováPeck and Lawrence, 1993; Figs 30, 33-35). The anterior and the posterior radial veins are connected by three or four radial cross-veins (r1-r4). The second radial crossvein is present in Omma (Kukalová-Peck and Lawrence, 1993; Figs 30, 31), but not in Tetraphalerus or in cupedid species (Fig. 7; Kukalová-Peck and Lawrence, 1993; Figs 33-35). In Polyphaga, Adephaga and Myxophaga only two radial cross-veins are present (Friedrich and Beutel, 2006; Fig. 25; Kukalová-Peck and Lawrence, 1993). Kukalová-Peck and Lawrence (1993) consider two cross-veins as the plesiomorphic condition in Coleoptera. As an outgroup comparison is not possible in this case, and the character remains ambiguous. A distinct zone of weakness or bending zone (medial hinge; Fig. 7: arrow; Kukalová-Peck and Lawrence, 1993; Figs $30,33-35)$ crossed by a folding line is present on the distal part of the medial bar $\left(\mathrm{MP}_{1+2}\right)$ in Archostemata (excluding Sikhotealinia: see below), Adephaga, and Myxophaga. It is completely absent from all Polyphaga with the exception of Scirtoidea (Friedrich and Beutel, 2006; Fig. 25). Two cross-veins connect the distal parts of the radius posterior (RP) and the medial bar $\left(\mathrm{MP}_{1+2}\right)$ distad of this hinge, forming the oblongum cell (Fig. 7: ob). The oblongum is a plesiomorphic character present in Cupedidae, Ommatidae, Adephaga, and Myxophaga (except for extremely miniaturized species). The fusion of the posterior ends of the cross-veins of the known Tetraphalerus species (Fig. 7; Kukalová-Peck and Lawrence, 1993; Fig. 33) is probably an autapomorphy of the genus. Another potential autapomorphy of Tetraphalerus is the small postero-mediad directed spur of the radius posterior (Fig. 7; Kukalová-Peck and Lawrence, 1993; Fig. 33). The medial spur is straight and laterally directed in all archostematan species (Fig. 7: ms; Kukalová-Peck and Lawrence, 1993: Figs 30, 32-35).

The hind wing of Micromalthus differs strongly from the ommatid and cupedid pattern. The apical field is rounded and enlarged, occupying about the distal half of the wing. The radial cell is small and the oblongum cell laterally indistinctly bordered (Kukalová-Peck and Lawrence, 1993; fig. 32). The venation of the medial field is simplified, but it shows a typical long radius posterior (Kukalová-Peck and Lawrence, 1993; Fig. 32). The anal field and its veins (AP) are completely absent. A strong reduction of the anal field combined with a very large apical field and the partial loss of veins, especially in the medial field, are typical effects of miniaturization shared for example by Myxophaga (Kukalová-Peck and Lawrence, 1993; Figs 23-29) and Clambidae (KukalováPeck and Lawrence, 1993; Figs 57-59; Friedrich and Beutel, 2006; Fig. 25D). The hind wings of Crowsoniella relicta are absent from the known specimens (Pace, 1975: p. 445). The hind wing venation of Sikhotealinia is strikingly dissimilar from what is found in all other archostematan species and strongly resembles the polyphagan type of wing venation (Hörnschemeyer, 2005; Fig. 5.9.C). Shared hind wing features of Sikhotealinia and Polyphaga are the absence of a closed oblongum cell, the small radial cell (also in Micromalthus) and the reduction of the radius posterior, which is represented by a short, medially directed spine. The general wing shape with a large, cuspidal apical field and the strongly shortened medial spur are very similar to the condition 
found in Hydrophilidae (cf. Kukalová-Peck and Lawrence, 1993; Figs 38-40). A bending zone or even a zone weakness is absent from the medial bar of Sikhotealinia, as it is the case in Polyphaga excl. Scirtoidea (Friedrich and Beutel, 2006: p. 308).

The thoracic muscular system provides important features for the high level phylogeny of beetles (Beutel and Haas, 2000) and Archostemata play a key role for the interpretation of this character system. Before this study, the thoracic muscles were only described in detail for a single species, Priacma serrata (Baehr, 1975). This was mainly because of the rareness of all archostematan species, and the resulting difficulty in obtaining material suitably fixed for dissection. The use of $\mu$-CT enabled us to reconstruct the muscle system of Tetraphalerus and Micromalthus with few specimens, and the use of this non-destructive technique will probably strongly increase the available anatomical information in the near future.

As pointed out in earlier studies, the archostematan thoracic muscle system is mainly characterized by features plesiomorphic for Coleoptera (Baehr, 1975; Beutel and Haas, 2000). However, some derived character states occur in Tetraphalerus in correlation with the elongated prothorax and other modifications of the skeleton. Mm. pronoti quartus and dorsoventralis primus are increased in size (Fig. 8B: M. 6, M. 12) compared with the condition in Priacma (Baehr, 1975; Figs 8, 9). M. prosterni primus (M. 9) is absent from Tetraphalerus, but generally present in other beetles, with very few exceptions (Larsén, 1966; Beutel and Haas, 2000). The typical point of insertion of $\mathrm{M}$. prosterni primus is the gular ridge (cf. Larsén, 1966). As this structure is absent from Tetraphalerus (Beutel et al., 2008), the muscle has probably shifted its attachment to the posterior-most margin of the head capsule, and is therefore not clearly delimited from $M$. prosterni secundus (M. 10).

M. furco-cervicalis (M. 11) is described for members of several endopterygote lineages such as Trichoptera (Maki, 1938: 9), Lepidoptera (cf. Matsuda, 1970; : Tab.XXI, op-s 2), Corydalinae (Kelsey, 1954: 67), and Mecoptera (with few exceptions; e.g. Hasken, 1939; Füller, 1955: 0 ism 1; Maki, 1938: 6). It does also occur in Archostemata (Fig. 8B; Baehr, 1975; Fig. 10), and its presence is likely a groundplan feature of Endopterygota and Coleoptera. The presence of $\mathrm{M}$. episterno-spinalis (M. 20) connecting the spinasternum I and the mesobasalare in Priacma (Baehr, 1975: 35) and Sialis (Czihak, 1953 ) is also likely a plesiomorphic feature. The absence in Tetraphalerus is correlated with the reduced condition of the spinasternum I (see above), which is likely fused with the posterior end of the profurca. It is conceivable that the unique presence of a medially intercrossing M. profurca-mesepisternalis (Figs 8A, and 10A,D,E: M. 21x) in Tetraphalerus is correlated with this condition, implying that it is in fact an episterno-spinal muscle with a slightly modified insertion. A discrete profurca-mesepisternal muscle is also present in Sialis (Czihak, 1953), but unlike in Tetraphalerus not intercrossing in the median plane. The homology of these muscles is unclear. Additional data on further archostematan species (e.g. Omma, cupedid genera) are necessary for a satisfying interpretation.

The mesothoracic dorsoventral indirect flight musculature of Tetraphalerus is as strongly developed as in Priacma (Figs 8A,B, 9, and 10E; Baehr, 1975; Figs 8, 13). Mm. noto-sternalis and noto-pleurocostalis longus (M. 44, M. 46) are distinctly smaller, but still present in Micromalthus (pers. obs. F. Friedrich). Both muscles belong to the groundplan of Pterygota, but are absent from all non-archostematan beetles (e.g. Larsén, 1966; Beutel and Komarek, 2004; Friedrich and Beutel, 2006; Ge et al., 2007). M. episterno-sternalis (M. 50), which connects the mesobasalare with the lateral proventrite does only occur in Archostemata [Figs 8B and 10F; Baehr, 1975; pers. obs. F. Friedrich (Micromalthus)]. The transfer of the origin of the muscle from the basalare to the anterior-most part of the anepisternum in Tetraphalerus is an autapomorphy of this genus or of Ommatidae. Another apomorphy found in Tetraphalerus is the modified origin of $\mathrm{M}$. episterno-coxalis ( $\mathrm{M}$. $61)$. It is distinctly enlarged and extends to the mesoventrite (Fig. 9).

The metathoracic musculature largely conforms to the typical archostematan pattern (Baehr, 1975; Beutel and Haas, 2000), but differs in a number of details from the condition in Priacma (Baehr, 1975) and in Micromalthus (pers. obs. F. Friedrich). The strongly developed M. noto-episternalis brevis (M. 89) is well developed in all archostematan beetles examined, but is always absent from Adephaga, Myxophaga and Polyphaga (Fig. 8C; pers. obs. F. Friedrich [Micromalthus]; Larsén, 1966; Baehr, 1975; Beutel and Haas, 2000; Friedrich and Beutel, 2006; Ge et al., 2007). M. trochantero-basalaris (M. 112) is absent from Tetraphalerus as in Adephaga, Myxophaga and Polyphaga (cf. Beutel and Haas, 2000), but present in Priacma (Baehr, 1975), Micromalthus (F. Friedrich, pess. obs.), and also in the neuropterid outgroup taxa (e.g. Korn, 1943; IIpm3; Kelsey, 1957: 166). M. noto-pleuralis (M. 92) is well developed in Priacma (Baehr, 1975) and Neuropterida (Czihak, 1953; Kelsey, 1957), but absent from Tetraphalerus, Micromalthus (F. Friedrich, pers. obs.) and all non-archostematan beetles (Beutel and Haas, 2000; Friedrich and Beutel, 2006; Ge et al., 2007).

The very thin M. episterno-spinalis and M. mesofurca-basalaris (M. 87, M. 88) are present in Priacma (Baehr, 1975: 67, 68), but are probably both absent from all non-archostematan beetles and in Tetraphalerus and Micromalthus. The absence of the extremely thin M. 87 could not be verified for Tetraphalerus with certainty 
because of the limited resolution of the $\mu$-CT images, but M. 88 is definitely missing. A mesofurca-metabasalar muscle occurs very rarely in Endopterygota ( $\mathrm{Myr}$ meleon, Korn, 1943: IIpm17; Lepidoptera, Nüesch, 1953: pv 8; Ehrlich and Davidson, 1961: 98; Ehrlich and Ehrlich, 1963: 98 in fig. 80). Metanepisternomesospinal muscles are not described in other endopterygote insects, but do occur in several hemimetabolous orders (e.g. Grylloblattodea, Blattodea, Zoraptera; Walker, 1938; Carbonell, 1947; Friedrich and Beutel, 2008)

\section{Phylogeny}

As in Beutel and Haas (2000) Coleoptera are very strongly supported statistically (Bremer support 24) and by numerous derived features mainly related to a strongly armoured body. Well-known autapomorphies are the absence of externally exposed membranes, forewings transformed into sclerotized elytra, elytral locking mechanisms (scutellar shield and alacristae), a simplified hind wing venation (see also Kukalová-Peck and Lawrence, 2004), hind wing folding and the underlying structural modifications (flexible anterior margin of the alae), a strongly or completely reduced abdominal sternite $\mathrm{I}$, and the retracted posterior abdominal segments. Another series of apomorphies is the loss of several thoracic muscles. In contrast to Beutel and Haas (2000), incompletely sclerotized elytra with window punctures are assigned to the groundplan of beetles. Further apomorphies revealed in a study also including fossil taxa (Beutel et al., 2008) are the presence of cuticular tubercles on most parts of the body surface and the presence of a broad prothoracic postcoxal bridge. As pointed out in Beutel and Haas (2000), most of the derived features are likely related to a preference of ancestral beetles for subcortical habitat (see Beutel et al., 2008). The strong mechanical protection of the body and the wedge-shaped prognathous head are apparently adaptations to penetrate narrow crevices. Arguably, the tuberculate surface found in Cupedidae and Ommatidae (Figs 2 and 4) is also correlated with the preference for subcortical habitats (Beutel et al., 2008). Similar surface modifications occur in woodassociated tenebrionoid beetles and Aradidae (see Beutel et al., 2008).

As in Beutel and Haas (2000) Archostemata were placed as sister group of the remaining beetle suborders. The support of the monophyly of the adephaganmyxophagan-polyphagan clade is distinctly stronger (Bremer support 11 versus 5) after the inclusion of potentially ancestral polyphagan groups (Scirtoidea, Dascillidae). The most important complex of evolutionary changes are simplifications of the thoracic skeleton and muscle system. This includes the reduction of the spinasternum I, the loss of the mesothoracic transverse ridge, fully sclerotized elytra without window punctures, a reduced and internalized metathoracic trochantin, several muscle losses, and the partial fusion of muscles in both pterothoracic segments. It was pointed out in Friedrich and Beutel (2006) and Ge et al. (2007) that the thoracic muscle system of Scirtoidea, Dascillidae and Derodontidae is not more plesiomorphic than in other groups of Polyphaga, and the results of our analysis shows that the conditions found in these groups do not reflect the coleopteran groundplan. It has to be noted that the presumably ancestral conditions are not preserved in all groups of Archostemata. The mesothoracic transverse ridge, the window punctures of the elytra, and the exposed metatrochantin are absent from Micromalthus and Crowsoniella (Pace, 1975; Hörnschemeyer, 2005), probably as a result of miniaturization (Beutel et al., 2008). The window punctures are also absent from Sikhotealinia (Lafer, 1996), and possibly also the exposed trochantin. Unfortunately, the opportunities to examine the only known specimen are very limited for obvious reasons.

The support for a clade comprising Myxophaga and Polyphaga is slightly better than in Beutel and Haas (2000) (Bremer support 4 versus 2). The larval leg with five segments and a single claw is unambiguously placed as a synapomorphy of both suborders. Another potential synapomorphy is the presence of a mandibular mola in adults, with secondary losses within Polyphaga. It was pointed out in Anton and Beutel (2006) that a feeding apparatus with large molae, and mandibular brushes interacting with hairy epipharyngeal and hypopharyngeal lobes may be a groundplan feature of the myxophagan-polyphagan clade. The condition generally found in Myxophaga and in presumably basal lineages of Polyphaga (Anton and Beutel, 2004) is likely related to primary microphagous feeding habits. We did not include the epipharyngeal and hypopharyngeal characters here, as detailed data are missing for many groups of Polyphaga. The fusion of the trochantin with the pleuron (e.g. Hlavac, 1972) was confirmed as a myxophagan-polyphagan synapomorphy. However, the two sclerites are also absent as separate elements in Micromalthus (see above). The fusion of the mesoventrites and metaventrites was not unambiguously confirmed as a synapomorphy of Myxophaga and Polyphaga, as the ancestral condition for Coleoptera excl. Archostemata could not be determined. However, the analysis shows clearly that pterothoracic ventrites connected by membranes, as found in Scirtoidea and Derodontidae result from reversal, as pointed out by Friedrich and Beutel (2006) and Ge et al. (2007). The loss of M. nototrochantinalis mesothoracic is another shared derived feature of the two suborders. However, the muscle is also absent from Tetraphalerus and Gyrinus.

The monophyletic origin of all suborders was confirmed with Adephaga having the lowest Bremer 
support (4 versus 1 in Beutel and Haas, 2000). Additional apomorphies of Adephaga not included here are the presence of pygidial defensive glands and the firmly connected abdominal sternites II-IV (Crowson, 1955; Lawrence and Newton, 1982).

The archostematan groups included here are mainly characterized by larval apomorphies likely associated with wood-boring habits (e.g. stout mandibles with three blunt apical teeth, enlarged, sclerotized and wedgeshaped ligula). However, larval features are unknown for Tetraphalerus, Crowsoniella, Sikhotealinia, and several cupedid genera. Autapomorphies of all archostematan groups (excluding stem group Coleoptera [e.g. $\dagger$ Tshekardocoleidae, $†$ Permocupedidae, $\uparrow$ Rhombocoleidae, †Triadocupedinae]; Beutel, 1997) are listed in Beutel et al. (2008). The branching pattern obtained is in agreement with previous studies (Beutel and Hörnschemeyer, 2002a,b; Hörnschemeyer et al., 2002, 2006; Beutel et al., 2008). A clade comprising Cupedidae and Micromalthidae, but not Ommatidae is also strongly supported by larval features (e.g. distinctly delimited quadrangular larval mola, prosternum with asperities; Beutel and Hörnschemeyer, 2002a,b; Beutel et al., 2008). In the analysis carried out here, the presence of cuticular scales is an archostematan apomorphy in the fast optimization mode. However, this peculiar surface structure is more likely a derived groundplan feature of Coleoptera in the broadest sense (Beutel et al., 2008).

A unique feature of the strongly miniaturized Myxophaga is the presence of an articulated tooth only on the left mandible (also confirmed for Lepiceridae; Anton and Beutel, 2006). Another unusual feature is the rounded larval prostheca (Beutel and Haas, 1998). The spiracular gills are very likely not an autapomorphy of the suborder, but a synapomorphy of Torridincolidae, Microsporidae and Hydroscaphidae. They are absent from the yet undescribed larvae of Lepiceridae ( $\mathrm{J}$. Lawrence, pers. comm.).

The monophyly of Polyphaga is strongly supported with a Bremer support of 8 versus 5 in Beutel and Haas (2000). Autapomorphies include the distinctly reduced and largely internalized propleuron, further muscle losses, modifications of the hind wing, and features of the wing articulation. The presence of cervical sclerites could be considered as a plesiomorphic condition but this would imply parallel losses in the other groups, which is less parsimonious than a secondary gain in Polyphaga (and tertiary loss in few subgroups). The presence of an oblongum cell forming a medial loop was suggested as a potential apomorphy of Coleoptera excluding Polyphaga by Kukalová-Peck and Lawrence (2004). This interpretation was not supported by the results of our study.

It is undisputed that the studies of Kukalová-Peck and Lawrence $(1993,2004)$ provided a rich source of data and that the proposed phylogenetic hypothesis therein cannot be ruled out yet. However, as pointed out in Beutel and Haas (2000), we consider it as problematic to use only one character system, which may have been strongly affected by selective pressure. The proposed branching pattern with a basal polyphagan lineage and Adephaga as sister group of Myxophaga requires 15 additional steps with our data set (constrained branching pattern using PAUP), which also includes characters used by Kukalová-Peck and Lawrence (1993, 2004). It is also in contrast to all hitherto published available results of molecular analyses (Shull et al., 2001; Caterino et al., 2002; Vogler, 2005) and to unpublished preliminary trees based on five different genes (Alex Wild, pers. comm.). In addition to this, the comparatively late appearance of beetles unambiguously identifiable as Polyphaga in the Upper Triassic is more in accord with the Crowsonian scenario supported here and in Beutel and Haas (2000). It was pointed out in Kukalová-Peck and Lawrence (2004) that the identification of detached elytra is problematic. The argument that polyphagan beetles may have existed earlier than documented in the fossil record (Kukalová-Peck and Lawrence, 2004) is not convincing. This is also true for other groups (e.g. Adephaga and Archostemata s.str.) and it appears somewhat unlikely that existing polyphagan taxa did not leave their traces in Lower Triassic deposits, which display a remarkable diversity of archostematan and adephagan species (e.g. Ponomarenko, 1977, 1995).

The branching pattern based on published molecular trees (Shull et al., 2001; Caterino et al., 2002) is less strongly in conflict with the results of our analyses. A scenario with the two large suborders as sister groups requires four additional steps with our data set. The $18 \mathrm{~S}$ rDNA-based hypotheses are somewhat weakened by the fact that Coleoptera and the suborders were constrained as monophyletic (Caterino et al., 2002). It was pointed out by Vogler (2005) that this gene provides meaningful phylogenetic information for some groups but not for others. Apparently, its phylogenetic signal is not sufficient for a reliable reconstruction of the relationships of the beetle suborders. The placement of Cupedidae as subordinate group within Myxophaga as shown in Hunt et al. (2007) appears very unlikely considering the morphological evidence. The controversy of coleopteran subordinal relationships may be solved by a combination of a broad and well documented morphological character set and an extensive molecular data set comprising different nuclear genes and the entire mitochondrial genome. This approach is followed in the current Beetle Tree of Life project.

\section{Evolution}

The transition from a form probably resembling extant Megaloptera (Crowson, 1975) to a protocoleopteran stage took probably place in the earliest Permian 
(Crowson, 1975; Labandeira, 1994). Crucial steps in the earliest evolution of Coleoptera was the formation of partly sclerotized elytra, a wedge-shaped head, and a strongly sclerotized body without any exposed membranes. It is very likely that the earliest beetles such as $\dagger$ Tshekardocoleidae were mainly adapted to penetrate into narrow subcortical spaces (i.e., under tree bark). An important change in the evolution of the beetle stemgroup was the morphological adaptation of the elytra to the abdomen. The tight fit resulting in the formation of a largely closed subelytral chamber reduced water loss via the tracheal system and was apparently a prerequisite to later multiple invasions of the aquatic environment (Beutel, 1997). Interestingly a similar evolutionary pattern is found in Heteroptera, which are characterized by hemielytra (see Crowson, 1995). A transformation likely correlated with the shortening and narrowing of the elytra was the development of a transverse wing folding mechanism, which unlike the longitudinal folding very likely does not belong to the groundplan of beetles (Beutel and Haas, 2000). Another change taking place in the Permian stage of beetle evolution was the loss of the broad prothoracic postcoxal bridge (Beutel, 1997). This reduced the mechanical protection to a certain degree but resulted in an increased mobility of the head-prothorax complex. A broad bridge has reevolved several times independently, as for example in Rhysodidae and Cicindelinae (Beutel, 1992). The evolutionary changes linked with the rise of Coleoptera s.str. were apparently inconspicuous. Two potential synapomorphies of the four extant beetle suborders are the narrowed prosternal process and the loss of the propleural suture (Beutel et al., 2008). In contrast to this, the splitting event resulting in Archostemata s.str. and the remaining beetle suborders was linked with numerous morphological transformations, especially a distinct simplification of the thoracic skeletomuscular system (see above and below).

Archostemata, as defined here, is the suborder that has preserved most ancestral features of Coleoptera, such as the incompletely sclerotized elytra, which are still activated during flight, a preserved mesothoracic katepisternum, an exposed metathoracic trochantin, and a relatively complete set of thoracic muscles. The group was widely distributed and moderately diverse in the early Mesozoic (Ponomarenko, 1969, 1995). The ommatid genus Tetraphalerus is today only represented in isolated areas of Argentina and possibly in adjacent countries, whereas the fossil record documents its wide distribution in the Jurassic. Extinct Tetraphalerus species are known from Lagerstätten in China, Russia, UK and Spain (Crowson, 1962; Ponomarenko, 1969, 2000; Tan et al., 2005). Extant archostematan beetles (with the exception of Crowsoniella relicta) are absent from Europe, but their former presence is documented by cupedid fossils in Baltic amber. The diversity of Archo- stemata dropped dramatically in the late Mesozoic (Ponomarenko, 1995), in contrast to that of nonarchostematan lineages of wood associated beetles. Rhysodidae (or Rhysodini; Bell and Bell, 1978), the only truly xylobiontic (i.e. xylem-inhabiting) adephagan beetles, are only a moderately successful group, but with c. 1000 described species are far more diverse than extant Archostemata. Within Polyphaga, more or less specialized xylobiontic habits have evolved many times independently, in a few groups of Scarabaeoidea, in several elateroid lineages (e.g. Eucnemidae), in Lymexylidae, in tenebrionoid and cucujoid families (e.g. Prostomidae, Pyrochroidae, Pythidae), in Buprestidae, in Cerambycidae, and in the curculionid subfamily Scolytinae. The most species rich xylobiontic groups, the elateriform Buprestidae and the cucujiform Cerambycidae, comprise 20000 and 35000 described species, respectively, and the Scolytinae includes some 6000 species (Farrell et al., 2001). Other than the ambrosia beetles (Farrell et al., 2001), these three groups are largely dependent on phloem and often attack living trees, while most others feed on fungi and slime-moulds inhabiting decaying trees. The number of wood associated polyphagan species is probably close to 100000 versus only 40 in Archostemata. The other main groups of wood-digesting insects, including the woodwasps (Hymenoptera: Anaxyelidae, Siricidae, Xiphydriidae) and Cossidae moths (Lepidoptera), number in the low hundreds.

One factor that might have contributed to the decline of Archostemata is the less efficient locomotory system, with more degrees of freedom in the exoskeleton and a comparatively complex muscle apparatus (Beutel and Haas, 2000; see above). The splitting event resulting in the rise of a lineage comprising all non-archostematan suborders was mainly marked by various simplifications of the thoracic exoskeleton (see above), and especially by a correlated distinct reduction of the muscle system. It was pointed out in Beutel and Haas (2000) that this resulted in a more efficient and more economic locomotory apparatus.

The known larvae of Archostemata are highly adapted wood-boring forms, or burrow in soil and feed on roots (e.g. Omma; Lawrence, 2001). It is likely that their wood-boring habits evolved in the early Triassic (Crowson, 1975; Labandeira, 1994). Larval groundplan features associated with the specialized xylobiontic life style are the sclerotized wedge-shaped head, the strongly sclerotized enlarged ligula, the more or less cylindrical, unsclerotized body, the shortened legs, and the tergal ampullae (Beutel and Hörnschemeyer, 2002a,b). In their morphology, archostematan larvae are obviously as specialized as any other xylophagous beetle larvae (e.g. Buprestidae, Cerambycidae) and very well adapted to their environment. However, one important feature distinguishing Archo- 
stemata from most or all xylobiontic polyphagan groups is that they were obviously primarily adapted to "primitive" gymnosperms (Crowson, 1975: Araucarioxylon). Unfortunately, there is very little known about the habitat preference of archostematan larvae (e.g. Fukuda, 1941). However, an association with coniferous trees is probably still maintained by most extant groups (e.g. Abies, Picea, Pinus, and Pseudotsuga; Fukuda, 1941; Lawrence, 1991; Hörnschemeyer, 2005), although larvae of Micromalthus were also found in wood of deciduous trees (Acacia, Eucalyptus; Lawrence, 1991). It is conceivable that Archostemata were less capable of adapting to the rapidly diversifying angiosperms in the late Jurassic and early Cretaceous than members of "more advanced" groups of beetles such as Tenebrionoidea or Cerambycidae, and were not subject to the apparent co-diversification that ensued (Farrell 1998). An environment-related feature lacking in Archostemata but characterizing beetles belonging to the extremely species-rich Cucujiformia, is the cryptonephric Malpighian tubules. These specialized excretory organs permit adult cucujiform beetles (and other insects) independence from moist environments, and allow existence in very arid habitats (e.g. Tenebrionidae $[c$. 18000 spp.]), and exposure on external plant parts (e.g. Chrysomelidae [c. 35000 spp.], Curculionoidea [c. 75000 spp.]).

The lack of information on the biology, habitat preference and immature stages of most species of Archostemata, especially of Jurodidae, Crowsoniellidae and Ommatidae, make evolutionary interpretations speculative. However, it appears plausible that a combination of factors outlined here have contributed to the peculiar diversification pattern in Coleoptera, with the nearly extinct Archostemata as the sister group of a clade comprising the highly specialized, mainly hygropetric and strongly miniaturized Myxophaga, the mainly predacious and ground-dwelling Adephaga (more than 30000 species), and the extremely successful Polyphaga, with numerous different life styles, but with xylobiontic or phytophagous habits in the most successful lineages.

\section{Acknowledgements}

We are greatly indebted to Dra. Adriana Marvaldi (Crycit, Mendoza, Argentina), Dr J.F. Lawrence (Gympie, CSIRO Canberra), Dr A.F. Newton (Field Museum, Chicago), and Dr S.A. Ślipiński (ANIC, CSIRO Canberra) for the gift of valuable material, and to PD Dr T. Hörnschemeyer (Universität Göttingen) for providing $\mu-\mathrm{CT}$ data (Tetraphalerus, Micromalthus) and valuable information. We are also very grateful for many valuable comments made by the two reviewers, Prof. Dr L. Vilhelmsen (Natural History Museum of Denmark) and Dr D. A. Pollock (Eastern New Mexico University). The project was carried out in the framework of the BToL project (NSF) and a project funded by the German Science Foundation (DFG) (BE 1789/4-1). Financial support by the DFG and NSF (travel support, Beetle Tree of Life workshop, Bozeman Montana) is gratefully acknowledged.

\section{References}

Acker, T.S., 1958. The comparative morphology of Stenorrhachus walkeri (MacLachlan) and of Nemopterella sp. (Neuroptera; Nemopteridae). Microentomology 23, 106-130.

Anton, E., Beutel, R.G., 2004. On the head morphology and systematic position of Helophorus (Coleoptera: Hydrophiloidea: Helophoridae). Zool. Anz. 242, 313-346.

Anton, E., Beutel, R.G., 2006. On the head morphology of Lepiceridae (Coleoptera: Myxophaga) and the systematic position of the family and suborder. Eur. J. Entomol. 103, 85-95.

Aspöck, H., Aspöck, U., 1991. Raphidioptera (Snake-flies, camelneckflies). In: CSIRO (Ed.), The Insects of Australia. Cornell University Press, Ithaca, New York, Vol. 1, pp. 516-520.

Atkins, D.M., 1958. Observations on the flight, wing movements and wing structure of male Priacma serrata (Lec.) (Coleoptera: Cupedidae). Can. Entomol. 90, 339-347.

Baehr, M., 1975. Skelett und Muskulatur des Thorax von Priacma serrata Leconte (Coleoptera, Cupedidae). Z. Morph. Tiere 81, 55101.

Baehr, M., 1976. Das Prothorakalskelett von Atractocerus (Lymexylonidae) und seine Bedeutung für die Phylogenie der Coleopteren, besonders der Polyphagen (Insecta: Coleoptera). Zoomorphology $85,39-58$.

Baehr, M., 1979. Vergleichende Untersuchungen am Skelett und an der Coxalmuskulatur des Prothorax der Coleoptera. Ein Beitrag zur Klärung der phylogenetischen Beziehungen der Adephaga (Coleoptera, Insecta). Zoologica 44, 1-76.

Balke, M., Ribera, I., Beutel, R.G., 2005. The systematic position of Aspidytidae, the diversification of Dytiscoidea (Coleoptera, Adephaga) and the phylogenetic signal of third codon positions. J. Zool. Syst. Evol. Res. 43, 223-242.

Barlet, J., 1996. Quelques precisions au sujet de Micromalthus (Insecta Coleoptera). Bull. Soc. Roy. Sci. Liège 65, 373-378.

Belkaceme, T., 1986. Skelet und Muskulatur der Hinterhüfte von Haliplus lineatocollis Mrsh. (Haliplidae, Coleoptera). Stuttg. Beitr. Naturk. (A) 393, 1-12.

Belkaceme, T., 1991. Skelet und Muskulatur des Kopfes und Thorax von Noterus laevis Sturm. Ein Beitrag zur Morphologie und Phylogenie der Noteridae (Coleoptera: Adephaga). Stuttg. Beitr. Naturk. (A) 462, 1-94.

Bell, R.T., Bell, J.R., 1978. Rhysodini of the world Part I. A new classification of the tribe, and a synopsis of Omoglymmius subgenus Nitiglymmius new subgenus (Coleoptera: Carabidae or Rhysodidae). Quaest. Entomol. 14, 43-88.

Beutel, R., 1986. Skelet und Muskulatur des Kopfes und Thorax von Hygrobia tarda (Herbst). Ein Beitrag zur Klärung der phylogenetischen Beziehungen der Hydradephaga (Insecta: Coleoptera). Stuttg. Beitr. Naturk. (A) 388, 1-54.

Beutel, R.G., 1988. Studies of the metathorax of the trout-stream beetle, Amphizoa lecontei Matthews (Coleoptera: Amphizoidae): Contribution towards clarification of the systematic position of Amphizoidae. Int. J. Insect Morphol. Embryol. 17, 63-81. 
Beutel, R.G., 1989a. The head of Spanglerogyrus albiventris Folkerts (Coleoptera: Gyrinidae). Contribution towards clarification of the phylogeny of Gyrinidae and Adephaga. Zool. Jb. Anat. 118, 431461.

Beutel, R.G., 1989b. The prothorax of Spanglerogyrus albiventris Folkerts, (1979 (Coleoptera, Gyrinidae). Contribution towards clarification of the phylogeny of Gyrinidae. Entomol. Basiliensia $13,151-173$.

Beutel, R.G., 1990a. Phylogenetic analysis of the family Gyrinidae (Coleoptera) based on meso- and metathoracic characters. Quaest. Entomol. 26, 163-191.

Beutel, R.G., 1990b. Metathoracic features of Omoglymmius hamatus and their significance for classification of Rhysodini (Coleoptera: Adephaga). Entomol. Gener. 15, 185-201.

Beutel, R.G., 1992. Phylogenetic analysis of thoracic structures of Carabidae (Coleoptera). Z. Zool. Syst. Evol.-Forsch. 30, 53-74.

Beutel, R.G., 1993. Phylogenetic analysis of Adephaga (Coleoptera) based on characters of the larval head. Syst. Entomol. 18, 127-147.

Beutel, R.G., 1994a. Phylogenetic analysis of Hydrophiloidea (Coleoptera: Polyphaga: Staphyliniformia) based on characters of the head of adults and larvae. Koleopterol. Rundsch. 64, 103-131.

Beutel, R.G., 1994b. Study on the systematic position of Systolosoma breve Solier (Adephaga: Trachypachidae) based on characters of the thorax. Stud. Neotrop. Fauna Environ. 29, 161-167.

Beutel, R.G., 1995a. The Adephaga (Coleoptera): Phylogenetic analysis and thoughts on the evolutionary history. In: Pakaluk, J., Slípinski, S.A. (Eds.), Biology, Phylogeny, and Classification of Coleoptera: Papers Celebrating the 80th Birthday of Roy A. Crowson. Muzeum i Instytut Zoologii PAN, Warszawa, pp. 173-217.

Beutel, R.G., 1995b. Phylogenetic analysis of Elateriformia (Coleoptera: Polyphaga) based on larval characters. J. Zool. Syst. Evol. Res. 33, 145-171.

Beutel, R.G., 1997. Über Phylogenese und Evolution der Coleoptera (Insecta), insbesondere der Adephaga. Verh. Naturwiss. Ver. Hamburg (NF) 31, 1-64.

Beutel, R.G., 1999. Morphology and evolution of the larval head structures of Hydrophiloidea and Histeroidea (Coeloptera: Staphylinidae). Tijdschr. Entomol. 142, 9-30.

Beutel, R.G., Gorb, S.N., 2001. Ultrastructure of attachment specializations of hexapods (Arthropoda): evolutionary patterns inferred from a revised ordinal phylogeny. J. Zool. Syst. Evol. Res. 39, 177207.

Beutel, R.G., Haas, A., 1998. Larval head morphology of Hydroscapha natans LeConte, 1874 (Coleoptera, Myxophaga, Hydroscaphidae) with special reference to miniaturization. Zoomorphology 118, 103-116.

Beutel, R.G., Haas, F., 2000. Phylogenetic relationships of the suborders of Coleoptera (Insecta). Cladistics 16, 103-141.

Beutel, R.G., Hörnschemeyer, T., 2002a. Larval morphology and phylogenetic position of Micromalthus debilis LeConte (Coleoptera: Micromalthidae). Syst. Entomol. 27, 169-190.

Beutel, R.G., Hörnschemeyer, T., 2002b. Description of the larva of Rhipsideigma raffrayi (Coleoptera: Archostemata), with phylogenetic and functional implications. Eur. J. Entomol. 99, 53-66.

Beutel, R.G., Komarek, A., 2004. Comparative study of thoracic structures of adults of Hydrophiloidea and Histeroidea with phylogenetic implications (Coleoptera, Polyphaga). Org. Divers. Evol. 4, 1-34.

Beutel, R.G., Leschen, R.A.B., 2005. Phylogenetic analysis of Staphyliniformia (Coleoptera) based on characters of larvae and adults. Syst. Entomol. 30, 510-548.

Beutel, R.G., Molenda, R., 1997. Comparative morphological study of larvae of Staphylinoidea (Coleoptera, Polyphaga) with phylogenetic implications. Zool. Anz. 236, 37-67.

Beutel, R.G., Pollock, D.A., 2000. Larval head morphology of Phycosecis litoralis (Pascoe) (Coleoptera, Phycosecidae) with phylogenetic implications. Invert. Tax. 14, 825-835.
Beutel, R.G., Roughley, R.E., 1987. On the systematic position of the genus Notomicrus Sharp (Hydradephaga, Coleoptera). Can. J. Zool. 65, 1898-1905.

Beutel, R.G., Roughley, R.E., 1988. On the systematic position of the family Gyrinidae (Coleoptera: Adephaga). Z. Zool. Syst. Evol.Forsch. 26, 380-400.

Beutel, R.G., Vanin, S.A., 2005. Torridincolidae. In: Beutel, R.G., Leschen, R.A.B. (Eds.), Coleoptera, Vol. I. Morphology and Systematics (Archostemata, Adephaga, Myxophaga, Polyphaga partim). Handbook of Zoology Vol. IV, Arthropoda: Insecta. De Gruyter, Berlin, New York, pp. 46-48.

Beutel, R.G., Maddison, D.R., Haas, A., 1999. Phylogenetic analysis of Myxophaga (Coleoptera) using larval characters. Syst. Entomol. 24, 171-192.

Beutel, R.G., Ge, S., Hörnschemeyer, T., 2008. On the head morphology of Tetraphalerus, the phylogeny of Archostemata and the basal branching events in Coleoptera. Cladistics 24, 270-298.

Blackwelder, R.E., 1936. Morphology of the coleopterous family Staphylinidae. Smiths. Misc. Coll. 94, 1-102.

Böving, A.G., Craighead, F.C., 1931. An illustrated synopsis of the principal larval forms of the order Coleoptera. Entomol. Am. 11, $1-125$.

Bremer, K., 1994. Branch support and tree stability. Cladistics 10, 295 304.

Brodsky, A.K., 1994. The Evolution of Insect Flight. Oxford University Press, Oxford, New York, Tokyo.

Campau, E.J., 1940. The morphology of Chauliognathus pennsylvanicus (De Geer) (Coleoptera: Cantharidae). Microentomology 5, 57-90.

Carbonell, C.S., 1947. The thoracic muscles of the cockroach Periplaneta americana (L.). Smiths. Misc. Coll. 107, 1-23.

Carlson, D.C., 1991. Lucanidae (Scarabaeoidea), Passalidae (Scarabaeoidea), Scarabaeidae (Scarabaeoidea). In: Stehr, F.W. (Ed.), Immature Insects. Kendall/Hunt Publishing Company, Dubuque, Vol. 2, pp. 372-384.

Caterino, M., Shull, V.L., Hammond, P.M., Vogler, A., 2002. Basal relationships of Coleoptera inferred from 18S rDNA sequences. Zool. Scr. 31, 1-49.

Crome, W., 1957. Zur Morphologie und Anatomie der Larve von Oryctes nasicornis L. (Col. Dynastidae). Dt. Entomol. Z. (N. F.) 4, 228-262.

Crowson, R.A., 1938. The metendosternite in Coleoptera: a comparative study. Trans. Roy. Entomol. Soc. Lond. 87, 397-416.

Crowson, R.A., 1944. Further studies on the metendosternite in Coleoptera. Trans. Roy. Entomol. Soc. Lond. 94, 273-310.

Crowson, R.A., 1955. The Natural Classification of the Families of Coleoptera. Nathaniel Lloyd and Co. Ltd, London.

Crowson, R.A., 1960. The phylogeny of the Coleoptera. Ann. Rev. Ent. 5, 111-134.

Crowson, R.A., 1962. Observations on the beetle family Cupedidae, with the descriptions of two new fossil forms and a key to the recent genera. Ann. Mag. Nat. Hist. 5, 147-157.

Crowson, R.A., 1975. The evolutionary history of Coleoptera, as documented by fossil and comparative evidence. Atti X Congr. Naz. Ital. Entomol. 47-90.

Crowson, R.A., 1995. Some interesting evolutionary parallels in Coleoptera. In: Lawrence, J.F., Newton, A.F. Jr (Eds.), Biology, Phylogeny, and Classification of Coleptera (Papers Celebrating the 80th Birthday of Roy A. Crowson). Muzeum i Instytut Zoologii PAN, Warschau, pp. 63-85.

Czihak, G., 1953. Beiträge zur Anatomie des Thorax von Sialis flavilatera L. Österr. Zool. Z. 4, 421-448.

Czihak, G., 1957. Beiträge zur Anatomie des Thorax von Ascalaphus macaronicus Scop., Myrmeleon europaeus McLach und Palpares libelluides Dalm. Zool. Jb. Anat. 75, 401-432.

Doyen, J.T., 1966. The skeletal anatomy of Tenebrio molitor (Coleoptera: Tenebrionidae). Misc. Publ. Entomol. Soc. Am. 5, 103-150. 
Ehrlich, P.R., Davidson, S.E., 1961. The internal anatomy of the Monarch butterfly, Danaus plexippus L. (Lepidoptera: Nymphalidae). Microentomology 24, 85-133.

Ehrlich, P.R., Ehrlich, A.H., 1963. The thoracic and basal abdominal musculature of the butterflies (Lepidoptera: Papilionoidea). Microentomology 25, 91-126.

Evans, M.E.G., 1974. Propleural structures in Coleoptera. Int. J. Insect. Morphol. Embryol. 3, 67-72.

Farrell, B.D., 1998. "Inordinate fondness" explained: why are these so many beetles? Science 281, 553-557.

Farrell, B.D., Sequeira, A.S., O'Meara, B.C., Normark, B.B., Chung, J.H., Jordal, B.H., 2001. The evolution of agriculture in beetles (Curculionidae: Scolytinae and Platypodinae). Evolution 55, 20112027.

Ferris, G.F., 1940. The morphology of Plega signata (Hagen) (Neuroptera: Mantispidae). Microentomology 5, 35-56.

Ferris, G.F., Pennebaker, P., 1939. The morphology of Agulla adnixa (Hagen) (Neuroptera: Raphidioptera). Microentomology 4, 121142.

Friedrich, F., Beutel, R.G., 2006. The pterothoracic skeletomuscular system of Scirtoidea (Coleoptera: Polyphaga) and its implications for the relationships of the beetle suborders. J. Zool. Syst. Evol. Res. 44, 290-315.

Friedrich, F., Beutel, R.G., 2008. The thorax of Zorotypus (Hexapoda, Zoraptera) and a new nomenclature for the musculature of Neoptera. Arthropod Struct. Dev. 37, 29-54.

Fukuda, A., 1941. Some ecological studies of Cupes clathratus. Trans. Nat. Hist. Soc. Formosa 31, 394-399.

Füller, H., 1955. Die Muskulatur des Thorax von Boreus westwoodi Hag. Zool. Jb. Anat. 74, 189-210.

Ge, S., Beutel, R.G., Yang, X.K., 2007. Thoracic morphology of adults of Derodontidae and Nosodendridae and its phylogenetic implications (Coleoptera). Syst. Entomol. 32, 635-667.

Goebbels, J., Weidemann, G., Dittrich, R., Mangler, M., Tomandl, G., 2002. Functionally graded porosity in ceramics - analysis with high resolution computed tomography. In: Singh, J.P. (Ed.): Innovative Processing and Synthesis of Ceramics, Glasses, and Composites V. Proceedings of the 2001 Annual Meeting and Exposition of the American Ceramic Society, Indianapolis, April 22-25, 2001. Ceramic. Trans. 129, 113-124.

Goloboff, P., 1995. NONA Version 1.5. Fundacion e Instituto Miguel Lillo, Tucuman.

Gwynne, D.T., 1995. Phylogeny of the Ensifera (Orthoptera): a hypotheses supporting multiple origins of acoustical signalling, complex spermatophores and maternal care in crickets, katydids, and weta. J. Orthoptera Res. 4, 203-218.

Haas, F., 1998. Geometrie, Mechanik und Evolution der Flügelfaltung bei den Coleoptera (Insecta). PhD thesis. FSU, Jena.

Haas, F., Beutel, R.G., 2001. Wing folding and the functional morphology of the wing base in Coleoptera. Zoology 4, 123-141.

Hansen, M., 1997. Phylogeny and classification of the staphyliniform beetle families (Coleoptera). Biol. Skr. Kong. Danske Vidensk. Selsk. 48, 1-339.

Hasken, W., 1939. Der Thorax von Panorpa communis L. Zool. Jb. Anat. 65, 295-338.

Heberdey, R.F., 1938. Beiträge zum Bau des Subelytralraumes und zur Atmung der Coelopteren. Z. Morph. Ökol. Tiere 33, 667-734.

Hlavac, T.F., 1972. The prothorax of Coleoptera: origin, major features of variation. Psyche 79, 123-149.

Hlavac, T.F., 1975. The prothorax of Coleoptera (except Bostrichiformia-Cucujiformia). Bull. Mus. Comp. Zool. 147, 137-183.

Hörnschemeyer, T., 1998. Morphologie und Evolution des Flügelgelenks der Coleoptera und Neuropteridae. Bonn. Zool. Monogr. 43, $1-127$.

Hörnschemeyer, T., 2004. Die Phylogenie der Archostemata (Insecta: Coleoptera) und die Evolution der Flügelbasis der Holometabolen Insekten. Habilitation thesis. Georg-August-Universität Göttingen.
Hörnschemeyer, T., 2005. Archostemata Kolbe, 1908. In: Beutel, R.G., Leschen, R.A.B. (Eds.), Coleoptera, Vol. I. Morphology and Systematics (Archostemata, Adephaga, Myxophaga, Polyphaga partim). Handbook of Zoology Vol. IV, Arthropoda: Insecta. De Gruyter, Berlin, New York, pp. 157-182.

Hörnschemeyer, T., Beutel, R.G., Pasop, F., 2002. Head structures of Priacma serrata Leconte (Coleoptera, Archostemata) inferred from X-ray tomography. J. Morphol. 252, 298-314.

Hörnschemeyer, T., Göbbels, J., Weidemann, G., Faber, C., Haase, A., 2006. The head morphology of Ascioplaga mimeta (Coleoptera: Archostemata) and the phylogeny of Archostemata. Eur. J. Entomol. 103, 409-423.

Huelsenbeck, J.P., Ronquist, F., 2001. MrBAYES: Bayesian inference of phylogenetic trees. Bioinformatics 17, 754-755.

Hunt, T., Bergsten, J., Levkanicova, Z., Papadopoulou, A., St John, O., Wild, R., Hammond, P.M., Ahrens, D., Balke, M., Caterino, M.S. et al., 2007. A comprehensive phylogeny of beetles reveals the evolutionary origins of a superradiation. Science 318, 19131916.

Kelsey, L.P., 1954. The skeleto-motor mechanism of the dobson fly, Corydalus cornutus. Part I. Head and prothorax. Cornell Univ. Mem. 334, 1-51.

Kelsey, L.P., 1957. The skeleto-motor mechanism of the dobson fly, Corydalus cornutus. Part II. Pterothorax. Cornell Univ. Mem. 346, $1-42$.

Klausnitzer, B., 1975. Probleme der Abgrenzung von Unterordnungen bei den Coleoptera. Entomol. Abh. Staatl. Mus. Tierk. Dresden 40, 269-275.

Korn, W., 1943. Die Muskulatur des Kopfes und des Thorax von Myrmeleon europaeus und ihre Metamorphose. Zool. Jb. Anat. 68, 273-330.

Kristensen, N.P., 1991. Phylogeny of extant hexapods. In: CSIRO (Ed.), The Insects of Australia, Vol. 1. Cornell University Press, Ithaca, New York, pp. 125-140.

Kukalová-Peck, J., 1991. Fossil history and the evolution of hexapod structures. In: CSIRO (Ed.), The Insects of Australia. Cornell University Press, Ithaca, New York, Vol. 1, pp. 141-179.

Kukalová-Peck, J., Lawrence, J.F., 1993. Evolution of the hind wing in Coleoptera. Can. Entomol. 125, 181-258.

Kukalová-Peck, J., Lawrence, J.F., 2004. Use of hind wing characters in assessing relationships among Coleopteran Suborders and major endoneopteran lineages. Eur. J. Entomol. 101, 95-144.

Labandeira, C.C., 1994. A compendium of fossil insect families. Milwaukee Publ. Mus. Contr. Biol. Geol. 88, 1-71.

Lafer, G.S., 1996. Fam. Sikhotealiniidae. In: Lafer, P.A. (Ed.), Key to the Insects of the Russian Far East. Dal'nauka, Vladivostok, Vol. III, Part 3, pp. 298-302.

Larsén, O., 1945a. Das Meron der Insekten. Kungl. Fysiograf. Sällskapets Lund Förhandl. 15, 96-104.

Larsén, O., 1945b. Die hintere Region der Insektenhüfte. Kungl. Fysiograf. Sällskapets Lund Förhandl. 15, 105-116.

Larsén, O., 1966. On the morphology and function of locomotor organs of the Gyrinidae and other Coleoptera. Opusc. Entomol. 30 (Suppl.), 1-241.

Lawrence, J.F., 1982. Coleoptera. In: Parker, S. (Ed.), Synopsis and Classification of Living Organisms. McGraw-Hill, New York, pp. $482-553$.

Lawrence, J.F., 1991. Cupedidae (Archostemata) (=Cupesidae). Micromalthidae (Archostemata). Eucinetidae (Eucinetoidea). Clambidae (Eucinetoidea). Dascillidae (Dascilloidea) (including Karumiidae). Derodontidae (Derodontoidea) (including Laricobiidae, Peltasticidae). In: Stehr, F.W. (Ed.), Immature Insects. Kendall/Hunt Publishing Company, Dubuque, Vol. 2, pp. 182184, 364-366, 369-370, 431-432.

Lawrence, J.F., 1999. The Australian Ommatidae (Coleoptera), with a new species, a putative larva and comments on the suborder Archostemata. Invert. Tax. 13, 369-390. 
Lawrence, J.F., 2001. A new genus of valdivian Scirtidae (Coleoptera) with comments on Scirtoidea and the beetle suborders. Spec. Publ. Jpn Coleopt. Soc. Osaka. 1, 351-361.

Lawrence, J.F., 2005. Scirtidae Fleming, 1821., Dascillidae GuérinMénneville, 1843. In: Beutel, R.G., Leschen, R.A.B. (Eds.), Coleoptera, Vol. I. Morphology and Systematics (Archostemata, Adephaga, Myxophaga, Polyphaga partim). Handbook of Zoology Vol. IV, Arthropoda: Insecta. De Gruyter, Berlin, New York, pp. $443-456$.

Lawrence, J.F., Newton, A.F. Jr, 1982. Evolution and classification of beetles. Ann. Rev. Ecol. Syst. 13, 261-290.

Lawrence, J.F., Newton, A.F. Jr, 1995. Families and subfamilies of Coleoptera (with selected genera, notes, references and data on family-group names). In: Pakaluk, J., Slípinski, S.A. (Eds.), Biology, Phylogeny, and Classification of Coleoptera: Papers Celebrating the 80th Birthday of Roy A. Crowson. Muzeum i Instytut Zoologii PAN, Warszawa, pp. 634-797.

Lawson, F.A., 1991. Chrysomelidae (Chrysomeloidea) (=Cassididae, Cryptocephalidae, Megalopodidae, Sagriidae, etc.). In: Stehr, F.W. (Ed.), Immature Insects. Kendall/Hunt Publishing Company, Dubuque, Vol. 2, pp. 568-585.

LeSage, L.R., 1991. Helodidae (Eucinetoidea) (= Cyphonidae, Scirtidae). In: Stehr, F.W. (Ed.), Immature Insects. Kendall/Hunt Publishing Company, Dubuque, Iowa, Vol. 2, pp. 366-369.

Leschen, R.A.B., 2005. Eucinetidae Lacordaire, 1857., Clambidae Fischer, 1821. In: Beutel, R.G., Leschen, R.A.B. (Eds.), Coleoptera, Vol. I. Morphology and Systematics (Archostemata, Adephaga, Myxophaga, Polyphaga partim). Handbook of Zoology Vol. IV, Arthropoda: Insecta. De Gruyter, Berlin, New York, pp. 433443.

Lewis, P.O., 2001. A likelihood approach to estimating phylogeny from discrete morphological character data. Syst. Biol. 50, 913925.

Maki, T., 1936. Studies on the skeletal structure, musculature and nervous system of the Alder Fly Chauliodes formosanus Petersen. Mem. Fac. Sci. Agric. Taihoku Imp. Univ. 16, 117-243.

Maki, T., 1938. Studies of the thoracic musculature of insects. Mem. Fac. Sci. Agric. Taihoku Imp. Univ. 24, 1-343.

Matsuda, R., 1956. The comparative morphology of the thorax in two species of insects. Microentomology 21, 1-65.

Matsuda, R., 1970. Morphology and evolution of the insect thorax. Mem. Entmol. Soc. Can. 76, 1-431.

Mickoleit, G., 1973. Über den Ovipositor der Neuropteroidea und Coleoptera und seine phylogenetische Bedeutung (Insecta, Holometabola). Z. Morph. Ökol. Tiere 74, 37-64.

Miller, F.W., 1933. Musculature of the lacewing (Chrysopa carnea) Neuroptera. J. Morphol. 55, 29-51.

New, T.R., 1989. Handbuch der Zoologie, Vol. IV, Arthropoda: Insecta; Planipennia (Lacewings). De Gruyter, Berlin/New York.

New, T.R., 1991. Neuroptera (Lacewings). In: CSIRO (Eds.), The Insects of Australia. Cornell University Press, Ithaca, Vol. 1, pp. 525-542.

New, T.R., Theischinger, G., 1993. Megaloptera, Alderflies, Dobsonflies. Handbuch der Zoologie, Vol. IV, (Arthropoda, Insecta), Part 33. Walter de Gruyter, Berlin.

Newton, A.F. Jr, 1991. Agyrtidae (Staphylinoidea). In: Stehr, F.W. (Ed.), Immature Insects. Kendall/Hunt Publishers, Dubuque, Vol. 2, pp. 324-326.

Newton, A.F. Jr, 2005. Agyrtidae. In: Beutel, R.G., Leschen, R.A.B. (Eds.), Coleoptera, Vol. I. Morphology and Systematics (Archostemata, Adephaga, Myxophaga, Polyphaga partim). Handbook of Zoology Vol. IV, Arthropoda: Insecta. De Gruyter, Berlin, New York, pp. 261-269.

Nixon, K.C., Carpenter, J.M., 1993. On outgroups. Cladistics 9, 413426.

Nüesch, H., 1953. The morphology of the thorax of Telea polyphemus (Lepidoptera).I. Skeleton and muscles. J. Morphol. 93, 589-609.
Pace, R., 1975. An exceptional endogenus beetle: Crowsoniella relicta n. gen. of Archostemata Tetraphaleridae from Central Italy. Boll. Mus. Civ. St. Nat. Verona 2, 445-458.

Ponomarenko, A.G., 1969. The historical development of archostematan beetles. (in Russian). Trudi paleont. Inst. Akad. Nauk SSSR $125,1-238$.

Ponomarenko, A.G., 1977. Suborder Adephaga. (in Russian). Trudi paleont. Inst. Akad. Nauk SSSR 161, 1-104.

Ponomarenko, A.G., 1995. The geological history of beetles. In: Pakaluk, J., Slípinski, S.A. (Eds.), Biology, Phylogeny, and Classification of Coleoptera: Papers Celebrating the 80th Birthday of Roy A. Crowson. Muzeum i Instytut Zoologii PAN, Warszawa, pp. $155-171$.

Ponomarenko, A.G., 2000. Beetles of the family Cupedidae from the Lower Cretaceous locality of Semen, Transbaikalia. Paleont. J. 34 (Suppl. 3), 317-322.

Reichardt, H., 1973. A critical study of the suborder Myxophaga, with a taxonomic revision of the Brazilian Torridincolidae and Hydroscaphidae (Coleoptera). Arq. Zool. (Sao Paulo) 24, 73 162.

Schneider, P., 1978. Die Flug- und Faltungstypen der Käfer. Zool. Jb. Anat. 99, 174-210.

Schneider, W., 1981. Zur Kopfmorphologie der Imago des Ölkäfers Lytta vesicatora (Coleoptera: Meloidea). Entomol. Gener. 7, 6987.

Scholtz, C., Grebennikov, V.V., 2005. Scarabaeiformia. In: Beutel, R.G., Leschen, R.A.B. (Eds.), Coleoptera, Vol. I. Morphology and Systematics (Archostemata, Adephaga, Myxophaga, Polyphaga partim). Handbook of Zoology Vol. IV, Arthropoda: Insecta. De Gruyter, Berlin, New York, pp. 345-425.

Shull, V.L., Vogler, A.P., Baker, M.D., Maddison, D.R., Hammond, P.M., 2001. Sequence alignment of 18 S ribosomal RNA and the basal relationships of adephagan beetles: evidence for monophyly of aquatic families and the placement of Trachypachidae. Syst. Biol. 50, 945-969.

Swofford, D.L., 2001. PAUP*: Phylogenetic Analysis Using Parsimony and Other Methods, Version 4.0b10. Computer program distributed by Sinauer Associates Inc., Sunderland, MA, USA.

Tan, J.-J., Ren, D., Liu, M., 2005. New ommatids from the Late Jurassic of western Liaoning, China (Coleoptera: Archostemata). Ins. Sci. 12, 207-216.

Tauber, C.A., 1991. Order Raphidioptera. Order Neuroptera. In: Stehr, F.W. (Ed.), Immature Insects. Kendall/Hunt Publishing Company, Dubuque, Vol. 2, pp. 123-143.

Theischinger, G., 1991. Megaloptera (alderflies, dobsonflies). In: Stehr, F.W. (Ed.), Immature Insects. Kendall/Hunt Publishing Company, Dubuque, Vol. 1, pp. 525-542.

Vogler, A.P., 2005. Molecular systematics of Coleoptera: what has been achieved so far? In: Beutel, R.G., Leschen, R.A.B. (Eds.), Coleoptera, Vol. I. Morphology and Systematics (Archostemata, Adephaga, Myxophaga, Polyphaga partim). Handbook of Zoology Vol. IV, Arthropoda: Insecta. De Gruyter, Berlin, New York, pp. 17-22.

Vulcano, M.A., Pereira, F.S., 1975. Cupesidae (Coleoptera). Arq. Inst. Biol. (São Paulo) 42, 31-68.

Walker, E.M., 1938. On the anatomy of Grylloblatta campodeiformis Walker, 3. Exoskeleton and musculature of the neck and thorax. Ann. Entomol. Soc. Am. 31, 588-640.

\section{Supporting Information}

Additional Supporting Information may be found in the online version of this article: 
Appendix S1. Homologisation of thoracic muscle nomenclatures used in present contribution and by several authors.

Appendix S2. "CLA233_S2.winc".

Appendix S3. Model parameters of Bayesian analyses.
Please note: Wiley-Blackwell are not responsible for the content or functionality of any supporting materials supplied by the authors. Any queries (other than missing material) should be directed to the corresponding author for the article. 